\title{
Toward FGM-free villages in Egypt: A mid-term evaluation and documentation of the FGM-free village project
}

\author{
Ghada Barsoum \\ Population Council \\ Nadia Rifaat \\ Omaima El-Gibaly \\ Nihal Elwan \\ Population Council \\ Natalie Forcier
}

Follow this and additional works at: https://knowledgecommons.popcouncil.org/departments_sbsr-pgy

Part of the Demography, Population, and Ecology Commons, Family, Life Course, and Society Commons, Gender and Sexuality Commons, International Public Health Commons, Sociology of Culture Commons, and the Women's Health Commons How does access to this work benefit you? Let us know!

\section{Recommended Citation}

Barsoum, Ghada, Nadia Rifaat, Omaima El-Gibaly, Nihal Elwan, and Natalie Forcier. 2009. "Toward FGMfree villages in Egypt: A mid-term evaluation and documentation of the FGM-free village project." Cairo: Population Council. 


\title{
Toward FGM-Free Villages in Egypt
}

\author{
A Mid-Term Evaluation and \\ Documentation of the \\ FGM-Free Village Project
}

Ghada Barsoum, Nadia Rifaat, Omaima El-Gibaly, Nihal Elwan, and Natalie Forcier

October 2009 


\section{(1) Population Council \\ Research that makes a difference}

The Population Council conducts research worldwide to improve policies, programs, and products in three areas: HIV and AIDS; poverty, gender, and youth; and reproductive health.

\section{Population Council}

West Asia and North Africa

59 Misr Helwan Agricultural Road, Maadi, Cairo, Egypt

Tel.: (+202) 2525-5965, (+202) 2525-5967, (+202) 2525-5968

Facsimile: (+202) 2525-5962

Email: pcouncil@popcouncil.org

http://www.popcouncil.org

\section{(c) 2009 The Population Council, Inc.}

Any part of this publication may be reproduced without permission for limited distribution, provided it is distributed without charge and the Population Council is acknowledged as its source. The Population Council would appreciate receiving a copy of any materials in which the text is used. 


\section{Table of Contents}

Executive Summary $\quad 1$

Introduction $\quad 5$

Background Information on FGM in Egypt $\quad 8$

$\begin{array}{ll}\text { An Historical Review of Efforts against FGM in Egypt } & 10\end{array}$

$\begin{array}{ll}\text { The FGM-Free Village Model: Project Documentation } & 17\end{array}$

$\begin{array}{ll}\text { The Socio-Cultural Approach } & 17\end{array}$

$\begin{array}{lr}\text { Program Objectives } & 18\end{array}$

$\begin{array}{ll}\text { Program Strategies } & 19\end{array}$

A Partnership Model: National and International Commitment 20

The FGM-Free Village Model: Documentation of the Programmatic Activities in the First Phase (2003-2006) 23

1. Institutional Set Up at the Central and Local Levels 23

2. Advocacy, Capacity Building and Networks 27

3. Community Initiatives and Village Public Declarations 32

4. Communications for Behavioral Impact through the Media 34

5. Monitoring and Evaluation 36

\begin{tabular}{ll}
\hline COMMUNITY-LEVEL IMPACT EVALUATION & 38
\end{tabular}

FGM-Free Village Model Impact at the Community Level 39

1. Data on the Impact of the intervention: Similarities between Intervention and Control Sites

2. Information and Knowledge about FGM $\quad 40$

3. Openness to Discuss FGM 48

4. Attitudes Toward FGM $\quad 50$

$\begin{array}{ll}\text { 5. Committed groups against FGM } & 61\end{array}$

6. Public Village Declarations against FGM 66 
EVALUATION OF NATIONAL-LEVEL EFFORTS

FGM-Free Village Model Impact: The National Level

1. The Effectiveness of the Project Structure at the National Level

2. Program Efforts to Combat the Medicalization of FGM

3. Advocacy Efforts on the Legal Aspects of FGM

4. Program Efforts in Media

5. Program Efforts with the Religious Discourse on FGM

6. Program Efforts in Mobilizing Youth as Agents of Social Change

90

Recommendations

Annex I: Time Line of Anti-FGM Efforts and Approaches in Egypt Since 1904

Annex II: Research Supported by the Resource Center on FGM and Violence against Women

Annex III: FGM-Free Village Model Advocacy and Capacity Building Efforts among University Students

Annex IV: A Listing of Awareness Activities and Social Services at the Community Level in all Six Governorates

Annex V: Characteristics of Control and Intervention Samples

Annex VI: Different Religious, Medical and Legal messages on FGM

Works Cited

Notes 


\section{List of Figures}

Figure 1: Decline in Circumcision by Current Age

Figure 2: Changes in person performing FGM between EDHS 1995 and EDHS 2005

Figure 3: Changes in Attitude toward FGM and Prevalence between EDHS 1995 and EDHS 2005

\section{List of Tables}

Table 1: Location of Focus Group Discussions by Governorate

Table 2: Quantitative intervention and control villages by governorate

Table 3: Perceptions of individuals (different groups) about the extent of FGM in his/her community

Table 4: Perceptions of Community Members Regarding the Approval of FGM among Influential Figures in their Communities

Table 5: Attitudes toward FGM if it is not practiced by others

Table 6: Knowledge about complications caused by FGM and of cases of girls who avoided circumcision

Table 7: Exposure to Information on fgm within the past two years

Table 8: Sources of information on FGM

Table 9: Types of information heard about FGM

Table 10: Impact of Information on views and behaviors related to FGM

Table 11: Openness to discuss FGM among young groups

Table 12: Views and Attitudes toward FGM

Table 13: Views on the importance of FGM

Table 14: Intention to circumcise daughters in the future

Table 15: Reasons for intention to circumcise girls 
Table 17: Educational characteristics of those intending to circumcise their daughters

Table 18: Educational characteristics of those NOT intending to circumcise their daughters 58

Table 19: Circumcision status of girls aged 10-15 and 16-24 by governorate 58

Table 20: Persons who perform FGM

Table 21: Individuals within the household responsible for the Decision to Circumcise

Table 22: Sense of self-efficacy among women not intending to circumcise their daughters

Table 23: Sense of self-efficacy among Young Females (10-15 and 16-24) and Young Males (16-24) with regards to FGM

Table 24: Background Characteristics of women in the intervention and control villages

Table 25: Circumcision status of women in the sample in both intervention and control sites

Table 26: Mothers' personal and past experiences with circumcision

Table 27: Characteristics of girls aged 10-15 in the intervention and control villages

Table 28: Characteristics of youth girls aged 16-24 in the intervention and control villages

Table 29: Characteristics of Young Men aged 16-24 in the intervention and control villages

Table 30: Characteristics of Men aged 24 and older in the intervention and control villages 


\section{Foreword}

FGM in Egypt is declining and has creeped out of the shadow of taboos. Today villages in Upper and Lower Egypt are declaring publicly their stance against FGM. Attitudes towards FGM, especially among young girls and future mothers, are excessively inclined towards abandoning the practice. Egypt has presently attained a socio-cultural environment conducive to change as the voices against the practice are louder than those supporting the continuity of FGM. The media has extensively contributed to this positive environment through continuous informative campaigns in the TV, Radio, Press and Internet. Furthermore, the renowned, authorized religious institutions, both Muslim and Christian, adopted a progressive child rights based discourse against FGM, which has encouraged families to realize that the practice violates the integrity of the body and soul of the girl child. The social hype was crowned in June 2008 when the Parliament approved the criminalization of FGM, in the context of the recent amendments made to the child law which were reached based on a comprehensive participatory process.

Due recognition is attributed to Egypt's First Lady Mrs. Suzanne Mubarak, Egypt's First Lady who has personally committed her time, effort, and passion to place FGM on Egypt's development agenda. In 2007 her Excellency supported the acceleration of anti-FGM efforts in Egypt, during the Regional Conference on Combating Violence Against Children, June 2007 when she launched the "Beginning of the End" Campaign to put an end to this practice that threatens the well being and lives of young girls.

There are many partners that I also want to acknowledge in this report as their contribution, sincerity and support have made the dreams of young girls to enjoy a life free of FGM, come true. I hereby acknowledge the key religious symbols in Egypt the Grand Imam of Al-Azhar, the late Dr. Mohamed Sayed Tantawi, Grand Mufti, Dr. Aly Gomaa, and Pope Shenouda the Third, Pope of the Coptic Orthodox Church who contributed to enlightening Egyptian families and enabling them to abandon the practice.

Numerous Ministries have supported the National Council for Childhood and Motherhood/Ministry of State for Family and Population and allocated extensive resources to translate Egypt's political commitment into tangible results. These ministries include: the Ministry of Justice, Ministry of Information, Ministry of Health, Ministry of Endowments (Awkaf), Ministry of Social Solidarity, Ministry of International Cooperation and the Attorney General.

There are specific figures I want to acknowledge who supported the NCCM to establish the core infrastructure of the project. Their dedication, pioneering vision and beliefs have brought us where we are today... Special recognition to Ms. Marie Assaad, founder of the National anti-FGM Task Force, Mr. Antonio Vigilante, former UN Resident Coordinator and Dr. Dina El Naggar, former UNDP Program Officer.

Other key partners built upon the primary efforts and contributions of others to keep the ongoing anti-FGM momentum and represented a unified initiative and successful model 
of partnership. Special recognition is awarded to the European Commission that exclusively supported phase II of the project. The partners include the Donors Assistance Group (DAG) ${ }^{1}$, UNDP, Plan International, UNFPA, UNIFEM and UNVs.

This project also demonstrates a partnership model with the Civil Society entities that devoted extensive efforts to the cause and furthermore, supported the Council at the grass roots level.

I wish to acknowledge the FGM Free Village Model Project team that showed their commitment and enthusiasm despite encountered hardships and controversies during the implementation of the project. Finally, I thank the Population Council that carried out this study that captured the most vital transitions and documented the Council's efforts to combat FGM.

The story is not over yet, the Ministry of State for Family and Population will continue intensifying its efforts until the day will come when Egypt is an FGM Free country.

Moushira Khattab

Minister of State for Family and Population

Cairo, Egypt

'DAG includes Italian Cooperation, USAID, CIDA, Netherlands, Denmark, Finland, Switzerland \& UNDP. 


\title{
Foreword
}

The abandonment of female genital mutilation (FGM) is a priority issue in Egypt. The Population Council is pleased to contribute to the knowledge base on interventions aiming at the abandonment of FGM by documenting the movement against FGM in Egypt and providing a mid-term evaluation and documentation of the FGM-Free Village Model implemented by the National Council for Childhood and Motherhood since 2003.

We hope that the information in this report will prove useful to a wide spectrum of audiences. We offer this report to policymakers, program implementers and those responsible for allocating resources in Egypt and elsewhere, in hope that its findings will strengthen efforts to abandon FGM around the world.

\author{
Safaa El-Kogali \\ Regional Director \\ Population Council \\ North Asia and West Africa \\ Cairo, October 2009
}




\section{Acknowledgements}

- here are many individuals without whom this study would not have been possible. We first want to thank the women and men who shared their views, attitudes and stories on FGM with us. We extend our sincere gratitude to members of the Egyptian Task Force against FGM, who supplied the research team with extensive information on their experiences and shared their documents and insights with us. Special thanks go to Ms. Marie Assaad, Coordinator of the Task Force, for the time she dedicated to addressing all the queries of the research team. We are also grateful to the core groups of professionals, including doctors, judges, and members of the media, for sharing their views and advocacy efforts against FGM with us. This study benefited significantly from the youth involved in the project and the United Nations Volunteers (UNVs), who were willing to share their experiences with us and assisted in survey data collection. The Council acknowledges the role of Dr. Hala Shukralla in the collection of the qualitative data and her contribution to earlier versions of this report.

Gratitude is due to the National Council for Childhood and Motherhood (NCCM) project team who worked tirelessly with Population Council researchers to produce this report. Special thanks go to H.E. Minister Moushira Khattab, Minister of State for Family and Planning Affairs for her support in her earlier capacity as the General Secretary of NCCM; Ms. Mona Amin, Project Coordinator; Dr. Vivian Fouad, Training Coordinator; Dr. Magdy Helmy, NGO Coordinator; Ms. Dalia Motaaz, Youth Coordinator; and Mr. Akmal Gamal and Ms. Walaa Hassan, Project Field Coordinators. We are also grateful to the UNDP team, including both current and former staff members who have been involved in this initiative. Mr. Antonio Vigilante, former UNDP Resident Representative, has provided the time to address our queries in relation to the early phases of this project. We also thank Mr. James Rawoly, current UNDP Resident Representative, for the time he gave to this study and Ms. Simon Galbiati, the UNDP Program Officer at the time of the evaluation. The genuine involvement of the NCCM/UNDP team provided the Council with valuable insights throughout this research process.

Population Council

West Asia and North Africa 


\section{Acronyms}

\begin{tabular}{ll} 
ASCE & Adolescents and Social Change in Egypt Survey \\
DAG & Donor Assistance Group \\
DHS & Demographic and Health Survey \\
EDHS & Egypt Demographic and Health Survey \\
FGD & Focus Group Discussion \\
FGM & Female Genital Mutilation \\
ICPD & International Conference on Population and Development \\
MICS & Micro-Indicator Cluster Surveys \\
MOHP & Ministry of Health and Population \\
NCCM & National Council for Childhood and Motherhood \\
NCPD & National Council on Population and Development \\
NGO & Non-Governmental Organization \\
UN & United Nations \\
UNDP & United Nations Development Program \\
UNFPA & United Nations Population Fund \\
UNICEF & United Nations Children's Fund \\
WHO & World Health Organization \\
UNV & United Nations Volunteer \\
\hline
\end{tabular}




\section{Executive Summary}

- he FGM-Free Village Model is implemented by the National Council for Childhood and Motherhood (NCCM) in partnership with the United Nations Development Programme (UNDP) and the Donor Assistance Group (DAG). Launched in 2003, the project represents Egypt's national initiative toward the elimination of the practice of FGM, which is highly prevalent in the country. Based on the 2005 Egypt Demographic Health Survey, 96 percent of ever-married women between the ages of 15 and 49 are circumcised. The objective of the project is to eliminate the social pressure on families to perform FGM on their daughters by fostering a socio-cultural environment conducive to the abandonment of the practice through the media messages, supportive policies, and community-based initiatives. The project started in sixty villages in Upper Egypt and is currently being scaled up in sixty more villages in the rest of the country.

This report is a mid-term evaluation and documentation of the process and approach of the FGM-Free Village Model. The objective of this report is to create a knowledge base of information to support policy dialogue on FGM and to assist in transferring knowledge about the model to other communities across Egypt and to other countries where FGM is practiced. The report identifies key elements of success as well as challenges and opportunities in order to better inform the efforts aimed at FGM abandonment in Egypt and elsewhere.

The analysis provided in this report is based on a review of the international literature on FGM, project documents pertaining to the history of the movement against FGM in Egypt, documents on the FGM-Free Village Model, and both quantitative and qualitative primary data collected for the specific purpose of this evaluation. The study team conducted a household survey in intervention and control sites in order to gauge the impact of community-level interventions by comparing data on target groups in both types of sites. Survey questions focused on changes in knowledge, attitudes, and behaviors related to FGM. Qualitative data in the form of in-depth interviews, focus group discussions, and case studies were conducted at both the community and national levels.

The key elements of success in the project include the following:

1. The project adopted an innovative, multi-pronged approach by engaging community members and leaders, religious leaders, health professionals, lawyers, judges, government officials, the media, youth groups, and nongovernmental organizations in efforts to abandon FGM. NCCM trained and mobilized core groups of advocates against FGM within these groups. The project also established a network of youth UN volunteers (UNVs) and trained them to provide messages against FGM in schools, youth centers and universities.

2. The project promoted a national dialogue on FGM and pushed for legal and policy reforms. The advocacy efforts that were mobilized after the FGM-related deaths of two young girls in the summer of 2007 were of critical importance. NCCM mobilized a campaign that eventually led to the issuance of a ministerial decree by the Ministry of Health(No. 271 in 2007) which bans FGM in all clinics and public and private hospitals, overruling 
an earlier 1996 ministerial decree that allowed FGM in hospitals for cases approved by doctors. NCCM advocacy efforts were also pivotal in the issuance of a landmark religious fatwa by the Grand Mufti of Egypt, which unequivocally condemned FGM.

3. Advocacy efforts by NCCM were crowned with the issuance of the Child Law in 2008, which criminalized FGM.

4. At the community level, NCCM mobilized public declarations against the practice of FGM. Village declarations constitute a pledge and a commitment by officials and religious leaders as well as youth and community members to end the practice of FGM. These declarations are mobilized by youth networks and community groups against FGM. At the time of this midterm evaluation, eight villages had made public declarations against FGM.

5. The Model adopts an integrated approach toward the elimination of the practice of FGM, combining awareness with the provision of demand-driven community services.

The FGM-Free Village Model integrates a number of key elements to change attitudes toward FGM. First, it adopts a non-coercive, non-judgmental approach toward FGM, focusing on the protection of human rights and the empowerment of girls and women. Second, it focuses on the community, seeking to raise awareness by allowing for venues of public discussion and reflection. Third, it mobilizes communities to act together against the practice. Fourth, it mobilizes these communities to organize public declarations against FGM. Fifth, it seeks to create a socio-cultural environment against FGM through the media and through supportive interventions at the community and governmental levels.

Impact evaluation at the community level shows the significant impact of the project in changing views and attitudes toward FGM among intervention groups. Comparing responses from women and men in intervention groups to those in nonintervention (control) villages, data analysis shows the following results:

- Men and women in both intervention and control groups reported receiving knowledge on FGM through the media, particularly through television. However, in terms of information retained, more than 78 percent of women in the intervention group retained information that FGM has negative health consequences, while only 30 percent of women in the control group retained the same information.

- In terms of the impact of information on decisions and attitudes toward FGM, 81 percent of women in the intervention group stated that the information received made them re-evaluate their views on girls' circumcision compared to only 17 percent of women in the control group. In addition, 76 percent of women in the intervention group who received information and who had uncircumcised girls noted that the information made them decide not to circumcise their daughters, while only 19 percent of women in similar situations in the control sample had the same response.

- $\quad$ Support for the continuation of the practice varied significantly between the intervention and control groups. Only 27 percent of women in the intervention group believed that FGM should 
continue, while 77 percent of women in the control group believed the same.

- In terms of misconceptions surrounding FGM, 25 percent of women in the intervention group believed that FGM was required by religion, while 59 percent of the women in the control group had similar beliefs. Additionally, women in the control sample were more likely to believe that FGM preserves virginity and protects against infidelity.

- Women in the intervention group were six times less likely than women in the control group to intend to circumcise their daughters (38 percent of women in intervention groups noted that they would not circumcise their daughters compared to only 7 percent of women in the control group).

This report shows that FGM is an entrenched generational problem that requires concerted efforts over an extended period of time. The report strongly recommends that efforts be continued through a sustained and protracted process. Advocacy and awareness raising efforts that take a holistic multi-sectoral approach constitute best practices that need to be continued in order to maintain impact for the coming generations. The following is a summary of the report's specific recommendations:

1. At the central level, the report recommends increasing the capacity of the project technical unit by adding more members. Trained UNVs can provide a pool of candidates for the expansion of the project technical unit. It is important to ensure the sustainability of the unit in order to advance its coordination activities with different stakeholders.
2. The positioning of the Project Technical Unit within the NCCM has allowed it to have access to the decision making bodies within relevant ministries through NCCM's Technical Advisory Committee. The study recommends maximizing the involvement of a number of stakeholders in the battle against FGM, including the Ministries of Education, Higher Education, Justice, Health and Population, and Religious Affairs. Furthermore, the message against FGM should be advocated within school and university curricula.

3. NGOs are important partners in this process. NCCM is equipped to provide training to different civil society organizations to combat FGM within their local communities. It is recommended that NCCM utilize this capacity by providing a strong training curriculum against FGM and a toolkit of best practices that would be part of NGO training and would be available to all NGOs, even those that are not part of the FGM-Free Village Model project.

4. To combat the medicalization of FGM, the report recommends opening a dialogue with the Physicians Syndicate and lobbying the syndicate to take a stronger stance regarding FGM. This entails efforts to support and disseminate information about Ministerial Decree No. 271. It is also time to include anti-FGM messages in university medical curricula and to disseminate the FGM manual and curricula among physicians to raise their awareness about the issue.

5. Groups claiming that FGM is mandated by religion constitute a major obstacle to efforts against FGM. The study recommends maximizing efforts with the Ministry of Awkaf to prepare 
qualified religious leaders to lead debates about the issue. A task force of religious scholars that are supportive of the case against FGM should be formed to convey the FGM abandonment message. Such efforts need to be supported by a wide dissemination of publications that provide arguments to refute allegations of the Islamic religious roots of FGM. The study also recommends wider dissemination of the fatwa condemning FGM and the booklet published by NCCM and authored by the Islamic thinker Dr. Mohamed Selim Al-Awa, which also condemns the practice. Religious internet sites have been an untapped resource that requires further attention from the project team.

6. Efforts with the media have been an important component of this project. NCCM has been developing a media strategy. Recommendations with regards to this component include the involvement of more policy makers and supportive religious leaders in media campaigns and the continuous production of media materials with clear and direct messages against FGM. It is recommended that a media consultant dedicated to this important aspect of the intervention join the project team.

7. At the governorate level, the study recommends the creation of task forces made up of a core group of advocates, including active NGOs in intervention governorates. These task forces would be supported by a committee comprising representatives of the different line ministries. These concerted efforts at the governorate level would ensure an immediate response to FGM-related issues and would provide support to communitylevel interventions.

8. Community-level recommendations include the provision of regular training activities to partner NGOs, the facilitation of networking opportunities among NGOs working against FGM to allow for cross fertilization and the development of best practices models, and the provision of monitoring and evaluation tools for NGOs which they can use to assess their own performance. Recommended new outreach strategies at the local level include more targeted efforts to reach adolescents in schools, youth groups in universities, and men, both young and old, with awareness activities against FGM. The study also recommends focusing on local Muslim religious leaders (imams) and providing them with training and targeted awarenessraising activities.

9. The FGM-Free Village Model has adopted a number of successful strategies and best practices that are central to interventions against FGM. These have included the use of an integrated development approach that mixes awareness raising with the provision of services. Of particular impact were the medical caravans provided in a number of governorates. These caravans address a real need at the community level and are appreciated by different community members. It is therefore recommended that more of these activities are incorporated into the program. It is also important to note that the presence of an integrated package supports efforts against FGM and pacifies groups that are supportive of the practice of FGM and hence are against the project's intervention. 


\section{Introduction}

\section{Summary of the Project}

T he FGM-Free Village Model is implemented by the National Council for Childhood and Motherhood (NCCM) in partnership with the United Nations Development Programme (UNDP) and the Donor Assistance Group (DAG). Launched in 2003, the project represents Egypt's national initiative toward the elimination of the practice of FGM, which is highly prevalent in the country. Based on the 2005 Egypt Demographic Health Survey, 96 percent of ever-married women between the ages of 15 and 49 are circumcised. The objective of the project is to eliminate the social pressure on families to perform FGM on their daughters by fostering a socio-cultural environment conducive to the abandonment of the practice through the media messages, supportive policies, and community-based initiatives. The project started in sixty villages in Upper Egypt and is currently being scaled up in sixty more villages in the rest of the country.

\section{Objective of the Mid-Term Evaluation}

The objective of this mid-term evaluation is to independently document and evaluate the process and methodology used by the FGM-Free Village Model project. This evaluation seeks to provide a basis for the expansion and replication of the model in other communities in Egypt and in other countries where FGM is practiced. In addition, this evaluation seeks to create a knowledge base to support policy dialogue on FGM. The documentation and evaluation paves the way for a larger scale replication of the project across the country. The documentation and evaluation also addresses key elements of success in order to define the project as a best practice and to identify challenges and lessons learned to support a solid expansion phase.

Specifically, this evaluation and documentation covers the following points:

1. The process and the methodology used by the FGM-Free Village Model project;

2. The impact of the project in terms of attitudes toward the practice of FGM;

3. Recommendations to scale up the project to reach national coverage.

\section{Research Methodology}

This evaluation uses a combination of qualitative and quantitative research methodologies in addition to an extensive review of project documents, documentation pertaining to the anti-FGM movement in Egypt, and international literature on the topic of FGM. Field work and data collection at the community level was conducted in December 2006. Building on this data, interviews with professional groups of judges, media representatives, doctors, and other stakeholders took place throughout the summer of 2007.

\section{The Qualitative Component}

The qualitative component of the evaluation documents the processes by which the anti-FGM movement became mainstreamed into the national agenda. It also documents the implementation process of the FGMFree Village Model, including impact and lessons learned. Focus group discussions and interviews were conducted with the NCCM Coordinating Group, members of the Egyptian Task Force against FGM, partner NGOs, United Nations volunteers, 
judges and attorneys, members of the media, religious leaders, project donors, and community members in seven villages across six of Egypt's twenty-six governorates.

The selection criteria for the villages included in the qualitative sample was based on a matrix developed with the NCCM Coordinating Group. The criteria included the type of NGO, a mix of Christian/Muslim affiliation, the project's experience and presence in the community, the level of success of the Model in the village, and geographic location. The level of success criteria included separate grades for NGOs from very good, good, moderate, weak, to very weak. In choosing the qualitative sample, every effort was made to ensure representation of various groups, including adult women, adult men, males aged 16-24 years, females aged 1624 years, and girls aged $10-15$ years. Focus group discussions were conducted in two villages in Beni Suef and one village in each of the governorates of Menya, Assiut,

Table 1: Location of Focus Group Discussions by Governorate

\begin{tabular}{ll}
\hline Governorate & Village \\
\hline Beni Suef & Ashment \\
Menya & Zl-Shokr \\
Assiut & Gaafarana \\
Sohag & Kom Gharib \\
Qena & Awlad Negm Bahgroua Nage' \\
Aswan & Kombol \\
\hline
\end{tabular}

Sohag, Qena and Aswan. Table 1 lists the villages where focus group discussions were conducted.

Qualitative information was analyzed to evaluate the primary objectives of the FGMFree Village Model. Key areas that remained unclear were discussed with the FGM-Free Village Model project team in a series of participatory interviews and consultative meetings.

\section{The Quantitative Component ${ }^{2}$}

The quantitative component comprised a survey of a random sample of individuals in eighteen villages in six governorates of Upper Egypt (six control sites and twelve intervention sites). A total of 3,150 individuals were interviewed: 2,100 from intervention sites and 1,050 from control sites. Only households with daughters between the ages of 7 and 13 and at least one young adult between the ages of 16 and 24 were selected for participation in the survey. The sample population included five sub-groups: adult women, adult men, males aged 16-24, females aged 16-24, and girls aged 10-15.

Five separate questionnaires were developed, with one for each sub-group. This research instrument was designed to collect data on a number of social variables, including demographic and socio-economic data, circumcision status, attitudes toward FGM, exposure to new information, self-efficacy in conveying health messages against FGM, informationseeking behavior, intention to circumcise daughters, openness in discussing FGM, religious beliefs surrounding the practice, gender roles, and reasons for the practice.

${ }^{2}$ This component was designed by Ragui Assaad, Regional Director of the Population Council in West Asia and North Africa at the time of the study, in collaboration with Dr. Omaima El Gibaly. 
Table 2: Quantitative intervention and control villages by governorate

\begin{tabular}{llll}
\hline Governorate & & Intervention Sites & \multicolumn{1}{c}{ Control Sites } \\
\hline Beni Suef & El-Shokr & Bani-Bekheit & $\begin{array}{l}\text { El-Sheikh Haroun } \\
\text { Tezment El-Gharbia }\end{array}$ \\
Menya & Tall'a & Abukorkas Elbalad & El-Hawarta \\
Assiut & Abnoub El-Hammam & Bani Zeid-Bouk & Bani-Ibrahim \\
Sohag & El-Kheyam & Banweit & Nagaa' Taye'e \\
Qena & El-Marees & Awlad Negm Bahgroua Nage' & El-Samayna \\
Aswan & El-Sa'ayda Kebly & Elkhatara & Wady Abbady \\
\hline
\end{tabular}




\section{Background Information on FGM in Egypt}

GM is widely practiced in Egypt.

- According to the 2005 Egypt

Demographic and Health Survey

(EDHS), 96 percent of ever-married women aged 15-49 have been circumcised. Data indicate that the primary reason for the continuing practice of FGM in Egypt is the belief that it is a good tradition, with 58 percent of women stating this rationale. Other responses include religion (31 percent), hygiene or cleanliness (36 percent), virginity (9 percent) and marriage prospects (9 percent). Of the women who gave these responses, 82 percent stated that the practice of FGM should continue (Yoder et al. 2004: 42). Furthermore, when asked if there were any benefits to not being circumcised, only 7.2 percent of the women stated that fewer medical complications would be a benefit, while 74.7 percent stated that there were no benefits to avoiding the procedure (Yoder et al. 2004: 198). Data on age at circumcision show that the majority of these women were circumcised between the ages of 5 and 14 .

The Demographic Health Survey of 1995 provides the first nationwide statistics on the prevalence of FGM in
Egypt. According to this survey, 97 percent of ever-married women in the 15-49 age group were circumcised (EDHS 1996). Subsequent DHS surveys in Egypt show the same level of prevalence, with incidence rates of 97 percent in 2000 and 96 percent in 2005 .

However, this prevalence rate decreases among adolescents, showing the impact of different interventions and growing awareness. For the first time, the 2005 EDHS included data on the circumcision status of girls aged 0-15. The data suggest a slow and steady decline in the rate of circumcision: 51 percent prevalence among girls aged 11-12, 69 percent for girls aged 13-14 and 77 percent for girls aged 1517 (El Zanaty and Way 2006: 212). This information is presented in Figure 1.

Data obtained from an independent study by the Population Council, based on the Adolescence and Social Change in Egypt (ASCE) Survey of 1997, demonstrate that girls in Egypt are 10 percentage points less likely to undergo FGM than girls of the preceding generation. The study also indicates a temporal link between the beginning of this decline and the 1994 International Conference on Population and Development (ICPD), when the movement against FGM in Egypt accelerated. ${ }^{1}$

Figure 1: Decline in Circumcision by Current Age

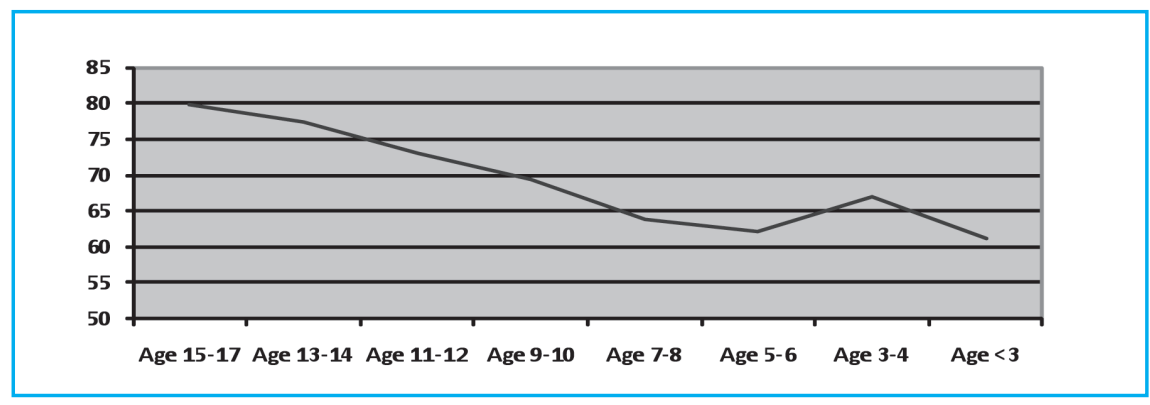

Source: El Zanaty and Way (2006: 212) 
More recently, a study by $\mathrm{WHO}$ in Egypt (Tag-Eldin et al. 2008) shows that the prevalence rate of FGM among school girls is 50.3 percent. While the study did not show prevalence by age group, it indicated that less than 57 percent of girls in secondary school are circumcised. The study highlights the strong impact of parents' education on girls' circumcision and shows that while 65 percent of daughters of illiterate mothers and fathers are circumcised, only 22.2 percent of daughters of mothers with university degrees and 19.5 percent of daughters of fathers with university degrees are circumcised.

EDHS data show that a significant transition has been made regarding the practitioners of FGM. In 1995, 79.5 percent of circumcisions were performed by traditional practitioners (dayas) and only 17.3 percent were performed by medical personnel. Yet, in 2000 the numbers were practically reversed, with 61.4 percent of circumcisions being performed by medical personnel and only 38.3 percent were

Figure 2: Changes in person performing FGM between EDHS 1995 and EDHS 2005

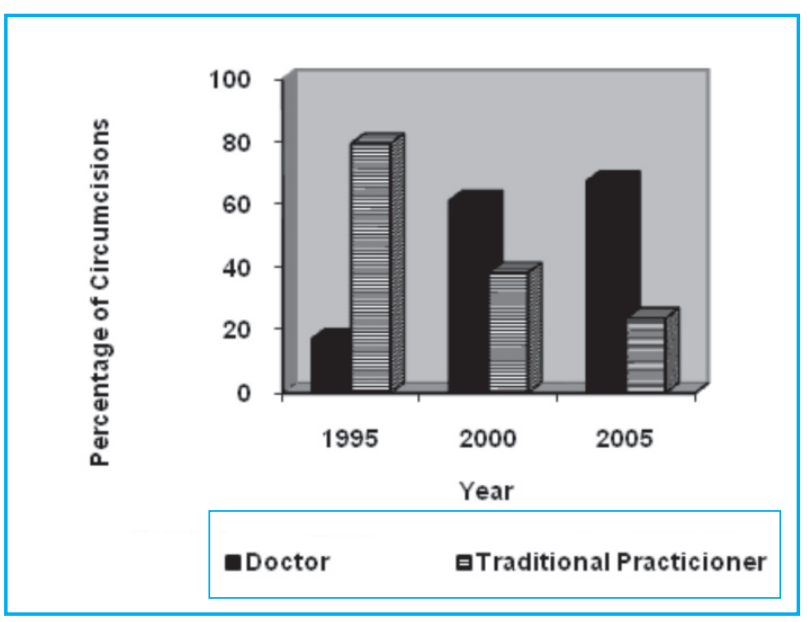

Source: Yoder et al. (2004: 49) and El Zanaty and Way (2006: 215) performed by traditional practitioners (Yoder et al. 2004: 37). The most recent data from 2005 show this trend to be continuing, with 67.6 percent of circumcisions performed by doctors and 24 percent by traditional practitioners (Zanaty and Way 2006: 215). This data is shown in Figure 2.

Additionally, EDHS data for 1995, 2000, and 2005 show that the number of women who support the continuation of FGM is declining. In 1995, 84 percent of women supported the practice, but by 2000 this number had dropped to 76.9 percent (Yoder et al. 2004: 40). In 2005, this number declined again to 68 percent (Zanaty and Way 2006: 217). Comparing DHS data for 1995, 2000 and 2005, analysis shows a slow transition in attitudes toward FGM among women. These attitudes, however, do not instantaneously translate into reduced prevalence, as these shifts in practice take generations. The changes in attitudes toward FGM abandonment compared to the prevalence of the practice are shown in Figure 3.

Figure 3: Changes in Attitude toward FGM and Prevalence between EDHS 1995 and EDHS 2005

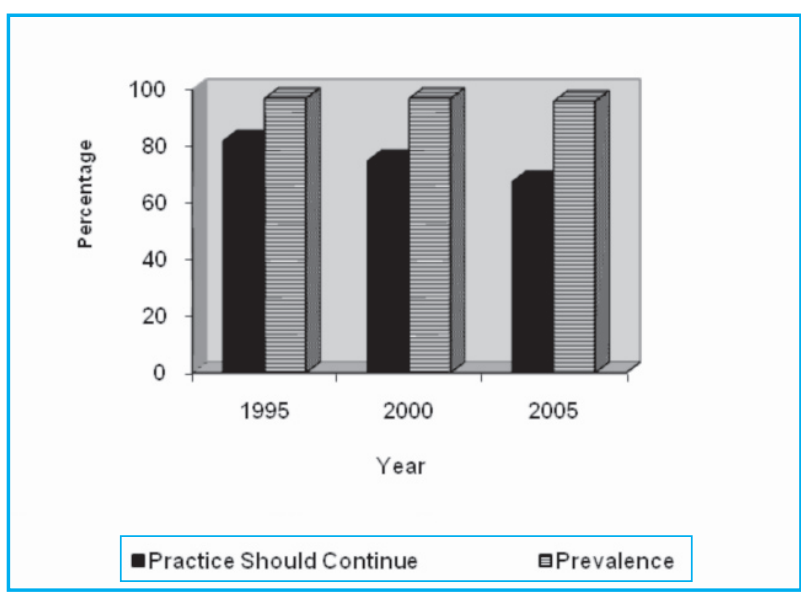

Source: Yoder et al. (2004: 49) and El Zanaty and Way (2006: 215) 


\section{An Historical Review of Efforts against FGM in Egypt}

\begin{abstract}
$\mathrm{A}$ Ithough efforts against FGM date back to the 1920s, these efforts were primarily based on individual initiatives and had little backing from established civil society organizations or the government. In this section, we list the major efforts that paved the way for the adoption of the anti-FGM program by the National Council of Childhood and Motherhood in 2003. This section includes a description of the activities of the Egyptian Task Force against FGM, which was formed soon after the International Conference on Population and Development (ICPD) in 1994. This Conference has been an important milestone in the history of the movement against FGM. A summary table in Annex I includes a listing of events covered in this section and shows the relationship between efforts targeting different sectors from 1904 to present.
\end{abstract}

\section{Lone Voices in the Early Twentieth Century}

The first known campaign to eradicate FGM dates back to the 1920s when the Egyptian Society of Physicians spoke against FGM with a proclamation stating the negative health effects associated with the practice. The proclamation was supported by several other prominent figures from the Ministry of Health, the press, and religious scholars (Wassef 1998: 8).

In 1928, Dr. Ali Ibrahim, a leading Egyptian surgeon and the founding member of the Egyptian Society for Physicians, announced at a conference held in Cairo that he had witnessed the negative effects associated with FGM. ${ }^{2}$ He also noted that it was not a recognized medical procedure and that he had never studied the practice himself or taught it to his students. Around the same period, Salama Musa, a prominent writer and journalist, who wrote extensively on issues related to women's education and liberation, considered the practice a social problem and declared that it should be stopped.

In 1957 and 1958, "Hawaa" magazine, a prominent publication that addressed women's issues at the time, published articles that discussed FGM and advised mothers not to force their daughters to undergo the practice. Under the title of "girls' circumcision," one of its articles pointed to previous research that stated, "Islam does not support circumcision and does not recommend it" (Wassef 1998: 1213).

\section{The Development of Religious Views on FGM in Egypt}

Religious opinions refuting FGM have been part of the public narrative since 1904. Sheikh Rasheed Reda, a religious leader, wrote about FGM in "Al Manar" magazine about FGM in an essay entitled "Female Circumcision: Obligatory or An Act of Sunna," where he quotes the early Islamic scholar Ibn Al-Munzir in noting "there is no evidence to refer to nor a Sunna to follow [in FGM]", meaning that there is no concrete evidence to support FGM as an act of Sunna. ${ }^{3}$

During the 1940s, Sheikh Sayed Sabiq, one of the most prominent Muslim scholars in Egypt at the time, began writing his famous encyclopedia, Figh AI Sunna, which he completed over a 20-year period. It is considered a main reference for students on issues of Islamic Law. In this book, it was stated that "the verses of the Prophet Mohamed ordaining female circumcision are weak and inauthentic." Similarly, in 1959, Ahmad Abdel Gawad, an Islamic scholar and author, documented the conflicting opinions of religious leaders and 
medical doctors in his book entitled Marital Happiness in Islam. He concluded that weak religious awareness among youth had led them to believe that FGM was necessary to protect against infidelity (Wassef 1998:

13). In the introduction to the book, it was noted that the presentation of conflicting opinions was intended to help readers shape their own opinions about FGM. However, it was also noted that "Islam does not have any clear judgments regarding this issue" and that there was a need for a law to prohibit FGM.

The late Sheikh Mahmoud Shaltout, the Egyptian Grand Mufti during the 1950s, issued a fatwa (ruling on Islamic law) in 1959 stating that "FGM, therefore, is not called for or required, neither under Islamic law nor morally or medically." In his book of fatwa and in the essay entitled "Female Circumcision," he writes, "we have concluded from the narrations on female circumcision that there is no evidence that supports circumcision as being part of the orthodox teachings of Islam (Sunna), a view expressed by some previous scholars too" (Helmy and Fouad 1994: 55).

Over the years, Islamic religious views on FGM witnessed significant changes. The religious discourse denouncing the practice has been in conflict with more recently mobilized groups that support the practice of FGM and accuse anti-FGM activists of following a western agenda. These conflicting voices were particularly strong during the ICPD in 1994, which witnessed the acceleration of efforts seeking to eliminate the practice.

On the Christian front, Bishop Gregorious, the Bishop of Scientific Research and Coptic Culture of the Coptic Orthodox Church, wrote a book in the 1960s entitled FGM in Christianity, in which he noted that FGM was not a
Christian practice. Also, in 1966, Dr. Samuel Habeeb, then Head of the Coptic Evangelical Organization for Social Services and later Head of the Coptic Evangelical Church, wrote an article entitled "Thoughts," in which he highlighted the risks of female circumcision and particularly warned dayas (traditional birth attendants) about continuing the practice (Wassef 1998: 15). These strong views by the Church leadership trickled down through members of the clergy to the laity, with no opposition documented.

\section{The Role of the Ministry of Health Prior to} the ICPD

In many discussions surrounding FGM, the views of physicians are central for two main reasons. First, physicians pioneered the fight against FGM, as noted in this section. Second, many religious leaders note that the decision to circumcise should be left to doctors, who should be consulted about whether a girl needs circumcision. With the increasing medicalization of the practice in Egypt, it is important to focus on the role of the Ministry of Health and its different decrees in relation to FGM.

A major milestone was the Ministry of Health's ministerial decree (Decree No. 7) issued on July 24, 1959. This decree stipulated that FGM should not be performed in any health units or hospitals operated by the Ministry of Health. The decree further stated that it was absolutely forbidden for someone other than a doctor to perform the procedure and that the operation should be a partial and not a total clitoridectomy. The unintended consequence of this decree was that it allowed for the medicalization of the practice outside of public hospitals (Wassef 1998: 15). The decree also defined the details of the procedure for doctors for "partial and not total clitoridectomy." 
After the ICPD, the Minister of Health and Population issued a decree in 1996 banning the practice of FGM in all hospitals in order to fix the major loophole in the earlier decree. The new decree provoked intense opposition from hard-line groups in support of the practice. As a result, the ministerial ban on FGM was repealed in June 1997 by ruling of the Administrative Court. This decision was appealed to Egypt's Highest Administrative Court and eventually the ministerial decree was upheld in Court of Appeals in December 1997 (Helmy 1999).

\section{Civil Society Efforts Prior to the ICPD}

The year 1979, declared the International Year of the Child by the UN, marked two major developments with regards to FGM in Egypt. The first was the commissioning of one of the early evidence-based studies on FGM by UNICEF. The study was conducted by Marie Assaad, later the Coordinator of the FGM Task Force. Assaad presented her results at a World Health Organization Conference in Khartoum, Sudan of that year. The emphasis of this research was on some of the sociological interpretations and rationale behind the practice. It was during this conference that Assaad's work provided one of the early links between FGM and issues of education and modernity. The second was the adoption of the FGM issue by one of the major nongovernmental organizations in Egypt, the Cairo Family Planning Association. The association was directed by Aziza Hussein, later a member of the Egyptian Task Force on FGM. The association adopted FGM as their single most pressing advocacy issue and organized a workshop entitled "The Bodily Mutilation of Young Females." The workshop emphasized the view that FGM is harmful for girls and women and that it is not recommended by religious practice. The workshop closed with the advocates calling for legislation to criminalize the practice of FGM. This was the first such forum to make an appeal to law (Hussein 2003: 48), and it led to a campaign against FGM that united multi-disciplinary experts from sociological, medical, religious, and legal backgrounds.

By 1985, the Cairo Family Planning Association became a founding member of the Inter-African Committee for the Eradication of Harmful Traditional Practices, which was based in Addis Ababa. As a culmination of these activities, the Egyptian Association for the Prevention of Practices Harmful to Women and Children was registered in March 1993 as an independent organization focusing on FGM (Helmy and Fouad 1994: 100). The Association produced publications concerning religious views on female circumcision (both Muslim and Christian) and its legal aspects, and organized training workshops and seminars throughout Egypt. It is considered one of the first organizations in Egypt to work on public education programs, consciousnessraising, and awareness of the harmful effects regarding FGM (Helmy 2000:80). The Association also held a series of meetings and supported putting FGM on the ICPD agenda.

It is evident from the above that FGM is an issue that has been subject to debate, with numerous voices calling for an end to the practice on medical, religious and political grounds since the early $20^{\text {th }}$ century. The momentum of the efforts to stop FGM during the 1970s and 1980s was slow. Efforts focused mainly on disseminating information on the health hazards of the practice. However, it was the ICPD and its aftermath that brought these efforts together in a more concerted and effective manner with the formation of the Task Force against FGM. 
The ICPD and the Formation of the Egyptian Task Force against FGM

The International Conference for Population and Development (ICPD), which was held in Cairo in 1994, was a milestone for the debate on population and development issues related to reproductive health rights including FGM. Local and international NGOs and human rights organizations called for a ban on FGM. In a synchronicity of events, widespread attention about FGM was sparked by graphic footage of a local barber in Cairo circumcising a 13-year-old girl. The footage was aired by the Cable News Network (CNN) the day before the ICPD began. The footage triggered national debate and Egyptian agencies questioned the necessity and safety of the practice. Long-time advocate Marie Assaad describes the footage as causing an "explosion" that was like "shock therapy." It was serious wake-up call for those concerned with human rights issues for women and children. The CNN footage had a twofold reaction whereby it was shocking to Egyptian society, and yet introducing the issue in this manner made it highly politicized, as some saw it as part of a Western conspiracy.

The ICPD prompted a national debate about FGM among government ministries, medical professionals, the media, and religious leaders. Following the ICPD, proponents of the practice launched a large-scale campaign against those who oppose FGM. A number of organizations, professional syndicates, and political groups joined the campaign. Conservative groups positioned FGM as a tradition that is integral to Egyptian identity, code of ethics, and morals. These groups also considered efforts against FGM as 'imposed' by the West. Supporters of FGM referred to it as a cultural, traditional, and religious dictate. In the same breath, they accused people who brought attention to FGM as exposing the country's dirty laundry. One of Egypt's renowned gynecologists made a statement to the press against speaking publicly about FGM and described do so as "a violation of the moral codes of the society" (El-Dawla 1999: 134).

Soon after the ICPD on October 9, 1994, the Minister of Health convened a special meeting of religious scholars, legal experts, medical practitioners, and members of the media to discuss the issue of FGM. The committee issued a statement condemning the practice of FGM. While many expected the Minister of Health to issue a ban on FGM, he instead passed a decree on October 25, 1994 that made the practice of FGM illegal outside of a hospital setting. The decree allowed physicians in public hospitals to perform FGM and recommended that public facilities should offer counseling services to educate families on the health risks of the practice. Despite the fact that the hazards of the practice were mentioned in the prologue, the decree legalized the performance of the practice, but only if performed by medical personnel. In other words, it supported the "medicalization" of FGM. Although the development of the law seemed to be aimed at decreasing the risks associated with circumcision under unhygienic conditions, it was a shock to those working against FGM and was considered a step backwards that ignored all past efforts to eradicate the practice (Helmy and Fouad 1994:110). The medicalization of FGM was regarded by some as an effort to placate extremist sectors and conservative trends in Egyptian society (Tadros 2000).

On the religious front, the issue continued to be contested. Sheikh GadAlhaq, the leader of Al Azhar at the time, which is the highest religious authority in Egypt, issued a fatwa affirming that FGM 
was congruent with Islamic teachings. The Egyptian Medical Syndicate called a meeting of religious leaders and medical professionals to discuss FGM within the context of Islam. The recommendations put forth by members of the meeting concurred with the fatwa and argued for continuation of the practice (Tadros 2000). At the same time, Sheikh Mohamed Sayed Tantawi publicly declared that FGM was not required by Islam and that it was a "habit not a [form of] worship". He also stated that there was no reference to FGM in the Quran and that "the Hadiths" concerning the issue were not based on strong evidence" (Helmy and Fouad 1994: 107).

It was in the midst of these heated debates that the Egyptian Task Force against FGM was established. This was one of the important outcomes of the ICPD. The Egyptian Task Force against FGM operated under the auspices of the National Committee for Population and Development (NCPD) of Egypt, which was formulated to carry out the recommendations of the ICPD. The task force remained under the NCPD's operation until 1999. The Task force was created to focus on one primary recommendation stipulated in the ICPD action plan, which was that "governments and communities should undertake quick procedures to eradicate FGM practices and protect women and girls from all similar, unnecessary, and dangerous practices" (Wassef 1998: 3). The aim of the task force was to place the practice of FGM on Egypt's agenda and to "engage different communities, activists, professionals, policy makers, the media, and grassroots communities in a dialogue that would lead to a reassessment of the social norms and beliefs on which the practice of FGM is based" (Tadros 2000: 6). The specific objectives of the Egyptian Task Force against FGM are:
- To create awareness regarding the harmful effects of FGM by disseminating accurate information, including information about its traditions and practice;

- To encourage activism against FGM by working with NGOs dedicated to the issue;

- To conduct vital research which can support the strategies and action plans designed to eradicate this practice;

- To train field workers to disseminate correct information regarding this practice; and,

- To provide the necessary resources to successfully carry out these activities (NGO Task Force 1996).

One of the recommendations of ICPD was to create a national body to implement its recommendations. This was the National Committee for Population and Development (NCPD), which was the umbrella organization under which the task force operated. By the beginning of 1995, the task force was recruiting individuals and NGOs from all arenas in its efforts against FGM. The task force adopted a "gender equal development approach," drawing from all aspects and allowing for the integration of health, gender equity, human rights, and culture issues in the struggle against FGM (Wassef 1998: 19). This approach identifies FGM as a social problem that represents violence against women and characterizes the dominancebased relationship between both genders. The development approach employed by the task force aims to address the motives behind FGM and to promote reproductive health and human rights (Wassef 1998: 4). ${ }^{4}$

The task force is made up of three committees: 
1. The policy/advocacy committee, which is concerned with communicating with decision makers.

2. The grassroots outreach committee, which organizes training and awareness activities to expand the base of NGOs working in the FGM field.

3. The research and studies committee, which is responsible for tracking and conducting relevant research. ${ }^{5}$

The task force also established the Resource Center on FGM and Violence against Women, the first organization of its kind in Egypt. It has an academic archive for researchers, audio-visual and communications materials for NGOs, and educational materials from all governorates in Egypt. The Center also functions as an information hub for individuals, agencies, and institutions. Moreover, the Center encourages individuals to conduct research to fill in gaps in the literature on FGM.

Some of the research supported by the Resource Center can be found in the Annex II.

The task force has become a model for the mobilization of social action against FGM (Helmy and Fouad 1994: 102). During the lifetime of the task force, its membership has extended to over 60 organizations from different governorates that have placed the issue of FGM on their agendas. Members from these organizations attend the monthly meetings of the task force and are involved in the discussion of all its decisions.

A number of important developments in the fight against FGM took place after the inception of the task force. These include the following:

1. In July 1996, the Minister of Health and Population issued Ministerial Decree
No. 261, which banned the practice of FGM in all hospitals (public or private), clinics or elsewhere by medical doctors and traditional circumcisers, and only allowed medical personnel to perform the practice "when necessary." The new decree provoked intense opposition from proponents of FGM who launched a campaign against the Minister and filed a lawsuit against him, alleging that such a decree had transcended the boundaries of his authority.

2. As a result of the opposition's efforts, the ministerial ban on FGM was repealed in June 1997 by a ruling of the Administrative Court. This decision was appealed to Egypt's Highest Administrative Court and eventually the ministerial decree was upheld in Court of Appeals in December 1997 (Helmy 1999).

3. In 1998, the discussion of FGM was incorporated into the programs of two large conferences. The first was the Conference for Population and Reproductive Health in Islamic Regions, hosted by the International Islamic Center for Population Studies and Research at Al Azhar University in February 1998. The recommendations from the conference included raising awareness among young males and females regarding puberty and promoting chastity through Islam rather than FGM; eliminating violence against women; and increasing knowledge on the issue of FGM and its relationship to religion and health, particularly noting that Islam does not require the practice and that only specialized doctors should perform FGM.

4. The Annual Conference of the Egyptian Obstetricians and Gynecologists 
Association in cooperation with the Egyptian Fertility Care Society was held in June 1998. The conference included an unprecedented plenary session on FGM, in which participants concluded that "FGM is harmful, unnecessary, and risky and it should not be conducted by a doctor who has vowed to respect the ethics of the medical profession."

5. Another important development during the 1999-2002 period was the Advocacy Component Project implemented by the Ministry of Health and Population (MOHP) in collaboration with the United Nations Population Fund (UNFPA). The project focused on reproductive health issues and FGM. Its main objective was to "increase commitment toward the ICPD goals of gender equity and equality, eliminate harmful practices against women and girl children, and [expand] male support."
6. Also during this time, task force members, NGOs, and other experts collaborated closely with the MOHP to produce a toolkit of six booklets entitled "No to Circumcision." This was a comprehensive reference on the subject and the first official MOHP document with an explicit and unambiguous title on FGM. The six booklets addressed the issue from a variety of perspectives: medical, cultural and social, religious (Muslim and Christian), and legal.

The advocacy committee of the task force approached the media through a series of workshops with media personnel (radio, television, and the press), Muslim and Christian religious leaders, and writers on reproductive health issues including FGM. The aim was to raise the awareness of participants regarding FGM and to help build a network of advocates against FGM. The task force provided a knowledge base for the FGM-Free Village Model. 


\section{The FGM-Free Village Model: Project Documentation}

T he FGM-Free Village Model is implemented by the National Council for Childhood and Motherhood (NCCM) in partnership with the United Nations Development Program (UNDP) and the Donor Assistance Group (DAG). Launched in 2003, the project represents Egypt's national initiative toward the elimination of the practice of FGM in Egypt. The project's activities are comprised of the following components:

1. Mobilizing the public at the grassroots level in 120 villages in Upper and Lower Egypt through partner NGOs and youth volunteers. The aim is to form pressure groups that are against the practice of FGM and that will announce their stance against the practice in a public declaration that their village will move toward abandoning FGM. Each NGO is responsible for organizing awareness sessions and providing concrete services in the villages where they work.

2. Establishing a network of youth UN volunteers (UNVs) who are well-trained, dedicated, and persuasive. The UNVs participate in the movement against FGM by working as field workers in villages, schools, youth centers, and universities, by raising awareness and promoting volunteerism.

3. Advocating to different concerned groups by raising their awareness and training them to become agents of change in their communities. These groups include the legal community, the medical community, media personnel, and involved ministries. The advocacy component with the aforementioned groups aims to overcome the medicalization of FGM, break the media taboo, encourage behavioral change through media messages, and lobby for a law that unequivocally criminalizes FGM.

4. Developing an integrated communications campaign with unified messages disseminated through media channels, including television, radio, billboard advertising, and theatre. This campaign involves NCCM/UNDP in collaboration with UNICEF, UNFPA, UNIFEM, and Plan International.

5. Forging strategic partnerships and creating a strong coordination mechanism under the leadership of NCCM. The UN has progressively harmonized and coordinated all activities regarding FGM through a national steering committee aimed at supporting a national strategy. Donors agreed to show their support as a coalition, rather than through the efforts of single institutions. Key ministries also coordinate their initiatives with NCCM.

\section{The Socio-Culltural Approach}

Building on lessons learned from previous efforts, particularly those of the Egyptian Task Force against FGM, the FGM-Free Village Model adopts a socio-cultural approach that aims at creating a general cultural and social trend in society which ultimately supports an environment that condemns FGM, its logic, and its justifications. The approach has three major axes:

1. Encouraging critical thinking: The socio-cultural approach is a noncoercive, non-judgmental approach that provides information on FGM that encourages a critical view of the 
practice of FGM and a reassessment of the tradition. The approach focuses on acknowledging the human rights of the girl child and condemning the practice as a harmful act. It recognizes FGM as a violation of human rights and the rights of the Egyptian girl child as stipulated in the 1989 Convention on the Rights of the Child (CRC) as well as the rights of women as stipulated in the Convention on the Elimination of All Forms of Discrimination against Women (CEDAW). ${ }^{6}$ It also provides a sociohistorical analysis of the FGM practice in Egypt and identifies its historical roots as an African tradition as well as its cultural and social justifications. It provides a scientific refutation of these and notes the long history of combating FGM in Egypt. The project develops religious messages - both Islamic and Christian - that delve into a deeper understanding of issues of chastity, honor, and the importance of having an equitable marital relationship. Furthermore, the approach highlights medical aspects with the aim of raising awareness on the importance and function of female reproductive organs and the inherent physical and psychological harm that results from FGM. This is combined with information showing that FGM is also a violation of the medical code of ethics. Finally, the approach strategically engages the media on the issue of FGM and presents a unified anti-FGM message in different media programs.

\section{Engaging many sectors in society:} The socio-cultural method addresses FGM as a practice based on social conventions that are deeply rooted in traditions. It therefore addresses the social, cultural, and religious environment to create a collective and coordinated partnership of groups against FGM. This aims to break through the taboos surrounding the FGM issue by engaging and mobilizing all sectors of society. This will require the medical and religious community, the media, decision-makers, and civil society activists to adopt a unified and clear message against FGM in order to undermine the cultural and social premise that supports it.

3. Supporting interactive local and national dialogue: The approach aims at creating an environment conducive to the initiation of dialogue, interaction, and advocacy and involves reflection on the social and cultural factors that support FGM rather than a rote-based message approach. Realizing that FGM cannot be abandoned solely through political commitment or legislation, efforts operate at the community level to support interactive dialogue targeting enlightened community leaders, youth, and different groups at the grassroots level.

\section{Program Objectives}

The program objectives of the FGM-Free Village Model are as follows:

1. Enhance awareness regarding the rights of the female child, as defined by the Convention on the Rights of the Child, with a focus on FGM and its relevance to the well-being of girl children, their empowerment, and their right to participate in decisions affecting their lives.

2. Train local NGOs to support the NGO advocacy network, which addresses FGM at the local and regional levels.

3. Create a network of informal community leaders to support advocacy activities at the village level. 
4. Implement clearly defined behavioral targets and impact indicators through a social marketing and advertising campaign.

5. Promote best practices with local NGOs which enable and empower girls and their families to make informed and healthy choices regarding their exposure to the practice of FGM.

6. Implement community service initiatives as incentives for mothers and families to participate in project activities.

7. Develop an Anti-FGM Toolkit with adaptable elements that can be customized to meet the needs of any community.

8. Implement monitoring and evaluation of project impacts at the village level which document and disseminate effective methodologies for an FGMFree Village.

9. Create a replicable knowledge base of updated, reliable, and consistent information at the national and local levels which supports best practices, public policy, and communications on FGM.

\section{Program Strategies}

The FGM-Free Village Model has relied on the following strategies:

1. Establishing and building the capacity of the technical unit at NCCM: The establishment of a project technical unit within NCCM that brings together experts from the Egyptian Task Force against FGM and the MOHP and is responsible for the management of all project activities.
2. Promoting a social environment against FGM: The project focuses on creating a social basis that rejects FGM. This was implemented in six governorates in Upper Egypt (Beni Suef, Menya, Assiut, Sohag, Qena, and Aswan) and four governorates in Lower Egypt (Kalyobiya, Gharbeya, Port Said, and Fayoum). Project activities include: partnerships with civil associations, partnerships with community leaders to motivate village communities, creation of core groups that adopt positive messages against FGM, coordination of public declarations against FGM, and initiatives that provide a variety of vital services to local communities.

3. Mobilizing a positive media strategy to combat FGM: The media is a vital tool for disseminating information and raising awareness regarding FGM. The FGM-Free Village Model project and NCCM have launched television and radio campaigns as well as extensive press coverage of FGM-related issues to spread a clear, direct, and unified antiFGM message.

4. Overcoming medicalization: The increased medicalization of FGM prompts the need to combat this trend directly by appealing to physicians with documented medical, historical, religious, and evidencebased information about the harmful effects of FGM. This involves raising the awareness of doctors, creating a group of anti-FGM advocates among physicians, and providing doctors with tools and skills to disseminate this knowledge within their communities.

5. Establishing the proper legal framework: In order to create a legal environment favorable to the abandonment of FGM, four steps have been taken: efforts toward proper 
enforcement of the Egyptian penal code which prohibits and penalizes the deliberate infliction of injury or the causation of permanent disability, lobbying for new legislation that criminalizes FGM, ensuring measures to enforce existing laws, and raising awareness among the legal community regarding FGM.

6. Mobilizing the role of youth in changing prevailing misconceptions: The project has relied on providing information about FGM to youth and their local communities. Youth are seen as dynamic agents of change, with many entry points in their communities, who are capable of undertaking a variety of awareness-raising activities among their peer groups and local communities.

7. Encouraging a national dialogue about FGM in Egypt: Previously, only a small number of NGOs and women's associations were concerned with FGM. However, NCCM has promoted the idea that FGM is an interrelated sociopolitical issue requiring a supportive environment to combat it.

8. Coordinating efforts at the political, executive, and international levels: NCCM has set a strategy for cooperation and coordination between governmental organizations and NGOs concerned with FGM. It has focused on achieving optimal benefit by avoiding multiplicity in activities, sharing experiences and expertise, and building on lessons learned from preceding efforts.

\section{A Partnership Model: National and International Commitment}

One of the important aspects of this project is the partnership that was realized between various stakeholders, including government agencies, civil society, and international organizations. Initially, three groups collaborated to formulate a comprehensive proposal for the FGM-Free Village Model project: UNDP, NCCM, and the Egyptian Task Force against FGM. NCCM committed itself to working toward FGM abandonment at the national level. UNDP assisted by providing seed money, mobilizing different donors, and providing technical assistance. The task force provided technical experience. This team laid the foundation for the FGM-Free Village Model with unprecedented collaboration and balance between experience and capacity.

NCCM is well positioned to coordinate different advocacy efforts involving expert groups among medical and legal professionals, national actors from political and public institutions, and the media. NCCM was established in 1988 as the highest national body entrusted with policymaking, planning, coordination, monitoring, and evaluation for the protection and development of children. NCCM is comprised of NGOs and experts in the field and has been involved in establishing policy, drafting legislation, and mainstreaming childhood development into Egypt's five year plans. The advisory committee is the policymaking body of NCCM. It has a ministerial committee which includes in its membership relevant ministries such as MOHP, MOE, Ministry of Social Solidarity and Ministry of Communications and Information. This committee functions as a coordination tool between NCCM and the policy-making level. NCCM first adopted the FGM issue in its 2002-2007 Strategic Orientation Document, which outlined the main framework and strategies of the Model. 
UNDP and Other UN Agencies

NCCM approached UNDP in 2002, seeking support for the development of a project that would address the issue of FGM from a human rights perspective and forge a strategic partnership with different national and international players that could lead to the collective abandonment of FGM. UNDP has been involved in the FGM-Free Village Model project since its inception and has played an important role in coordinating and organizing project discussions and activities with other UN agencies and donors. Together with NCCM, UNDP developed the FGM-Free Village Model project over a period of four months. During that time, wide consultations and research were conducted, building on previous efforts of the National Anti-FGM Task Force and on best practices provided by other countries.

At the time of project formulation, Antonio Vigilante, the Resident

Representative of UNDP, was also the UN Resident Coordinator and the Chair of the Donor Assistance Group (DAG). These two functions allowed UNDP to coordinate and organize the different UN agencies already working on the issue of FGM and facilitate access to donors and financial resources. Other UN initiatives against FGM in Egypt include UNICEF's program, the FGM Abandonment Program (FGMAP), which was initiated in 2002. ${ }^{7}$ FGMAP supports initiatives to prevent FGM/C at the subnational level in 40 specific communities in four governorates in Upper Egypt. It uses the Positive Deviance Approach, which focuses on individuals who deviate from conventional societal expectations to circumcise girls. Other agencies, such as UNFPA or UNIFEM, did not have specific FGM programs but rather integrated FGM abandonment messages into their reproductive health, gender, women's rights, and violence against women programs. ${ }^{8}$

The United Nations Volunteers (UNV) were also involved in the FGM-Free Village Program. ${ }^{9}$ The use of project funds allocated to the potential recruitment of UNVs sparked the development of a well structured volunteer movement. In order to provide further support to this momentum, the project began to recruit outstanding volunteers as UNVs in the last quarter of 2004. At present, a total of 50 UNVs are involved in the project, which represents over 65 percent of the total UNV program in Egypt.

Throughout the duration of the project, UN agencies have progressively harmonized their interventions and increased their coordination under the umbrella of NCCM. In the first phase of the project, the objective of the coordination exercise was primarily information sharing to avoid overlapping geographical spots and replication of activities with the same target group. With time, the UN agencies agreed on the vitality of coordination together and with NCCM while planning for their respective programs.

In 2007, a memorandum of understanding (MOU) was signed between UNDP, UNFPA, UNIFEM, and NCCM for the first time, allowing all joint interventions to be integrated within a unified framework and given access to joint resources. Joint cooperation and planning focused mainly on three specific areas: developing and implementing a joint communications strategy with clear and unified messages against FGM; developing a unified mechanism for work with the MOHP to create a single manual and curriculum for physicians on FGM.

Along with UNDP, seven countries 
contributed to the first phase (2003-2005) of the FGM-Free Village Model project: Italy, the Netherlands, Denmark, Canada, the United States, Finland, and Switzerland. The European Union joined in the second stage (2005), and its support allowed the project to extend until 2008 as well as expand its outreach from 60 to 120 villages and the number of governorates from 6 to $10 . .^{10}$ UNFPA and UNIFEM also pooled resources with the FGM-Free Village Model in 2007, while UNICEF continued coordinating with the project. It is safe to note that the innovative approach and the multi-dimensional strategy of the FGM-Free Village Model has attracted many donors committed to the elimination of FGM.

Given the sensitive nature of the issue and allegations that it is part of a Western agenda, donors agreed to operate with low visibility at the community and village levels. ${ }^{11}$ UNDP/NCCM agreed with the donors that only the logo of NCCM would be advertised as part of the campaign for the project. When appropriate, the logo of DAG was used to identify the support of the donor within the coalition. Donors also agreed to accept a unified format of reporting from UNDP, which was essential for the smooth operation of the project. The unified format facilitates the administrative operation of the project, as each donor usually requires a different format.

Coordination amongst donors and $\mathrm{UN}$ agencies is crucial for effective interventions. Two mechanisms have been introduced to avoid overlapping and to maximize the specific contribution of each specialized agency. These include a biannual steering committee and a regular coordination committee. The steering committee for the FGM-Free Village Model helps to ensure coordination and follow up. The steering committee is also responsible for making decisions relevant to the strategic course of the project. The steering committee is chaired by the NCCM Secretary General and the UN Resident. Its members include heads of UN agencies (UNDP, UNICEF, UNFPA, and UNIFEM) and line ministries such as the Ministry of Health and Population (MOHP) and the Ministry of International Cooperation (MIC). Although the steering committee offers an important venue for sharing and reinforcing key political issues, there was a need to discuss the technicalities of the project and the coordination between $\mathrm{UN}$ agencies in greater depth. The coordination committee was therefore created by UNDP in 2005 to develop closer cooperation between all of the partners. 


\section{The FGM-Free Village Model:} Documentation of the Programmatic Activities in the First Phase (2003-2006)

\footnotetext{
s noted earlier, the FGM-Free Village

$\Lambda$ Model has five major components. These are:
}

1. Institutional setup at the central and local levels.

2. Advocacy, capacity building, and networks.

3. Community initiatives.

4. Communications for behavioral impact.

5. Monitoring and evaluation.

In this section, we discuss activities undertaken as part of these five components.

\section{Institutional Set Up at the Central and Local Levels}

The institutional setup of the Model comprises three levels:

\section{A. Project Technical Unit at NCCM:}

This central unit is responsible for managing the day-to-day activities of the project; following-up on project implementation at the governorate level; managing the technical and financial components of the project; managing and disseminating the public education component, which focuses on the sociocultural elements of the project at the national level; and finally, coordinating and supporting the different activities and meetings of the various mechanisms that are included in the project's organizational chart. The project technical unit is led by the project program coordinator, who is supported by three additional coordinators with the following duties: coordinate and oversee the activities of local and implementing NGOs (NGO coordinator), plan and train all project staff, including focal NGOs, local NGOs, and UNVs as well as different target groups at the central level such as media, legal, religious, and medical personnel (training coordinator), and supervise the United Nations Volunteers (UNV) (youth coordinator). A UNDP program officer is also involved fulltime in the follow up and coordination of activities between donors, UN agencies, and NCCM.

\section{B. Project Units at the Local Level:}

Twelve NGOs were contracted in the six targeted governorates (two focal NGOs per governorate). Unlike many development projects, the NGOs were not grant recipients but were service providers that were sub-contracted to implement project activities at the village and governorate levels. One-year renewable contracts were based on a clearly defined scope of work and terms of payments in line with performance evaluation and submitted progress reports. This arrangement provided greater flexibility to the project, more accountability from NGOs, and the ability to replace NGOs whose performance did not meet project requirements. Preparations for an expansion phase to reach 60 additional villages began in 2005 . Four additional governorates in Lower Egypt were selected for project expansion: Kalyobiya, Fayoum, Gharbeya, and Port Said. Preparations for the expansion phase involved identifying new partner NGOs in Lower Egypt (two in each governorate). Eight additional focal NGOs in Lower Egypt were identified for implementation in the expansion phase and contracted in 2006. As per the contractual agreements with the 
focal NGOs, each NGO has set up a local project office with three full-time staff (one project director and two field coordinators) and a part-time secretary and accountant. Assistance was provided for operating costs. The NGOs were required to submit technical progress reports and financial reports on a quarterly basis to the NCCM project team. Partner NGOs were selected at the governorate level based on the following criteria:

- Capacity and practical experience in networking with NGOs at the local level.

- Administrative and technical capacity to undertake and report on project implementation at the local level as indicated in the terms of reference.

- Prior experience in the selected villages or in neighboring villages.

- Prior experience in dealing with social developmental issues, preferably issues related to empowerment of women and the rights of the girl child.

- Credibility and recognition within the local community.

Focal NGOs at the governorate level are a vital entry point to villages and local communities through their networks and existing development work. Their work at the local level has been channeled through community development associations, youth centers, and other smaller NGOs. A series of trainings was provided to NGOs to raise their capacity:

1. A one-day seminar for NGOs provided them with public education materials on FGM and information about the lessons gained from previous interventions addressing this practice.
In addition, an inventory was compiled of all printed material, including the medical, social, religious, and legislative perspectives related to the issue. This inventory served as a resource kit which supported the work at the village level. Training programs targeted community workers within NGOs, creating a cadre of advocates which would successfully carry out programs and activities and integrate anti-FGM messages into the various development activities in the village.

2. Focal NGOs were also trained on the village profile methodology, which aims at determining baseline social and cultural trends in intervention sites and identifying key community leaders. The scope of the training included topics such as: community mobilization methods, data collection and qualitative social indicators, an introduction to family counseling, communications techniques, data entry and analysis, and report writing. There were two phases to the village profile process. The initial phase included twelve villages (two villages per governorate where the focal NGOs were based) and was conducted by the Egyptian Society for Population Studies and Reproductive Health (ESPSRH), which provided hands-on training for focal NGO staff to implement the process in the remaining intervention sites. In the second phase, each focal NGO was responsible for leading the village profile process in four villages using the methods applied in the initial phase. Technical support was provided by the project team and ESPSRH as needed.

3. The project team conducted two workshops for focal NGOs: one for those in the northern governorates of Upper Egypt (Beni Suef, Menya, and 
Assiut), which was held in Menya; and another for the southern governorates of Upper Egypt (Sohag, Qena, and Aswan), held in the city of Luxor in Qena governorate. The objectives of these workshops were to follow up on the progress of the village profiles, share the collective experiences of NGOs in their implementation, and identify training needs for NGOs to raise their capacity. The workshops introduced the experience of judges in managing FGM cases, which were presented to the court as cases of violence and medical malpractice. The training needs of the NGOs were also assessed by the project team and these needs were found to include planning tools, reporting skills, and communications skills.

In preparation for the expansion phase into Lower Egypt, village profile training was provided for NGOs in Lower Egypt in 2006. The training was provided in collaboration with key field coordinators from the Upper Egyptian NGOs. The project team incorporated key indicators in the village profile studies, ensuring that the scope of the studies focused closely on local community attitudes toward girls' rights and FGM specifically. This helped in defining the most effective entry points for addressing FGM in new villages. The village profile studies also helped to analyze existing services and community needs in order to develop effective initiatives that were responsive to the community, especially in sectors like education and health which directly influence the quality of life of families and children.

NCCM also organized training courses for community leaders in each of the six governorates involved in the project in 2004. These workshops included religious leaders, community leaders, women's group leaders, youth leaders, physicians, lawyers, and members of the local councils. The training was held in Cairo to ensure that the FGM messages came from the central unit team, stressing that no form of FGM was acceptable and that there would be no compromise or midway solutions regarding the practice. The training curriculum was developed with the support of a number of experts who provided simplified answers to social inquiries on FGM from the medical, religious (Muslim and Christian), legal, and social perspectives, in addition to statistical data about the practice nationwide. The village profiles were disseminated to the NGOs and community leaders to help reveal the attitudes of the respective villages toward FGM. The training also helped initiate relationships with influential groups in the community, promote consensus, and gain local support throughout the project period, thereby guaranteeing sustainability and local ownership of the model.

\section{Youth Unit and UN Volunteers (UNVs):}

The FGM-Free Village Model recognizes that youth are a vital link in changing prevailing misconceptions. The project team provided youth groups with training on communications and training of trainers (TOT) in order to enhance their communications skills to raise awareness on FGM. A listing of these activities is included in Annex III. Within the scope of the youth awareness component, camps were organized by the Ministry of Youth and supported by NCCM. The FGM-Free Village Model project team participated in these youth camps held in the cities of Port Said and Nuweiba. A dialogue session with the directors of youth centers was also conducted and information supporting the elimination of FGM was introduced. The session offered a good forum for exchanging different views on the FGM practice and its causality. As shown in details in 
Annex III, the project also held a series of training courses for university students from Helwan, Menoufia, Ain Shams, Alexandria and Zagazig Universities.

UNVs have been an integral component of NCCM's intervention. The initial group of UNVs had eleven members. The group of UNVs now has a total of 42 highly dynamic and motivated youth under the supervision and mentoring of youth coordinators. They are divided into six groups working in the different locations in Upper and Lower Egypt. They are primarily active within the following functions:

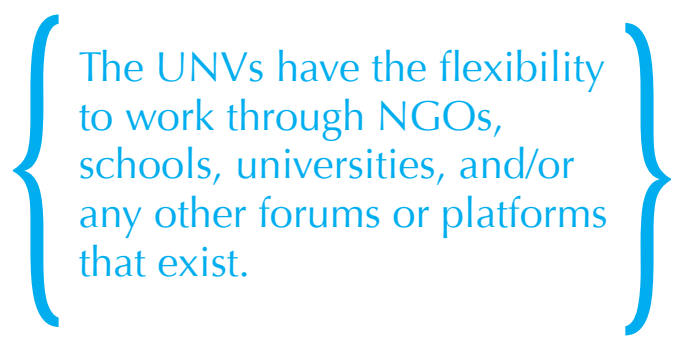

- Fieldwork

- Outdoor campaigning, awarenessraising, marketing, and communications

- Evaluation and monitoring of the project as well as the engaged NGOs

In addition to these UNV groups, the project team recruited two full-time UNV specialists to work with the $\mathrm{NGO}$ coordinator in monitoring the NGOs in Upper Egypt, and two additional specialists to monitor the NGOs in Lower Egypt. Each UNV oversees three governorates. They play a critical role, especially in the planning and reporting phases, when they help NGOs develop plans and help compile progress reports that are then submitted to the NGO coordinator. A demanding workload prompted the hiring of additional assistants for each governorate to monitor the activities of the NGOs in Assiut and Menya.

Some of the activities undertaken by UNVs include the following:

1. In Beni Suef, one of the UNVs became a teacher and took an active role against FGM in his school. His work targeted teachers (one of whom joined the UNVs), students, and parents. His entry point, as he states, was $t$ supply the school library with books on FGM and establish a special corner in the library with a poster of 'the Egyptian girl'. He also staged competitions for the students to submit book reports on the issue, in order to get them engaged on the topic. With the help of his colleagues, he further extended his work to two other schools. UNVs in general have provided critical entry points to schools and students which are a very important target group for achieving an effective end to this practice.

2. A group of doctors who joined the UNVs formed a student support group at Ain Shams University called 'Fikra' (idea) and began to work on the issue of FGM through different entry points. These students faced strong opposition from hard-line students as they coordinated seminars at their universities against FGM.

3. One young woman from Menya, who is a member of the National Democratic Party (NDP), stated that the project enabled her to influence other NDP members. The training she had received enabled her to organize a seminar for the NDP in Beni Mazar. She stated that she was confident she had been able to 
influence other members, even from the older generation.

\section{Advocacy, Capacity Building and Networks}

At both the village and national levels, the project aims to raise awareness against FGM and advocate for its abandonment. Partners at these levels include NGOs, youth groups, community leaders, physicians, judges, media personnel, and networks of international entities against FGM.

\section{A. Advocacy Efforts with Physicians}

Given the increasing medicalization of the practice of FGM, NCCM mobilized a group of "Doctors Against FGM." These doctors pronounced FGM a violation of the code of medical ethics and an act of malpractice and issued a declaration against FGM. Doctors in intervention villages received training at three workshops during the month of November 2005 to raise their awareness against the practice. Between August and December 2006, eight groups of physicians - a total of 151 physicians - were trained in cooperation with the Faculty of Medicine at Sohag University. The training focused on reproductive health and the elimination of harmful practices against women such as FGM.

Programmatic activities with physicians include the following:

1. Developing a unified curriculum for doctors within the MOHP under the umbrella of NCCM. Different manuals were produced by different organizations in the past. In collaboration with the MOHP and different UN agencies, the project unified the existing manuals and integrated them with additional advocacy tools. A training kit for doctors has been developed and efforts are under way to train physicians in counseling methods to approach families and discuss FGM-related issues in greater depth.

2. Training 112 doctors who work in the health units of the sixty project villages, as well as officials from the MOHP in the six governorates. This was provided through three workshops in November 2005 in Cairo in cooperation with the Egyptian Fertility Care Society, using the project's medical curriculum against FGM.

3. Providing training workshops for 151 physicians in the Sohag University Faculty of Medicine in 2006. Training was provided to medical professionals in collaboration with Eyoun El Wadi, a medical NGO based in Cairo.

\section{B. Advocacy Efforts with Judges in the} Judiciary System

Advocacy efforts with legislators focused on achieving the following:

- Raising public awareness about the legal aspects of the practice, i.e. that FGM is a crime for which the perpetrator (physician or other practitioner) and whoever supports or encourages it is penalized under Egyptian law. In addition, encouraging people to report cases of FGM incidence.

- Raising awareness among legislators about the religious, social, health, and legal aspects of FGM with the purpose of defining FGM as a "premeditated crime against the girl child."

Programmatic activities on the legal front include the following: 
1. NCCM hosted the Afro-Arab Conference on Legal Tools \& FGM in June 2003, which was chaired by Egypt's First Lady Suzanne Mubarak. The conference was attended by 28 African and Arab countries that are working to stop the continuation of FGM. The conference resulted in the Cairo Declaration on the Legal Reference of FGM, which states that laws are "essential for abandoning the practice, yet raising public awareness, advocacy, and the role of civil society is essential to affect any laws or ministerial decrees."

2. In line with the Cairo Declaration, the project incorporated a legal perspective into its FGM manual and curricula and in training courses for community leaders, mass media, youth, and civil society members. These courses indicated that it is important to raise awareness on the legal aspects of FGM as many people are not aware that the Egyptian Civic Code condemns FGM.

3. A three-day training workshop for 50 judges and district attorneys was held in July 2006 in Ein El Sokhna in the governorate of Suez. The main objectives of the training were to review all national and international conventions on child rights, analyze and assess all legislative measures related to FGM, and provide legal personnel with in-depth information on the social and medical dimensions of FGM within the framework of child rights.

4. Three research papers were submitted by a selected group of judges who participated in the legal training workshop. The concept papers addressed possible social service punishments for parents (i.e. attending a training course on the detriments of FGM) and more severe reprimand for practitioners (whether service providers or traditional practitioners like barbers or midwives) in order to reduce the practice in the future.

5. A legal curriculum was designed and included in the FGM manual.

\section{Advocacy Efforts with Media Personnel}

The project has been working with the media since its inception. In 2006, a media advisor was commissioned to deliver workshops for media personnel and creative comic book artists. The project established a preliminary plan of action for addressing the media, using unified messages against FGM in order to eliminate misinterpretations and misquotations. The media advisor held two focus group discussions for television and radio personnel and another focus group discussion for journalists. The aim of the focus group discussions was to assess the primary needs of media personnel in order to enhance their performance regarding the introduction of child rights issues on FGM. The project held a three-day workshop for selected media personnel to develop a guidebook for television, radio and press personnel on FGM. The purpose of the training was to ensure that media coverage would not instigate negative feelings among the public and would raise awareness against FGM, particularly for families with girls at risk. A media guidebook has been prepared to be used by all involved media personnel.

Media challenges were identified through focus group discussions and workshops for national and independent media representatives. The discussions also focused on appropriate strategies and best practices for a sustainable media campaign against FGM. 
The following awareness raising activities were conducted for media personnel:

\begin{tabular}{|c|c|c|c|}
\hline Date & Target Groups & Objectives & Outcome \\
\hline $\begin{array}{l}\text { April and May } \\
2006\end{array}$ & $\begin{array}{c}\text { Three focus groups for } \\
\text { media personnel } \\
\text { (days 3) }\end{array}$ & $\begin{array}{l}\text { Identifying media challenges } \\
\text { Analyzing media content } \\
\text { addressing FGM }\end{array}$ & $\begin{array}{l}\text { Addressing the inconsistencies } \\
\text { in media messages }\end{array}$ \\
\hline June 2006 & $\begin{array}{l}\text { Workshop for media } \\
\text { experts } \\
\text { (days 3) }\end{array}$ & $\begin{array}{l}\text { Production of a media guidebook } \\
\text { in light of FGD outcomes }\end{array}$ & $\begin{array}{l}\text { Agreement on the main } \\
\text { elements to be included in the } \\
\text { media guidebook }\end{array}$ \\
\hline January 2007 & $\begin{array}{l}\text { Workshop for media } \\
\text { experts } \\
\text { (days 2) }\end{array}$ & Testing the media guidebook & $\begin{array}{l}\text { Identifying clear, specific, and } \\
\text { integrated media messages }\end{array}$ \\
\hline May 2007 & $\begin{array}{l}\text { Four workshops for project } \\
\text { team } \\
\text { (day } 1)\end{array}$ & Communications policy & $\begin{array}{l}\text { Developing an integrated } \\
\text { communications policy for } \\
\text { all project partners including } \\
\text { other UN FGM projects }\end{array}$ \\
\hline
\end{tabular}

The media advisor also delivered a training course for UNVs on the different means of documenting project activities through field interviews using a digital camera. The UNVs were also trained on how to use raw footage and how to incorporate it into an attractive form that would create an interesting story to benefit young people.

The project also held a media training workshop for script writers and comic strip artists in which FGM was introduced as a central topic. The training sought to enable these creative writers to incorporate appropriate messages pertaining to child rights and FGM into their work.

D. Advocacy Efforts to Mainstream FGM in Other Projects by NCCM and other Organizations

Linking the FGM-Free Village Model with other projects within NCCM and with other organizations and projects outside NCCM provided a greater number of entry points, which helped integrate antiFGM messages into other projects and activities and expand its reach. Within NCCM, technical assistance was provided by the FGM-Free Village Model project team to other NCCM programs, mainly the education/gender unit of NCCM, the Environment Project, and the Child Labor Program. Most of this technical assistance was in the form of awareness seminars for youth (male and female) and community and religious leaders. Over 40 sessions were held in Northern Cairo and Manshiet Nasser in 2005 in collaboration with the Environment North Cairo Project and the Child Labor Program. Also, a two kilometer March for Child Rights was organized in March 2005 and FGM was covered. An additional 13 seminars on FGM from a comprehensive perspective were held in 
Manshiet Nasser in collaboration with the Child Labor Program at NCCM, supported by the Italian Cooperation. These seminars were held at the Child Labor Program's NGO office and were attended by middleaged and young men and women. An anti-FGM awareness group of 105 men and women was formed to help convince other families to abandon the practice. Anti-FGM messages were also introduced in NCCM's Girls Education Project. In addition, the project incorporated a session in Beni Suef and Sohag. Also, as part of NCCM's Community Schools Building Initiative, sessions were provided in Beni Suef and Duweka.

The project collaborated with UNFPA's Reproductive Health Project for Youth and Adolescents on a campaign against FGM in high schools in the governorates of Menoufia, Sharkia, Ismailia, Fayoum, Menya, Assiut, Sohag, and Qena (two schools per governorate). The issue of FGM was discussed within the broader context of child rights. Girls, young teachers, and NGO personnel were addressed. Training courses for high school students and their supervisors were also offered. The two projects agreed to continue supporting schools at the governorate level. A number of meetings held with students were highly attended, showing their interest in the issue.

Contacts were made with USAID's Catalyst Project to coordinate putting the FGM-Free Village Model project on their map of clinics to be renovated in order to upgrade the health facilities of the participating villages, as there was community consensus that health facilities should be upgraded. The cost of renovation would be shared between the two partners, thus strengthening community services at the village level and integrating the FGM issue within other projects.
The UNDP program officer facilitated contacts with another UNDP project: the information and community technology (ICT) project that is currently working in Upper Egypt through a mobile unit that provides ICT training and literacy classes. The FGM-Free Village Model project, in collaboration with the Mobile Information Technology Clubs (MITC) project, the Ministry of Communications and Information Technology, the Italian Cooperation, and UNDP, launched a pioneer initiative in Upper Egypt in which the FGM project facilitated the process of linking various communities to the MITC project. The MITC project helped enhance trainers' capacities through different functional literacy computer programs. During the training sessions, project facilitators incorporated anti-FGM messages that responded to the public's inquiries on the issue, thus responding directly to the social and practical needs of the community. The initiative started with the Young Muslim Men Association and FGM-Free Village Model project in Menya governorate. The UNVs facilitated the training of 3350 youth (males and females) from the village of Abukorkas Elbalad. The feedback received by both projects reflected the extent to which there is a genuine need in local communities to acquire innovative learning methods in order to broaden the educational and cultural scope of future generations. Based on the positive impact of this initiative, the Coptic Evangelical Organization for Social Services (CEOSS) facilitated the same process in other communities in Menya. At the end of June, the MITC project moved to Benban Village and will probably move to the informal settlement of Mahmoudiah in Aswan governorate based on the request of the communities and Governor of Aswan. The process shall be facilitated in Aswan by the governorate and the Egyptian Association 
for Community Initiatives and Development with the support of the FGM-Free Village Model project.

The project also provided support to Plan International during the formulation phase of its intervention against FGM. The project team distributed the advocacy toolkit that was produced by the project to UNICEF and UNFPA in order to support their interventions at the community level. This helped to unify messages related to FGM, thereby avoiding confusion among the public. This toolkit included the training manual, the booklet on the religious perspective, calendars, copies of religious and medical training tapes, and posters.

\section{E. Advocacy and Networking Efforts at the International Level}

Organizing and participating in international forums, seminars, and initiatives on FGM is a key component in coordinating initiatives at the international level. Involving and mobilizing all social actors from the international level to the community level strengthens the message to abandon FGM. A number of activities have been undertaken as part of this project component:

1. In June 2003, NCCM sponsored the Afro-Arab Expert Consultation on Legal Tools and the Prevention of FGM Conference, held under the leadership of First Lady Mrs. Suzanne Mubarak, who chaired the proceedings. During this conference, 28 African and Arab countries met in Cairo to define both the legal content and strategies for more effective legislation to prevent FGM. The Consultation approved "The Cairo Declaration for the Elimination of Female Genital Mutilation," which encourages all governments to pass legislation aimed at the progressive elimination of FGM. The declaration includes 17 recommendations to ensure that these laws become effective measures of prevention. This declaration was successfully amended in June 2008.

2. As a follow up to the Afro-Arab Expert Consultation Conference, the project team set up a Cairo Declaration Task Force to support NCCM in instituting the Cairo Declaration. The first meeting of the Cairo Declaration Task Force was held at NCCM in July 2003. During this meeting, it was agreed that the FGM-Free Village Model project would emphasize the principles of the declaration within its work plans and identify policy gaps. The task force also works to promote links to the legal establishment and identifies references to FGM in Egyptian legislation through the assessment of judicial experience in past years. This work has been implemented in coordination with concerned ministries.

3. Subsequent to the Cairo Declaration and the identification of policy gaps, it was decided to build legal consensus on all language pertaining to FGM cases, publicize cases in the newspapers and the media, and inform the public of girls' rights.

4. NCCM participated in UNICEF's "The Way Forward" Workshop on FGM, organized in Nairobi, Kenya and held from September 30 to October 2, 2003. The workshop brought together fortytwo participants from seven country offices (Egypt, Oman, Sudan, Eritrea, Ethiopia, Somalia, and Kenya) and aimed to develop an approach to FGM programming that is consistent with human rights and community capacity development. The FGM-Free 
Village Model was presented by the project team as an example of a human rights approach in Egypt. The Egyptian Delegation, headed by the NCCM Secretary General and supported by the project team along with UNDP, participated in the Nairobi Conference on FGM and the Maputo Protocol of September 16-18, 2004 hosted by No Peace without Justice, in which participating African countries presented their programs. The Nairobi Conference recommendations were aligned with the Cairo Declaration, and this created momentum at the national and regional levels. Local Egyptian newspapers covered the Nairobi conference as a main follow up to the Cairo Conference on Legal Tools and FGM.

5. NCCM participated in the Technical Workshop on FGM in Mali (November 30 - December 4, 2004), hosted by the UNICEF Geneva headquarters office. At this workshop, Egypt presented the FGM-Free Village Model as a successful example of participation and intervention at the community level.

6. NCCM participated in the regional conference "Together for Combating Violence against Young Girls," held in Sana'a, Yemen on May 30-31, 2007. The conference brought together the countries of Egypt, Djibouti, Oman, Sudan, and Yemen to discuss violence against women, particularly physical violence in the form of FGM. The conference was sponsored by the Yemeni Minister of Human Rights, hosted by the Yemeni Women's Union, and supported by UNICEF and UNFPA. The conference was also attended by representatives of the Yemeni Women's Union branches in the governorates as well as NGOs, representatives of the Ministries of Endowments,
Health, Education, Social Affairs, and Labor, and other stakeholders in Yemen. The participants agreed on recommendations to establish an Arab Anti-FGM Network, utilizing the policies and strategies that have been used in the context of the Arab Women's Union. Other recommendations included criminalizing FGM, providing a unified religious view on the practice, and activating the role of the media in all its audio visual or written forms in order to raise awareness.

\section{Community Initiatives and Village Public Declarations}

One of the important components of the FGM-Free Village Model is the promotion and support of community initiatives that provide needed services to the local communities and villages, such as healthcare, education, micro-loans, literacy education, computer centers, and nurseries. These initiatives also mobilize communities in selecting, planning, and implementing FGM awareness-raising activities. They also provide demand-driven services to the community in order to anchor and mainstream anti-FGM messages as part of other activities. Community initiatives are implemented by partner focal NGOs, local community development associations, and governorate-level youth groups.

The initiatives carried out in the villages of the six governorates have supported advocacy and awareness-raising activities, service provision, and the organization of public declarations against FGM.

Advocacy and awareness-raising activities included seminars that addressed different groups and community members in the villages. Some of the topics tackled in these seminars include: 
- Reproductive health and FGM;

- FGM from medical, religious, legal, and social perspectives;

- Child rights and protecting the girl child;

- Violence and discrimination against women;

- The physical, social, and psychological harm caused by FGM;

- Equality between men and women in Islam;

- Islam's honoring of women; and

- The activation of the role of local communities in fighting FGM.

Other activities included home visits to families, youth camps, and sporting events where anti-FGM handouts and materials were disseminated. Activities also aimed to create support groups against the practice among religious leaders, physicians, and other community members and to integrate anti-FGM messages in religion and literacy classes.

Demand-driven community services varied across governorates and villages. These included activities such as the provision of computer facilities and computer courses for youth, skills development classes, payment of registration fees for families to obtain electronic national ID cards, health programs and the establishment of medical centers, and the provision of water and electricity services. There were also capital improvement projects, such as renovating nurseries, providing small loans for implementing informal sector projects, establishing small libraries in the villages and providing them project materials, and establishing spaces or clubs for women's activities. Also, school scholarships for girls and other activities were provided.
Annex III includes a listing of social services and awareness activities in the six governorates of the intervention during the first phase of the program.

Project activities also mobilized the public village declarations against FGM. These declarations constitute a pledge and a commitment by officials, religious leaders, youth, and community members to put an end to the practice of FGM. Village declarations are the outcome of two or more years of devoted efforts and activities carried out by officials, community and religious leaders, women activists, and village youth of both genders. The declarations are usually made during official and public ceremonies attended by the NCCM Secretary General, as well as local religious and women's leaders, representatives of NGOs and international organizations, and village youth of both genders. The declarations are signed by community members and leaders at the end of the ceremony to document the process and make it official.

Declarations of villages and communities as part of the project activities include (in chronological order):

1) Benban village, Aswan governorate (June 22, 2005)

2) "Stop FGM" Declaration in: Abu Qorqas Village - Markaz Abu Qorqas - Menya Governorate (November 30, 2005)

3) "Efforts against FGM Continue" Declaration in Al Gazair village, Markaz Samalout, Menya governorate (December 15, 2005)

4) Kom Gharib village, Sohag governorate (June 2006). The declaration was produced through strong participation 
of youth activists and other community leaders.

Zahrat Al A'qab Declaration: "One Stance against FGM" in Greater $\mathrm{Al} \mathrm{A}^{\prime}$ qab village, Aswan governorate (December 22, 2006)

5) Bint Enaiba Declaration: "Enough, stop It" in Enaiba village, Markaz Nasr Al Noba, Aswan governorate (December 23, 2006)

\section{Communications for Behavioral Impact through the Media}

Key objectives of this component include the following:

1. Provide clear and unified messages on FGM to the public from a comprehensive perspective, thus empowering confused parents to abandon the practice.

2. Continue supporting the national dialogue on FGM as a child rights issue. This includes two main components: the media component and the development of an FGM-Free Village Model Toolkit with adaptable elements that can be customized to meet the needs of any community.

The media component builds on the main messages that have been identified as influencing families' decisions to practice FGM. A media campaign entitled "El Bent Mysria" (The Egyptian Girl) was launched by the project. This campaign has three main messages:

1. "No to Deprivation from Education"

2. "No to FGM"

3. "No to Early Marriage"
The infomercial "El Bent Mysria" was the first of its kind to be aired on national television. It addressed the issue of FGM from the religious perspective, whereby a sheikh and a priest underlined that neither Islam nor Christianity encourages the practice of FGM. It emphasized that FGM has no medical grounds and that physicians who perform female circumcision are in fact violating the ethics of the medical profession. It also addressed some of the most common misconceptions about FGM and was geared toward answering inquiries surrounding the practice. Posters from the infomercial were displayed in metro stations for three consecutive months.

The "El Bent Mysria" campaign was aired on both radio and television. Other radio programs were also produced to provide awareness against FGM for outreach in rural areas. NCCM provided technical assistance on FGM for the popular radio program "Rabat El Beyout," which addresses women. The "El Bent Mysria" campaign initiated large-scale press coverage that included newspaper articles and reports from target villages in Upper Egypt that presented actual cases and reflected public opinion on the issue. NCCM also published the periodical magazine "El Bent Mysria," which serves as documentation of program activities and communicates simple direct messages to the public. Furthermore, the project has mobilized a number of writers from leading newspapers and the Ministry of Culture to contribute to the journal and has published the works of young advocates concerned with the issue. For the third edition of "El Bent Mysria," the project contracted a young professional journalist who is an anti-FGM advocate and has published a series of articles on the detriments of FGM for young girls in the national magazine "Sabah El Kheir." Daily newspapers such as "Al-Ahram" and "Al-Akhbar" have 
regularly covered events related to the FGM-Free Village Model project in addition to all FGM activities under the umbrella of NCCM. Furthermore, the women's magazine "Nesf El-Donia" started a section on FGM, focusing on mothers and fathers who showed their courage and abandoned the practice.

Media efforts were very pivotal in raising awareness after the FGM-related deaths of two girls in Upper Egypt. The independent newspaper "El Masry El Youm" followed up on the story and contacted NCCM and the project team to inform them of the girls' deaths and to get feedback from the project team. The independent media carried the story and played an important role in the anti-FGM campaign.

NCCM did an assessment of its media strategy in 2006. This assessment resulted in the formulation of a media guidebook. This guidebook includes information, resources, and quality and ethical standards for the media.

The FGM-Free Village Model developed a toolkit on FGM for dissemination. The main element of the toolkit is a manual in which frequently asked questions on FGM are addressed. This manual is entitled "FGM...Until When?" (Khetan Al-Enath... Ila Matta?). It relies on an interactive approach which demonstrates that social beliefs and misconceptions supportive of FGM are opposed to documented scientific, religious, historical, and legal facts that show the futility of the practice and its adverse consequences. The religious perspective, which is included in this manual, was also published as a separate document entitled "FGM from an Islamic Perspective" ("Khetan Al-Enath men Manzour Islami"). This document responds to the religious debate and addresses all the religious inquiries highlighted in the media throughout the year. The booklet was written by Islamic Scholar Dr. Selim El Awa, Secretary General of the International Union of Islamic Scholars. The booklet was distributed by Al-Ahram Publishing House outlets at a nominal cost (one Egyptian pound). NGOs disseminated copies in villages and UNVs disseminated them to selected mosques in Cairo and at university seminars. Dr. El Awa's views were also published in "Al-Ahram" newspaper and in an Arabic think tank magazine called "Weghat Nazar."

The project produced other materials and publications. These include documentation of the process of the first anti-FGM declaration in Benban, Aswan in a book entitled "Daughters of Benban... Shut This Door" ("Bent Benban...Eghlequ haza El-Bab"), published in 2006. The book incorporated other development actions in the village six months after the declaration and was written by a professional journalist. A small booklet was also published in both Arabic and English in 2005 which included the text of the Benban Declaration as well as the Cairo Declaration on Legal Tools to Prevent FGM.

Another book entitled "Breaking the Silence: Real Stories on FGM from Upper Egypt" ("Kasr Hagez Al-Samt: Qessass Waqe'ya 'an Khetan Al-Enath Men Sa'eed Misr") was published in cooperation with one of the partner focal NGOs, CEOSS, in Beni Suef. The book presents the stories and experiences of 46 women in which they recount the pain and trauma they experienced while undergoing the procedure of FGM as young girls, as well as the negative implications of the procedure in later life, both in terms of their health and their marital relationships.

Other media materials produced by the project include an annual calendar which 
contains short messages related to FGM from a holistic perspective. This calendar is perceived as one of the most attractive printed tools because it is used by village NGO personnel, governors' offices, schools, and medical units. The project extracted the medical oath from the FGM training manual and produced a poster for health facilities in order to raise public awareness on the rights of the clients of health facilities. This poster clearly acknowledges that FGM is a violation of the medical oath. The project also reproduced the messages of the "El Bent Mysria" television campaign in a poster to target families, community leaders, teachers, and youth. A third poster was produced that shows FGM as a violent practice against the girl child.

NCCM shared the above materials with other interventions and projects that focus on the FGM issue. These materials include the training manual, the booklet on the religious perspective, calendars, copies of religious and medical training tapes, and posters.

\section{Monitoring and Evaluation}

\section{Village Profile}

An important tool implemented by the FGM-Free Village Model project was the village profile process. This process aimed to determine baseline socio-cultural trends within the sixty villages targeted by the project. It was also intended as a tool for further monitoring and evaluation of project interventions and a means for identifying community initiatives.

The baseline data that were gathered about project intervention sites was a critical introductory tool to the communities. It also served as a measuring tool for monitoring and evaluation. The village profiles provided details on the attitudes of women, men, youth, and young girls toward gender issues, including girls' education, FGM, female employment, girls' status in the family, role distribution within the family, and early marriage. Furthermore, the village profiles identified community leaders for the FGM-Free Village Model project to train and empower with relevant information on FGM in order for them to influence and change the attitudes of their communities toward FGM.

Thus, the village profiles were critical in assessing the socio-cultural and religious factors related to the prevalence and perpetuation of the practice of FGM among various social groups in society. In this way, the profiles could determine possible entry points for each community under study and identify qualitative indicators for socio-cultural trends and popular tendencies relevant to the practice of FGM. NCCM assigned the Egyptian Society for Population Studies and Reproductive Health (ESPSRH) the task of executing the study "Village Profiles of FGM in Upper Egyptian Governorates." This study was conducted in two villages in each of the six governorates of Upper Egypt (Aswan, Qena, Sohag, Assiut, Menya, and Beni Suef). The governorates and the villages were selected by NCCM.

\section{Project Monitoring}

The project recruited a monitoring and evaluation advisor in 2004 who helps to monitor activities at the local level and standardize reporting procedures for the twelve NGOs. The advisor has identified a set of indicators to facilitate impact evaluation. The advisor's job assignment includes strengthening the village profile process and establishing reporting formats for NGOs in coordination with the NGO coordinator. Monitoring the activities of partner NGOs is an on-going process. The 
NGO coordinator is assisted by two field coordinators who regularly visit project sites and NGOs. They provide reports on progress, challenges, and future plans. This is in addition to the reports and periodical proposals for future action submitted by NGOs to NCCM for approval. Grants are made following the approval of NCCM and the UNDP program officer. Monitoring and evaluation of activities on the ground occurs through follow-up visits in each governorate by NCCM project team members. During field visits to CDAs and youth centers in the targeted villages, project team members meet with the staff working for the project, share visions and concerns in order to suggest recommendations, and assess materials, equipment and supplies purchased or produced through the project.

Community project teams have been established in all of the communities. The number of teams in each community varies from two to twelve persons according to the influence of the NGO. Community project teams are entrusted with conducting home visits. The capacity for conducting home visits, in both coverage and effectiveness, varies according to the strength and capacity of the project teams and consequently of the responsible NGO.

The project has also designated six fulltime UNVs contracted from the six Upper Egypt governorates to monitor activities in the field and report to the monitoring and evaluation officer. Furthermore, a standard technical reporting format for the focal NGOs was developed by the project team in order to closely assess the project's impact on target groups and the effectiveness of services provided in the field.

This mid-term evaluation is part of the project's monitoring and evaluation component. A set of evaluation indicators has been developed by the project team. These indicators have guided the outline of the evaluation report. These indicators are:

- Change in knowledge, language, and terminology on all aspects of FGM.

- Change in attitudes; a change from approval to disapproval of the practice or a change in intention to circumcise a daughter.

- Committed groups (youth, doctors, religious leaders, NGO activists, and the media) who advocate against the practice of FGM.

- Public declarations against the practice of FGM in respective villages.

- New groups that have been engaged in project activities (e.g. school and university students, academics, media representatives, opinion leaders, and government officials).

- Public discussion around FGM. Is FGM still a taboo subject in public discussion or is the issue of FGM raised repeatedly in the press, television, radio, and the internet?

- Effectiveness, appropriateness, and flexibility of the project's approaches and tools and the potential for their replication in other project sites. 


\section{COMMUNITY- LEVEL IMPACT EVALUATION}




\section{FGM-Free Village Model Impact at the Community Level}

T he evaluation in this report builds on both qualitative and quantitative data collected as described in the methodology section of this report. The quantitative data collected from intervention and control sites revealed a wealth of insights into the impact of the project intervention at the community level and allowed for comparing attitudes and behaviors of respondents who were part of the intervention and control samples. The qualitative data collection component focused on prevailing attitudes regarding the practice, reasons for performing FGM, and the effectiveness of different program components. The aim of focus group discussions with men and women was to provide a deeper understanding of the dynamics pertaining to the practice of FGM. issues:

The analysis will focus on the following

- Change in knowledge, language, and terminology on all aspects of FGM.

- Change in attitudes: a change from approval to disapproval of the practice or a change in intention to circumcise a daughter.

- Committed groups (youth, doctors, religious leaders, and NGO activists) against FGM.

- Public declarations against the practice of FGM in respective villages.

- Public openness to discuss FGM.

- Challenges and opportunities.

It is important to note that data was collected in December 2006 at the mid-term point of the intervention. The components of the intervention being assessed are training and advocacy efforts at the central level for physicians, judges, media personnel, and adolescent and youth groups and lobbying efforts with MOHP to change laws related to FGM.

This section assesses the impact of community-level interventions. These include awareness-raising activities in the form of seminars; small group meetings among target families, young men and women, community leaders, and schools; and services to the community, primarily in education and health. Community efforts also involved mobilizing community groups to create public declarations against FGM.

\section{Data on the Impact of the intervention: Similarities between Intervention and Control Sites}

As noted in the methodology section, the evaluation uses a quasi-experimental approach, comparing intervention sites to control sites of similar characteristics in order to detect changes that can be attributed to the intervention. Intervention and control sites have fairly similar background characteristics so that any differences observed in the data between them can be attributed to the impact of the project. In analyzing the data on socio-cultural and social background, we found that two of the intervention sites were predominantly Christian villages, though none of the control sites were. Because these villages had some different background characteristics, we decided to exclude them from the analysis so as to ensure that the intervention and control villages were as similar as possible. The remaining intervention and control villages had a comparable mix of Christians and Muslims and were similar in the following characteristics: 
1. Ever-married women's circumcision status: 99 percent of women in the intervention sites were circumcised, compared to 99.5 percent in the control sites. The circumcision rate of women in predominantly Christian intervention sites was much lower at 81 percent.

2. Ever-married women's age structure: The mean age of ever-married women in the intervention and control sites was about 39 .

3. Marital status: 91 percent of evermarried women in the intervention sites were still married compared to 93 percent of women in the control sites, with most of the remaining being widowed.

4. Socio-economic status: 28 percent of ever-married women were in the lowest socioeconomic status compared to 31 percent in control sites. Only 14 percent of ever-married women were in that status in the predominantly Christian intervention sites.

5. Practitioner of FGM: 90 percent of circumcised ever-married women in both settings were circumcised by a traditional practitioner (daya).

There were slight differences between the intervention and control sites in women's educational levels, living arrangements, and family size. Fifty percent of women in the intervention sites were illiterate compared to 65 percent in the control sites. In terms of living arrangements, 78 percent of women in intervention sites were living in nuclear families compared to 73 percent of those in control sites. The average number of living children was 5.1 in intervention sites compared to 5.5 in control sites. Nevertheless, these differences are fairly minor and not enough to invalidate conclusions in the outcomes that can be attributed to the project.

The background characteristics of girls in the 10-15 and 16-24 age groups in both the intervention and control sites were also very similar. They were similar in their education characteristics, with the majority of girls aged 10-15 attending school (about 93 percent). Girls aged 16-24 also shared some similarities related to drop-out rates and non-attendance, with fewer than 20 percent of girls in both the intervention and control groups receiving no schooling or having dropped out of school before completing the primary stage. Also, very few girls in the two age groups and in both the intervention and control groups were wage earners.

Tables 27 and 28 in Annex $V$ provide details on the different characteristics of girls in both age groups.

The background characteristics of male respondents in both the control and intervention samples were also similar. The majority of young men aged 16-24 in both samples had a secondary education and only 11 percent of young men in the intervention sample and 15 percent in the control sample attained university education. Among older men, about 20 percent of men in both the intervention and control sites had no schooling. Tables 29 and 30 in Annex $V$ provide details on the different characteristics of men in both age groups.

\section{Information and Knowledge about FGM}

This section documents changes in information, knowledge, language, and terminology on all aspects of FGM, comparing data from the intervention and control groups. 
The FGM-Free Village Model is based on a socio-cultural approach which seeks to create an environment conducive for individuals to renounce the practice of FGM. As part of this approach, it is important for community members to believe that society, and in particular their own community, is against the practice in order to be able to take a personal stance against it. In this section, we include an analysis of individuals' perceptions about the views of opinion makers and other leaders in their communities. Table 3 shows the perceptions of women, men, young men, young women, and girls on the extent of FGM in their communities. The table shows that in control sites, respondents from all age groups were more inclined to believe in the universality of FGM in their communities than those in the intervention group. More than 92 percent of women in the control sites agreed with the statement that all people in their communities circumcise their daughters as opposed to 45 percent of women in the intervention group. Similarly, the views of young and old men, young and old women, and girls varied widely between the control and intervention sites. For example, young women in the control sample were twice as likely to believe in the universality of FGM in their communities (86 percent compared to 40 percent in the intervention group). Among girls, 89 percent believed in the universality of the practice in their communities in control sites, while only 39 percent in the intervention sites believed so. This shows that the interventions managed to shake long-held beliefs in the universality of FGM in these communities. This is an important step in changing attitudes and behaviors toward FGM because it facilitates the creation of a socio-cultural environment conducive to the abandonment of the practice.

Similarly, when we asked respondents about their perceptions of the views of important opinion makers on FGM, there was a significant difference between the intervention and control groups.

Table 3: Perceptions of individuals (different groups) about the extent of FGM in his/her community

\begin{tabular}{|c|c|c|c|c|c|c|c|c|c|c|c|}
\hline & \multicolumn{2}{|c|}{$\begin{array}{c}\text { Women } \\
\%\end{array}$} & \multicolumn{2}{|c|}{$\begin{array}{c}\text { Men } \\
\%\end{array}$} & \multicolumn{2}{|c|}{$\begin{array}{c}\text { Young men } \\
\%\end{array}$} & \multicolumn{2}{|c|}{$\begin{array}{c}\text { Young women } \\
\%\end{array}$} & \multicolumn{3}{|c|}{$\begin{array}{c}\text { Girls } \\
\%\end{array}$} \\
\hline $\begin{array}{l}\text { In your } \\
\text { community ... }\end{array}$ & C & I & C & I & C & I & C & I & C & & \\
\hline All do circumcise & 93 & 45 & 81 & 57 & 74 & 52 & 86 & 40 & 85 & & \\
\hline $\begin{array}{l}\text { Most of them } \\
\text { circumcise }\end{array}$ & 5 & 31 & 10 & 20 & 17 & 22 & 10 & 41 & 7 & & \\
\hline $\begin{array}{l}\text { Only a few } \\
\text { circumcise }\end{array}$ & 1 & 11 & 6 & 16 & 7 & 15 & 2 & 11 & 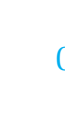 & & \\
\hline $\begin{array}{l}\text { No one } \\
\text { circumcises }\end{array}$ & 0 & 11 & 1 & 5 & 2 & 7 & 1 & 6 & & & \\
\hline Don't know & 2 & 3 & 1 & 2 & 2 & 4 & 2 & 2 & 2 & & 10 \\
\hline (Total (N & 202 & 303 & 171 & 269 & 176 & 287 & 189 & 289 & 162 & & 25 \\
\hline
\end{tabular}

C: Control Site; I: Intervention Group 
As Table 4 shows, respondents in intervention sites were less inclined to believe in the approval of FGM among teachers, doctors, religious leaders, community leaders, and influential families in the community. In control sites, more informants believed that teachers and influential families were supportive of FGM. Surprisingly, more informants believed so of teachers than of religious leaders. Similarly, among the intervention group, teachers were seen as one of the groups most attached to the practice by most informants. The data in this table highlight the important role that teachers play in building consensus on FGM.

The data reveal an interesting finding regarding the views of imams, as shown in Table 4. In the intervention communities, a significantly smaller proportion of people believed in the support of imams for FGM compared to those in control sites (33 percent as opposed to 90 percent of women in the intervention and control groups, respectively). This highlights the impact of the program in changing attitudes about the support of local religious leaders for FGM in the intervention sites. However, it is important to note that the differences between intervention and control sites on this dimension are much smaller among husbands and young men than among married women and young women. This underscores the need to intensify educational efforts among men.

In order to understand the role that social pressure plays on the decision to circumcise a daughter, we specifically asked respondents the following question: "If you left your village to live in a place where people did not practice FGM, would you circumcise your daughter?" As shown in Table 5, the responses demonstrate the role of social pressure in this decision. Women in the intervention groups were more likely to note that they would abandon the practice in this hypothetical situation (44 percent of women in the intervention group compared to 27 percent of women in the control group). Similarly, men in the intervention group were more likely to abandon the practice given this hypothetical situation compared to men in the control group (47 percent compared to 42 percent). These results assert the importance of public declarations against FGM. Such declarations can alleviate the social pressures on families to perpetuate

Table 4: Perceptions of Community Members Regarding the Approval of FGM among Influential Figures in their Communities

\begin{tabular}{lcccccccccr}
\hline & $\begin{array}{c}\text { Women } \\
\%\end{array}$ & $\begin{array}{c}\text { Men } \\
\%\end{array}$ & \multicolumn{3}{c}{$\begin{array}{c}\text { Young men } \\
\%\end{array}$} & $\begin{array}{c}\text { Young women } \\
\%\end{array}$ & \multicolumn{2}{c}{$\begin{array}{c}\text { Girls } \\
\%\end{array}$} \\
& C & I & C & I & C & I & C & I & C & I \\
& 94 & 48 & 90 & 76 & 88 & 69 & 99 & 43 & 94 & 49 \\
Teachers & 82 & 29 & 80 & 55 & 78 & 53 & 76 & 23 & 85 & 44 \\
Health clinic doctors & 90 & 33 & 88 & 67 & 86 & 66 & 83 & 33 & 88 & 42 \\
Imams & 96 & 44 & 87 & 68 & 89 & 69 & 98 & 54 & 97 & 51 \\
Community leaders & 97 & 57 & 91 & 73 & 91 & 77 & 97 & 62 & 99 & 64 \\
Influential families & & & & & & & & & & \\
\hline
\end{tabular}


the practice of FGM, as they see important figures in their communities denouncing it in public.

We asked respondents about their immediate circle of family and neighbors and if they knew of cases of girls who had suffered complications from FGM; if they knew of girls who had died because of
FGM; and if they knew of girls who had avoided FGM until marriage. Replies to these questions varied significantly between the intervention and control sites, as Table 6 shows. Individuals among the intervention group were more knowledgeable about cases of complications and deaths due to circumcision. $^{12}$ Interestingly, young women in intervention sites were the group most

Table 5: Attitudes toward FGM if it is not practiced by others

\begin{tabular}{|c|c|c|c|c|}
\hline & \multicolumn{2}{|c|}{ Women } & \multicolumn{2}{|c|}{ Men } \\
\hline & $\mathrm{C}$ & I & $\mathrm{C}$ & I \\
\hline & $\%$ & $\%$ & $\%$ & $\%$ \\
\hline \multirow{2}{*}{\multicolumn{5}{|c|}{$\begin{array}{l}\text { If you left your village to live in a } \\
\text { place where people did not practice } \\
\text { FGM, would you circumcise your } \\
\text { daughter in the future? }\end{array}$}} \\
\hline & & & & \\
\hline Yes & 64 & 45 & 57 & 48 \\
\hline No & 27 & 44 & 42 & 47 \\
\hline Don't know & 10 & 12 & 1 & 6 \\
\hline
\end{tabular}

Table 6: Knowledge about complications caused by FGM and of cases of girls who avoided circumcision

\begin{tabular}{|c|c|c|c|c|c|c|c|c|c|c|}
\hline \multirow{2}{*}{$\begin{array}{l}\text { Knowledge about } \\
\text { complications caused } \\
\text { by FGM }\end{array}$} & \multicolumn{2}{|c|}{ Women } & \multicolumn{2}{|c|}{ Men } & \multicolumn{2}{|c|}{ Young men } & \multicolumn{2}{|c|}{ Young women } & \multicolumn{2}{|c|}{ Girls } \\
\hline & C & I & $\mathrm{C}$ & I & $\mathrm{C}$ & I & C & I & $\mathrm{C}$ & \\
\hline $\begin{array}{l}\text { Heard of a girl that } \\
\text { died of FGM }\end{array}$ & 3.0 & 7.6 & 1.2 & 13.3 & 0.6 & 2.1 & 1.6 & 8.0 & 0.6 & 5.8 \\
\hline $\begin{array}{l}\text { Personally know of } \\
\text { girls who have not } \\
\text { been circumcised }\end{array}$ & 8.0 & 7.3 & 11.1 & 15.9 & 5.7 & 10.6 & 7.1 & 22.9 & 4.9 & 6.9 \\
\hline $\begin{array}{l}\text { Witnessed any serious } \\
\text { complications }\end{array}$ & 18.2 & 27.0 & 9.9 & 13.3 & 7.3 & 9.4 & 23.8 & 37.5 & 23.3 & 11.1 \\
\hline
\end{tabular}


attuned to the existence of uncircumcised girls that had gotten married (23 percent in the intervention group compared to 7 percent in the control group). Adult married women in both control and intervention groups were the least knowledgeable of such cases.

\section{a) Exposure to Information on FGM}

When comparing data from the control and intervention groups, all age groups in the intervention sample showed a higher level of exposure to information about FGM. While women showed the greatest difference in the level of information received, men showed the least. As Table 7 shows, women in the intervention group were more likely to have received information on FGM (55 percent of women in the intervention group compared to 43 percent of women in the control sample). Among girls, those who were in the intervention group were twice as likely to have received information on FGM as girls in the control sites (28 percent compared to 12 percent).

Table 7 shows that the messages on FGM were not exclusively available to the intervention group. The table shows that a significant proportion of women and men from all age groups in the control sample were also exposed to these messages. As will be shown shortly, the role of the media in information dissemination on FGM was not limited to groups in the intervention localities. This explains why Table 7 shows that people in the control group were also receiving messages against FGM. However, the level of intensity and exposure in the intervention sites is much higher, which is revealed in the differences in the level of exposure shown in the table. In what follows we discuss the types of information received by each group and its impact on attitudes toward FGM.

As shown in Table 8, the major source of information for all groups has been television. Programs on FGM aired on Egyptian television have proven to be a very powerful tool in reaching families, in both the control and intervention samples. Among all groups of respondents in both the intervention and control sites, television ranked highest on the list of sources of information on FGM. It is understandable that the emphasis on television as an information source was stronger in control groups, given the fact that the intervention group had other sources of information such as seminars and group meetings. Therefore, in control sites, television was the medium most mentioned with regards to getting information on FGM. Among women in the control group, more than 77 percent received information on FGM through television. Young men and women had even higher exposure levels to television messages, with over 81 percent of young men and women receiving information on FGM through television.

Among the intervention group, the importance of other sources of information varied according to the age and gender of the group. For women and girls in both age groups, seminars and home visits ranked second and third as the main sources of information (after television). Family relatives also played an important role for women as a source of information. For men in both age groups, seminars and newspapers were the second and third most mentioned sources. 
Table 7: Exposure to Information on fgm within the past two years

\begin{tabular}{lrrr}
\hline Group & Control group & $\begin{array}{c}\text { Intervention } \\
\text { group }\end{array}$ & $\begin{array}{c}\text { Percentage point } \\
\text { difference }\end{array}$ \\
\hline Women & $43 \%$ & $55 \%$ & 12 \\
Girls (10-15 years) & $12 \%$ & $28 \%$ & 16 \\
Men & $29 \%$ & $34 \%$ & 5 \\
Young Men (16-24 years) & $24 \%$ & $38 \%$ & 14 \\
\hline
\end{tabular}

Table 8: Sources of information on FGM

\begin{tabular}{|c|c|c|c|c|c|c|c|c|c|c|}
\hline & \multicolumn{2}{|c|}{ Women } & \multicolumn{2}{|c|}{ Men } & \multicolumn{2}{|c|}{ Young men } & \multicolumn{2}{|c|}{$\begin{array}{l}\text { Young women } \\
\quad(16-24)\end{array}$} & \multicolumn{2}{|c|}{$\begin{array}{c}\text { Girls } \\
(10-15)\end{array}$} \\
\hline & $\%$ & & $\%$ & & $\%$ & & $\%$ & & $\%$ & \\
\hline & $\mathrm{C}$ & I & $\mathrm{C}$ & 1 & $\mathrm{C}$ & I & $\mathrm{C}$ & I & $\mathrm{C}$ & I \\
\hline Television & 77 & 62 & 84 & 74 & 81 & 73 & 82 & 68 & 74 & 53 \\
\hline Radio & 8 & 3 & 18 & 2 & 14 & 4 & 4 & 1 & 5 & 1 \\
\hline Newspapers/magazines & 8 & 3 & 16 & 17 & 12 & 13 & 15 & 6 & 0 & 3 \\
\hline Pamphlets & 0 & 10 & 2 & 3 & 7 & 0 & 7 & 9 & 11 & 10 \\
\hline Flyers & 3 & 12 & 2 & 2 & 2 & 0 & 11 & 16 & 5 & 4 \\
\hline Community gatherings & 0 & 4 & 6 & 6 & 0 & 13 & 6 & 1 & 0 & 4 \\
\hline Husband & 3 & 2 & 0 & 0 & 0 & 0 & 2 & 0 & & \\
\hline Home visits & 15 & 52 & 0 & 2 & 2 & 0 & 13 & 30 & 5 & 20 \\
\hline Health center staff & 5 & 11 & 0 & 3 & 2 & 4 & 15 & 4 & 0 & 1 \\
\hline $\begin{array}{l}\text { Educational classes/ } \\
\text { group meetings }\end{array}$ & 11 & 14 & 0 & 10 & 5 & 7 & 9 & 10 & 5 & 7 \\
\hline Relatives & 18 & 10 & 8 & 8 & 12 & 4 & 13 & 6 & 21 & 16 \\
\hline Seminars & 8 & 67 & 16 & 50 & 19 & 39 & 18 & 71 & 0 & 66 \\
\hline Other & 2 & 2 & 6 & 6 & 5 & 5 & 6 & 7 & 16 & 14 \\
\hline Total (N) & 66 & 187 & 50 & 91 & 42 & 110 & 55 & 166 & 19 & 74 \\
\hline
\end{tabular}

Note: Responses do not add up to 100 percent since multiple answers were allowed. 
b) Retention Level of Information on FGM and Type of information Retained

While a significant proportion of respondents in both the intervention and control sites received information on FGM, we asked about the type of information received and actually retained about the practice. Table 9 shows what individuals actually "remembered" about FGM. It is important to note that this table does not summarize the information provided (this summary is provided in the analysis of media messages later in the report), but rather what people remembered from the messages received. The table indicates that for all groups, the information most retained was that FGM is not good for girls.
Women and girls were more receptive of and knowledgeable about the health complications of FGM. More than 73 percent of women in the intervention group retained information that FGM was a harmful practice as opposed to 59 percent of women in control sites. Similarly, 78 percent of women in the intervention group retained information on the health complications of FGM. While the most retained type of information by all groups has been that FGM is harmful, the ranking of the type of information on specific issues varied significantly among age groups. All groups emphasized the health complications of FGM as the message most retained on FGM. Young women in the intervention group were the group

Table 9: Types of information heard about FGM

\begin{tabular}{|c|c|c|c|c|c|c|c|c|c|c|}
\hline & \multicolumn{2}{|c|}{$\begin{array}{c}\text { Women } \\
\text { \% }\end{array}$} & \multicolumn{2}{|l|}{$\begin{array}{c}\text { Men } \\
\%\end{array}$} & \multicolumn{2}{|c|}{$\begin{array}{c}\text { Young men } \\
\%\end{array}$} & \multicolumn{2}{|c|}{$\begin{array}{c}\text { Young women } \\
\%\end{array}$} & \multicolumn{2}{|c|}{$\begin{array}{c}\text { Girls } \\
\%\end{array}$} \\
\hline & C & I & $\mathrm{C}$ & I & C & I & C & I & $\mathrm{C}$ & I \\
\hline $\begin{array}{l}\text { FGM is a harmful } \\
\text { practice }\end{array}$ & 59 & 73 & 62 & 69 & 52 & 69 & 64 & 70 & 68 & 72 \\
\hline $\begin{array}{l}\text { Religious views on } \\
\text { FGM }\end{array}$ & 23 & 23 & 40 & 40 & 33 & 31 & 38 & 31 & 37 & 34 \\
\hline $\begin{array}{l}\text { Health } \\
\text { complications of } \\
\text { FGM }\end{array}$ & 30 & 78 & 48 & 37 & 45 & 40 & 53 & 78 & 42 & 78 \\
\hline $\begin{array}{l}\text { Psychological } \\
\text { complications of } \\
\text { FGM }\end{array}$ & 15 & 43 & 0 & 14 & 14 & 17 & 29 & 51 & 21 & 32 \\
\hline $\begin{array}{l}\text { FGM is damaging } \\
\text { to the marital } \\
\text { relationship }\end{array}$ & 9 & 37 & 8 & 4 & 24 & 10 & 16 & 26 & 5 & 12 \\
\hline $\begin{array}{l}\text { Discussing attitudes } \\
\text { \& beliefs in Egypt }\end{array}$ & 5 & 18 & 10 & 3 & 10 & 5 & 18 & 15 & 11 & 10 \\
\hline Other & 12 & 6 & 4 & 6 & 0 & 7 & 9 & 2 & 11 & 5 \\
\hline Total (N) & 66 & 187 & 50 & 91 & 42 & 110 & 55 & 166 & 19 & 74 \\
\hline
\end{tabular}

Note: Responses do not add up to 100 percent since several multiple answers were allowed. 
most attuned to the harms of FGM to marital relationships, followed by older married women (51 percent and 43 percent respectively). <<edits ok? >> Older men in both the intervention and control samples were the group most interested in the religious argument on FGM, followed by young women and young men (40 percent, 38 percent, and 33 percent respectively).

Although media efforts reached both the intervention and control groups, Table 10 shows that the impact of the information delivered was much stronger among the intervention group. Table 10 shows that women who received information about FGM in the three age groups were more likely to say that the information has influenced them and made them reevaluate the necessity of FGM. The table also shows that men were less inclined to reevaluate their stance. Only 51 percent of men, as opposed to 81 percent of women in the intervention group, were ready to reevaluate their stance on FGM as a result of information received on the practice.

Table 10 shows three degrees of conviction, with the first pertaining to a reevaluation of a person's stance, the second to the contemplation stage, and the third to the actual decision not to circumcise. The table shows that while the information delivered made people reevaluate their stance on FGM, more efforts are needed to get them to the final stage of deciding not to circumcise.

Similar results were obtained in focus group discussions. The following shows that messages about the harmful effects of FGM have been successfully disseminated, as seen in some of the respondents' remarks in target communities. Some of these women have become aware of their own personal health problems as a result of FGM. Men also noted that lack of sexual desire was evidence of the continued negative health impacts of FGM. There was also general consensus that a girl who did not undergo FGM would not suffer from health problems as a result, contrary to some of the myths related to FGM. In a focus group discussion in Assiut, after listing the many harms of FGM, a woman summarized all of these negative effects in one poignant statement:

"It is enough that a part of the body is being cut." (woman respondent in the Assiut focus group discussion)

Table 10: Impact of Information on views and behaviors related to FGM

\begin{tabular}{|c|c|c|c|c|c|c|c|c|c|c|}
\hline & Wom & & Men & & Young $n$ & en & $\begin{array}{l}\text { Your } \\
\text { wom }\end{array}$ & & Girls & \\
\hline & $\%$ & & $\%$ & & $\%$ & & $\%$ & & $\%$ & \\
\hline & $\mathrm{C}$ & 1 & $\mathrm{C}$ & I & $\mathrm{C}$ & I & C & I & C & I \\
\hline $\begin{array}{l}\text { Made you reevaluate } \\
\text { girls' circumcision \& it's } \\
\text { necessity }\end{array}$ & 17 & 81 & 31 & 51 & 41 & 58 & 47 & 86 & 47 & 76 \\
\hline $\begin{array}{l}\text { Made you think about not } \\
\text { circumcising your daughter }\end{array}$ & 19 & 80 & 27 & 49 & 29 & 56 & 38 & 80 & 53 & 84 \\
\hline $\begin{array}{l}\text { Made you decide not to } \\
\text { circumcise your daughter }\end{array}$ & 13 & 77 & 39 & 59 & 26 & 53 & 42 & 78 & 47 & 80 \\
\hline Total (N) & 48 & 130 & 49 & 90 & 42 & 110 & 55 & 166 & 19 & 74 \\
\hline
\end{tabular}


Qualitative data show that women were the most outspoken respondents about the harms of FGM. Many of them recounted personal experiences:

"My daughter bled, she was about to die. This is ignorance because people had no idea about the severe harms of circumcision."

"I circumcised my daughter because her grandmother insisted. She started hemorrhaging and was bleeding all day. The bed was full of blood. Until today she is afraid of marriage."

"There are two moments in a woman's life that she can never forget - her circumcision and the night of her marriage."

(respondents in the Beni Suef focus group discussion).

Focus group discussions with young males and females in Assiut revealed that they do not foresee a stigma associated with not being circumcised for three reasons:

1. The ritual is performed in secrecy, so there is no way to tell if a girl has undergone FGM or not;

2. The standards for choosing a wife are not limited to whether she has or has not undergone FGM;

3. Influential families in the villages never share the circumcision status of their daughters.

\section{Openness to Discuss FGM}

As is the case in many Middle Eastern and North African societies, sexuality is not a publicly discussed subject. FGM has been a taboo subject of discussion in Egyptian society for a long time. FGM has always been a private matter not to be discussed publicly. The evaluation study results show that this is significantly changing, especially in recent years. Today there appears to be more openness to discuss FGM, most likely because anti-FGM messages are repeatedly covered in the press, on television, and on the radio. The national-level analysis will focus more on this issue later in the report. This section looks at the impact of the intervention on the degree of openness to discuss FGM among community members.

Results indicate that the prevailing taboo nature and silence about FGM has been effectively broken. Table 11 demonstrates that a minority of respondents from all groups were shy to talk about FGM. These results were consistent among both the control and intervention groups. This shows that the change in attitude is not just due to local efforts within specific communities but also to the national media campaign, which openly brought up the issue. Table 11 shows the level of openness among young people to discuss FGM. As would be expected from cultural norms, young men are clearly more comfortable discussing the issue than young women. However, the table also shows that women in the intervention group were more open to the idea of attending meetings about FGM compared to women in the control group.

The table also shows that doctors can be effective conduits for messages against FGM, since most respondents (up to 88 percent of young men in the intervention sites) were willing to listen to doctors about FGM.

Table 11 includes data collected before the onset of an intensive media campaign that followed the unfortunate death of an eleven-year-old girl in Menya. The issue of 
FGM was widely discussed as a result of this campaign. For example, the newspaper "Al-Masry Al-Youm" posted a poll page on its website in August 2007, in which 23,000 people participated. This reflects great interest and openness to discussing the issue.
Poll results showed that 50 percent of respondents were against a ban on FGM, 45 percent were for a ban, and 5 percent were not interested. The results show the need for more efforts using different channels of communication to address different groups.

Table 11: Openness to discuss FGM among young groups

\begin{tabular}{l}
\hline \\
"I would be shy to talk to my family \\
about circumcision, even if it is my or my \\
sister's circumcision."
\end{tabular}

Always

Most of the time

Rarely

Never

Girls (10-15)

Girls (16-24)

Young men (16-24)

$\%$

C I

\%

$\%$

Is it shameful to talk circumcision?

Yes

No

Sometimes

$\begin{array}{rrrrrr}40 & 32 & 36 & 34 & 60 & 19 \\ 16 & 23 & 23 & 29 & 16 & 26 \\ 20 & 32 & 32 & 16 & 16 & 32 \\ 24 & 13 & 10 & 21 & 8 & 23\end{array}$

19

26

32

If your friend/neighbor comes to talk with you about the necessity of a girl's circumcision, would you talk to her?*

$\begin{array}{lllll}\text { Yes } & 28 & 33 & 45 & 63 \\ \text { No } & 46 & 48 & 39 & 27 \\ \text { Don't know } & 25 & 19 & 16 & 10\end{array}$

If your class teacher asks you to your class about circumcision of girls, would you agree?

Yes

$22 \quad 26$

No

$67 \quad 63$

N/A

$N / A$

N/A

N/A

Not applicable

$12 \quad 12$

If the doctor of your rural health unit (RHU) invites people of the village to a discussion on circumcision, would you go?

\begin{tabular}{lrrrrrr} 
Yes & 61 & 71 & 76 & 81 & 83 & 88 \\
No & 25 & 20 & 19 & 14 & 17 & 9 \\
Don't know & 14 & 10 & 6 & 5 & 0 & 3 \\
\hline
\end{tabular}

*Groups were asked different questions. 


\section{Attitudes Toward FGM}

Table 12 shows substantial differences among all age groups between the attitudes of individuals in the intervention and control groups toward FGM. In the intervention group, women and girls in the three age groups were less likely to report that circumcision is required by religion; that the practice should continue; that men and women want it to continue; that it preserves virginity; or that it protects against infidelity. Women in the intervention group were also less likely to worry about what others would say if they didn't circumcise their daughters, and less likely to believe that men prefer to marry circumcised girls. These women were also more likely to believe that FGM could lead to death and that doctors who perform it should be criminalized.

While the differences between men in the intervention and control sites are not as significant as the differences between women in both sites, Table 12 shows a relative change in men's attitudes toward FGM in the intervention sites. For instance, while 80 percent of men in control sites believed that FGM should continue, 63 percent of men in intervention sites believed the same.

In general, it was obvious that women were more receptive to the messages against FGM and their views were more supportive of efforts seeking its abandonment. For example, while 25 percent of women in the intervention sample believed that FGM is required by religion, more than 50 percent of men in the intervention group believed the same. Moreover, a significant proportion of men in the intervention group supported the notion that men prefer to marry circumcised women. Similarly, more than half the men in the intervention group noted that they would feel guilty if they did not circumcise their daughters. While more men in control sites believed the same (71 percent compared to 54 percent), this again shows that men are an important target group that requires more persuasion and efforts in the fight against FGM.

Interestingly, the difference between younger and older men in both sites shows that the younger group is more susceptible to change. Younger men were less likely to believe that FGM should continue (with a 10 percentage point difference). They were also less likely to believe that FGM is required by religion or that the practice is necessary for women's chastity and fidelity. Younger men also showed less interest in marrying circumcised women. Significantly, younger men were unanimously not worried about the influence of gossip if their daughters were not married.

\section{a. Views on the Importance of FGM}

Table 13 shows that women and girls in the three age groups in the intervention sample were more inclined to believe that FGM is not necessary. We asked respondents explicit questions regarding what they believed about FGM. The table shows a clear difference between the views of this group and those of the control group, where more women believed in the importance of the practice. There is a particularly dramatic difference between the views of females aged 16-24 in the intervention and control sites about the necessity of FGM. Females aged 1624 in the control sites were three times more likely to believe that FGM was very important than those in the intervention group. 
Table 12: Views and Attitudes toward FGM

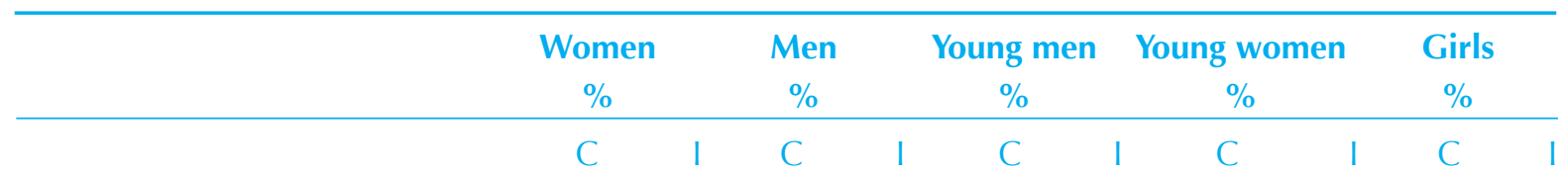

Religious obligation:

Yes

No

Don't know

FGM should continue:

Yes

No

Don't know

Men want FGM to remain:

Yes

No

Don't know

Men prefer to marry girls with

FGM:

Yes

No

Don't know

I worry about gossip if I don't circumcise my daughter:

Yes

No

Don't know

Women want FGM to remain:

Yes

No

Don't know

FGM prevents adultery:

\begin{tabular}{lrrrrrrrrrr} 
Yes & 40 & 13 & 66 & 45 & 50 & 38 & 23 & 10 & $\ldots$ \\
No & 38 & 77 & 25 & 42 & 31 & 48 & 48 & 72 & 100 & 100 \\
Don't know & 22 & 10 & 9 & 14 & 19 & 15 & 29 & 18 & $\ldots$ \\
\hline
\end{tabular}

$\begin{array}{rrrrrrrrrr}59 & 25 & 63 & 51 & 55 & 47 & 50 & 27 & 48 & 25 \\ 15 & 58 & 20 & 29 & 26 & 37 & 29 & 64 & 25 & 24 \\ 26 & 17 & 18 & 20 & 19 & 16 & 21 & 9 & 28 & 51\end{array}$

$\begin{array}{llllllllll}77 & 27 & 80 & 63 & 72 & 52 & 51 & 26 & 67 & 26\end{array}$

$\begin{array}{llllllllll}12 & 63 & 18 & 30 & 20 & 43 & 38 & 65 & 21 & 61\end{array}$

$\begin{array}{llllllllll}10 & 10 & 2 & 7 & 8 & 6 & 11 & 9 & 13 & 14\end{array}$

$\begin{array}{rrrrrrrrrr}63 & 30 & 82 & 67 & 75 & 61 & 43 & 26 & 35 & 22 \\ 7 & 42 & 14 & 26 & 18 & 30 & 5 & 31 & 7 & 23 \\ 30 & 28 & 5 & 7 & 7 & 9 & 52 & 43 & 57 & 56\end{array}$

$\begin{array}{rrrrrrrrrr}68 & 39 & 85 & 68 & 70 & 60 & 55 & 32 & 39 & 25 \\ 6 & 31 & 12 & 25 & 10 & 25 & 43 & 15 & 4 & 14 \\ 25 & 31 & 3 & 7 & 20 & 16 & 2 & 54 & 57 & 61\end{array}$

$\begin{array}{llllllllll}74 & 33 & 61 & 44 & \ldots & \ldots & 69 & 27 & 60 & 26\end{array}$

$\begin{array}{llllllllll}24 & 65 & 38 & 53 & 100 & 100 & 27 & 71 & 24 & 58\end{array}$

$\begin{array}{llllllllll}3 & 2 & 1 & 3 & \ldots & \ldots & 4 & 2 & 16 & 15\end{array}$

$\begin{array}{rrrrrrrrrr}89 & 43 & 85 & 67 & 68 & 57 & 84 & 52 & 78 & 44 \\ 6 & 46 & 9 & 22 & 10 & 22 & 6 & 37 & 3 & 30 \\ 6 & 11 & 6 & 11 & 22 & 21 & 10 & 11 & 19 & 26\end{array}$

continued $»$ 
FGM can cause health

complications:

Yes

No

Don't know

$\begin{array}{rrrrrrrrrr}23 & 67 & 27 & 41 & 26 & 40 & 37 & 72 & 27 & 63 \\ 68 & 30 & 68 & 51 & 64 & 51 & 56 & 24 & 60 & 28 \\ 9 & 3 & 5 & 8 & 10 & 9 & 7 & 4 & 14 & 9\end{array}$

FGM can cause death:

Yes

No

$\begin{array}{rrrrrrrrrr}8 & 47 & 15 & 23 & 13 & 20 & 16 & 48 & 11 & 41 \\ 87 & 49 & 79 & 68 & 77 & 68 & 77 & 47 & 79 & 48 \\ 6 & 5 & 6 & 9 & 10 & 12 & 7 & 5 & 11 & 11\end{array}$

Physicians who perform FGM can be put in jail:

Yes

No

Don't know

$\begin{array}{llllllllll}68 & 37 & 59 & 40 & 50 & 49 & 62 & 37 & 59 & 33\end{array}$

Feeling guilty if I don't

circumcise my daughter:

Yes

$\begin{array}{rrrrrrrrrr}78 & 33 & 71 & 54 & \ldots & \ldots & 62 & 24 & 62 & 26 \\ 16 & 63 & 27 & 42 & 100 & 100 & 27 & 69 & 21 & 16 \\ 6 & 4 & 2 & 5 & \ldots & \ldots & 11 & 7 & 17 & 58\end{array}$

Don't know

18

$17 \quad 17$

21

25

$\begin{array}{lll}9 & 23 & 20\end{array}$

FGM is necessary for girl's chastity:

\begin{tabular}{lrrrrrrrrrr} 
Yes & 77 & 29 & 84 & 67 & 73 & 50 & 53 & 25 & 50 & 22 \\
No & 16 & 69 & 14 & 30 & 18 & 36 & 33 & 67 & 22 & 53 \\
Don't know & 7 & 3 & 2 & 3 & 9 & 14 & 14 & 8 & 29 & 24 \\
Total (N) & 202 & 303 & 171 & 269 & 177 & 287 & 189 & 289 & 162 & 255 \\
\hline
\end{tabular}


Table 13: Views on the importance of FGM

\begin{tabular}{|c|c|c|c|}
\hline Group and Views & $\begin{array}{l}\mathrm{C} \\
\%\end{array}$ & $\begin{array}{l}\text { I } \\
\%\end{array}$ & $\begin{array}{l}\text { Percentage point } \\
\text { difference }\end{array}$ \\
\hline \multicolumn{4}{|l|}{ Women } \\
\hline Very important & 67 & 35 & 32 \\
\hline Somewhat important & 6 & 13 & 7 \\
\hline Not very important & 5 & 10 & 4 \\
\hline Unnecessary & 17 & 38 & 21 \\
\hline Don't know & 5 & 5 & 0 \\
\hline \multicolumn{4}{|l|}{ Girls 10-15 } \\
\hline Very important & 56 & 23 & 33 \\
\hline Somewhat important & 12 & 15 & 3 \\
\hline Not very important & 7 & 9 & 2 \\
\hline Unnecessary & 9 & 36 & 27 \\
\hline Don't know & 16 & 17 & 1 \\
\hline \multicolumn{4}{|l|}{ Girls 16-24 } \\
\hline Very important & 61 & 21 & 40 \\
\hline Somewhat important & 13 & 19 & 6 \\
\hline Not very important & 5 & 6 & 2 \\
\hline Unnecessary & 12 & 47 & 34 \\
\hline Don't know & 9 & 7 & 2 \\
\hline \multicolumn{4}{|l|}{ Male Youth 16-24 } \\
\hline Very important & 66 & 50 & 16 \\
\hline Somewhat important & 9 & 14 & 5 \\
\hline Not very important & 6 & 14 & 7 \\
\hline Unnecessary & 8 & 16 & 8 \\
\hline Don't know & 11 & 7 & 4 \\
\hline \multicolumn{4}{|l|}{ Men } \\
\hline Very important & 69 & 56 & 13 \\
\hline Somewhat important & 9 & 13 & 3 \\
\hline Not very important & 6 & 14 & 8 \\
\hline Unnecessary & 6 & 13 & 7 \\
\hline Don't know & 9 & 3 & 6 \\
\hline
\end{tabular}


The percentage of males (young and old) in the intervention group who noted that FGM was unnecessary was double that of the control group. However, the data show that men require more targeted attention from anti-FGM interventions.

These results are confirmed by qualitative field work. In focus group discussions, women were more inclined to believe that FGM is unnecessary, while men were more supportive of the practice. In a focus group discussion with women in the governorate of Beni Suef, a woman noted:

"This is ignorance (about FGM). A girl is well behaved if she is well brought up (without need for circumcision)."

"They try to protect a girl's honor by cutting this part of her body to ensure she will always remember the pain, but this is unfair and she will be frightened for the rest of her life."

The same opinions were repeated in the governorate of Menya:

"This is ignorance; all women have problems because of circumcision."

To demonstrate the difference in opinion between men and women, in the focus group discussion with men in the same community, men noted:

"Circumcision is a must; we must all circumcise [our daughters]."

"I declare that we are for circumcision; a girl who is not circumcised might as well walk around in the village naked."

"If a girl is not circumcised, she will have strong sexual urges that she cannot control."
The above quotes show the connection between circumcision and behavioral propriety for women. In the following quote, those in favor of the practice connected the anti-FGM fight with the opinion that it is a Western conspiracy and part of international politics, noting:

"This is a western conspiracy to distract us from what is happening [with the war) in Iraq." (FGD, men in Sohag)

Moreover, as the quantitative data show, not all women are convinced of the harms of FGM. In some focus group discussions with women, the practice is praised:

"[We do it] so that the girl is clean and chaste and she can have a future with her husband." (FGD, women in Qena)

"We do it for cleanliness, and for the girl not to be (morally) loose. Nothing (wrong) will happen if this part is taken."

Data from the field show the strong role of local religious leaders in giving conflicting messages on FGM. A young woman in a focus group discussion in Qena notes:

"Some sheikhs came to the seminars. They didn't say haram (forbidden) and they didn't say halal (legitimate)." (FGD - young women, in Qena)

It is important to note that these focus group discussions took place before the issuance of a fatwa in the summer of 2007 which declared FGM as prohibited in Islam.

The battle against FGM is full of challenges. Even when the religious and medical arguments are refuted, parents continue to worry about the need to 
circumcise their daughters, as the following quote from the focus group discussion of women in Sohag shows:

"Both my husband and I are religiously and medically convinced that FGM is wrong. However we are still worried about the girls since we didn't circumcise them." (women in Sohag)

These responses and the complexities related to FGM help to explain the following section on intentions to circumcise daughters. The following section presents the intentions of families with uncircumcised girls to either circumcise or not circumcise their daughters.

\section{b. Intentions to Circumcise}

We asked parents with uncircumcised girls as well as young males and females (as future parents) about their intentions to circumcise their daughters. Table 14 shows the differences in intentions between the control and intervention groups. Women in the intervention group were six times less likely to circumcise their daughters than women in the control group. However, the responses from this group reveal that a great deal of ambivalence does remain, with a significant proportion of women noting that they did not know about their future intentions. Responses from young unmarried women show that those in the intervention group were three times less likely to circumcise their daughters than those in the control sample.

Similarly, Table 14 shows that men in the intervention group were less likely to circumcise their daughters than men in the control group. Data on young men were comparable to older men.

Reasons for intending to circumcise daughters show the areas that the intervention will need to target in the future. The three most important reasons highlighted by women were: respect for customs and traditions, beautification, and the need to decrease women's sexual desire and preserve their virginity. While the majority of men also highlighted customs and traditions, more men were inclined to think of religion as a reason for circumcising their daughters.

Those who were receptive to the messages against FGM and decided not to circumcise their daughters provided reasons for their decision. Table 16 shows a polarization of the rationales of men

Table 14: Intention to circumcise daughters in the future

\begin{tabular}{lccrcccrr}
\hline & $\begin{array}{c}\text { Women } \\
\%\end{array}$ & \multicolumn{2}{c}{$\begin{array}{c}\text { Men } \\
\%\end{array}$} & \multicolumn{2}{c}{$\begin{array}{c}\text { Young men } \\
\%\end{array}$} & \multicolumn{2}{c}{$\begin{array}{c}\text { Young women } \\
\%\end{array}$} \\
& \multicolumn{1}{c}{$\mathrm{C}$} & $\mathrm{I}$ & $\mathrm{C}$ & $\mathrm{I}$ & $\mathrm{C}$ & $\mathrm{I}$ & $\mathrm{C}$ & I \\
Will not & & & & & & & & \\
circumcise & 7 & 38 & 17 & 42 & 27 & 43 & 19 & 57 \\
Will circumcise & 53 & 13 & 81 & 54 & 65 & 45 & 62 & 24 \\
Don't know & 41 & 49 & 2 & 4 & 10 & 12 & 19 & 19 \\
Total (N) & 190 & 280 & 84 & 135 & 177 & 287 & 189 & 289 \\
\hline
\end{tabular}


Table 15: Reasons for intention to circumcise girls

\begin{tabular}{|c|c|c|c|c|c|c|c|c|}
\hline & \multicolumn{2}{|c|}{$\begin{array}{c}\text { Women } \\
\%\end{array}$} & \multicolumn{2}{|l|}{$\begin{array}{c}\text { Men } \\
\%\end{array}$} & \multicolumn{2}{|c|}{$\begin{array}{l}\text { Young men } \\
\%\end{array}$} & \multicolumn{2}{|c|}{$\begin{array}{c}\text { Young women } \\
\%\end{array}$} \\
\hline & C & I & $\mathrm{C}$ & I & $\mathrm{C}$ & I & $\mathrm{C}$ & I \\
\hline $\begin{array}{l}\text { Decrease sexual desire and } \\
\text { preserve virginity }\end{array}$ & 24 & 50 & 34 & 32 & 36 & 26 & 21 & 31 \\
\hline Cleanliness & & & 38 & 47 & 49 & 38 & 41 & 34 \\
\hline Customs \& habits & 82 & 90 & 79 & 80 & 89 & 82 & 86 & 81 \\
\hline Follow religious beliefs & 30 & 28 & 59 & 58 & 65 & 47 & 33 & 35 \\
\hline More pleasurable for the man & 13 & 22 & 10 & 8 & 7 & 8 & 9 & 10 \\
\hline Increased ability to marry & 24 & 14 & 7 & 4 & 4 & 5 & 19 & 21 \\
\hline Esteemed and greater beauty & 43 & 56 & 4 & 3 & 5 & 2 & 20 & 28 \\
\hline Other & 6 & 3 & 12 & 14 & 0 & 1 & 9 & 6 \\
\hline Don't know & 5 & 3 & 2 & 0 & 1 & 2 & 6 & 4 \\
\hline Total (N) & 101 & 36 & 68 & 73 & 113 & 130 & 118 & 68 \\
\hline
\end{tabular}

Note: Responses don't add up to 100 percent since multiple answers were allowed.

and women. For women, the decision not to circumcise is primarily connected with not wanting to inflict pain and cause health complications for their daughters. While this reason also appeared among men's responses, other reasons were also important for men. These include the fact that FGM is not required by religion (the second most important reason) and sexual pleasure for both male and female partners. The religious argument in support for FGM was most important for young men. For young women, similar to their mothers, it was the experience of pain and the worry about health complications that convinced them not to circumcise their daughters in the future. The religious argument was also important for young women. For both young males and females, the notion that FGM is an old custom was highlighted as an important reason not to circumcise daughters. This is expected as young people usually tend to question customs and traditions. It is important for this group to get a clear message that FGM is a custom that is not required by religion.

We compared the educational background of those who intended to circumcise their daughters with those who stated they would not. Data in Tables 17 and 18 show that the educational backgrounds of the two groups were fairly similar. However, the results indicate that education has a slightly positive impact on the decision to circumcise, with educated respondents from all groups being less likely to circumcise. The limited size of educated respondents in all sample groups does not allow for further extrapolation based on this variable. 
Table 16: Rationale to not circumcise girls in the future

\begin{tabular}{|c|c|c|c|c|c|c|c|c|}
\hline & \multicolumn{2}{|c|}{$\begin{array}{c}\text { Women } \\
\%\end{array}$} & \multicolumn{2}{|c|}{$\begin{array}{c}\text { Men } \\
\%\end{array}$} & \multicolumn{2}{|c|}{$\begin{array}{c}\text { Young men } \\
\%\end{array}$} & \multicolumn{2}{|c|}{$\begin{array}{c}\text { Young women } \\
\%\end{array}$} \\
\hline & $\mathrm{C}$ & I & $\mathrm{C}$ & I & $\mathrm{C}$ & I & $\mathrm{C}$ & I \\
\hline Not convinced with FGM & 61 & 42 & 50 & 36 & 36 & 55 & 56 & 57 \\
\hline $\begin{array}{l}\text { It is not a religious } \\
\text { obligation }\end{array}$ & 44 & 28 & 21 & 34 & 45 & 48 & 36 & 38 \\
\hline $\begin{array}{l}\text { Worried about causing pain } \\
\& \text { complications for girls }\end{array}$ & 78 & 85 & 50 & 45 & 40 & 35 & 58 & 80 \\
\hline Religion forbids it & 28 & 20 & 7 & 5 & 23 & 13 & 33 & 24 \\
\hline Better chance to get married & 22 & 21 & 7 & 2 & 9 & 3 & 19 & 21 \\
\hline More pleasure for the man & 33 & 22 & 0 & 18 & 9 & 1 & 25 & 22 \\
\hline More pleasure for girl & 28 & 21 & 7 & 18 & 4 & 4 & 19 & 19 \\
\hline It is an old custom & 61 & 46 & 7 & 11 & 21 & 20 & 58 & 47 \\
\hline $\begin{array}{l}\text { It is a violation of a girl's } \\
\text { body \& rights }\end{array}$ & 44 & 35 & 7 & 9 & 13 & 8 & 36 & 39 \\
\hline Other & 0 & 0 & 21 & 5 & 11 & 12 & 11 & 10 \\
\hline Don't know & 22 & 6 & 0 & 0 & 0 & 0 & 3 & 2 \\
\hline Total (N) & 18 & 116 & 14 & 56 & 47 & 123 & 36 & 166 \\
\hline
\end{tabular}

Note: Responses do not add up to 100 percent since several reasons were mentioned.

Table 17: Educational characteristics of those intending to circumcise their daughters

\begin{tabular}{|c|c|c|c|c|c|c|c|c|}
\hline & $\begin{array}{c}\text { Women } \\
\%\end{array}$ & & $\begin{array}{c}\text { Men } \\
\%\end{array}$ & & $\begin{array}{c}\text { Young men } \\
\quad \% \\
\end{array}$ & & $\begin{array}{c}\text { Young wome } \\
\% \\
\end{array}$ & \\
\hline & $\mathrm{C}$ & I & $\mathrm{C}$ & I & $\mathrm{C}$ & 1 & $\mathrm{C}$ & I \\
\hline Illiterate & 62 & 44 & 24 & 15 & 4 & 6 & 14 & 10 \\
\hline $\begin{array}{l}\text { Didn't complete } \\
\text { Primary }\end{array}$ & 18 & 31 & 27 & 15 & 3 & 3 & 7 & 6 \\
\hline Primary/ preparatory & 13 & 11 & 18 & 18 & 26 & 29 & 40 & 32 \\
\hline $\begin{array}{l}\text { Secondary/ technical } \\
\text { / university/ higher }\end{array}$ & 7 & 14 & 32 & 52 & 68 & 62 & 39 & 52 \\
\hline Total & 100 & 36 & 68 & 73 & 113 & 130 & 118 & 68 \\
\hline
\end{tabular}


Table 18: Educational characteristics of those NOT intending to circumcise their daughters

\begin{tabular}{|c|c|c|c|c|c|c|c|c|}
\hline & $\begin{array}{c}\text { Women } \\
\%\end{array}$ & & $\begin{array}{c}\text { Men } \\
\%\end{array}$ & & $\begin{array}{c}\text { Young men } \\
\%\end{array}$ & & $\begin{array}{c}\text { Young wome } \\
\%\end{array}$ & \\
\hline & $\mathrm{C}$ & I & $\mathrm{C}$ & I & $\mathrm{C}$ & I & C & I \\
\hline Illiterate & 54 & 49 & 21 & 29 & 0 & 2 & 6 & 19 \\
\hline $\begin{array}{l}\text { Didn't complete } \\
\text { primary }\end{array}$ & 8 & 20 & 29 & 11 & 2 & 0 & 0 & 2 \\
\hline Primary/ preparatory & 0 & 13 & 21 & 20 & 26 & 28 & 46 & 34 \\
\hline $\begin{array}{l}\text { Secondary/ technical / } \\
\text { university/ higher }\end{array}$ & 39 & 19 & 29 & 41 & 72 & 69 & 49 & 45 \\
\hline Total & 13 & 107 & 14 & 56 & 47 & 124 & 35 & 166 \\
\hline
\end{tabular}

\section{c. Circumcision Status of Girls}

Table 19 shows that girls aged 10-15 in the intervention group were less likely to be circumcised than those in the control group. Among all six governorates in the study, data show an 8 percentage point difference in the likelihood of circumcision between the intervention and control groups. While we need to be cautious about these figures, because younger girls could still be circumcised after the time of the survey, the difference between the two groups shows the impact of the intervention.

The data show slight differences in the circumcision rates of girls aged 16-24 between the intervention and control sites. This is an expected outcome, as the threeyear intervention could not have possibly reached these older girls.

Table 19: Circumcision status of girls aged 10-

15 and 16-24 by governorate

\begin{tabular}{lcccr}
\hline & $\begin{array}{c}\text { Girls (10-15 yrs) } \\
\text { \% }\end{array}$ & \multicolumn{2}{c}{$\begin{array}{c}\text { Girls (16-24 yrs) } \\
\text { \% }\end{array}$} \\
\hline \multirow{2}{*}{ * Beni Suef } & C & I & C & । \\
Menya & 33 & 56 & 85 & 97 \\
Assiut & 98 & 57 & 100 & 97 \\
Sohag & 90 & 75 & 96 & 97 \\
Qena & 97 & 62 & 100 & 91 \\
Aswan & 95 & 94 & 100 & 97 \\
Average & 87 & 98 & 97 & 97 \\
\hline
\end{tabular}

* The number of girls is too little to allow for analysis at the governorate level. 


\section{d. Evidence on the Growing Medicalization of FGM}

We asked mothers to provide information about the individuals who performed the circumcision of their daughters. Their responses confirm the growing medicalization of the practice, which was first detected by the 2005 DHS, with more than 65 percent of circumcised girls in rural areas having been circumcised by doctors. Table 20 compares data on the persons who circumcised daughters to data from their mothers and highlights the generational differences in the practice. While 90 percent of mothers in both the control and intervention sites were circumcised by dayas, more than 42 percent of girls in both groups were circumcised by doctors. These results correspond with data from the Egypt Demographic Health Survey, which shows that 67.6 percent of circumcisions are performed by doctors (Zanaty and Way 2006: 215).

Qualitative research further explains this medicalization trend. A woman in Sohag states:

"The doctor is better than the daya because his tools are sterilized, he uses anesthesia, and he can save the girl if she starts hemorrhaging."

Given the increased publicity about two recent deaths from circumcisions performed by doctors, it is hoped that confidence in the medicalization of FGM will be diminished.

It is worth noting that women who were against FGM were quick to link the growing involvement of doctors in the practice with economic reasons. These comments were made in Assiut in the focus group discussion for women:

"They get money that way, how would they say circumcision is harmful?"

Focus group discussions also demonstrate that midwives (dayas) in some communities pass from house to house seeking customers. In Sohag, focus group discussions revealed that paramedics also actively seek customers in this way. Respondents in focus group discussions also referred to "men in white coats" who visit communities and knock on doors offering their services to circumcise girls.

Table 20: Persons who perform FGM

\begin{tabular}{lcrcr}
\hline & $\begin{array}{c}\text { Data on daughters } \\
\%\end{array}$ & \multicolumn{2}{c}{$\begin{array}{c}\text { Data on mothers } \\
\%\end{array}$} \\
\hline Doctor & $\mathrm{C}$ & $\mathrm{I}$ & $\mathrm{C}$ & I \\
Nurse & 43 & 48 & & \\
Daya/ midwife & 18 & 8 & $* 11$ & 10 \\
Barber & 36 & 42 & 90 & 90 \\
Gypsy woman from outside the village & 1 & 1 & & \\
Don't know & & 1 & & \\
Total number of circumcised daughters $(\mathrm{N})$ & 465 & 631 & & \\
\hline
\end{tabular}

* includes nurses, doctors and others. 


\section{f. Decision-Making Processes within the Household}

As community members become exposed to information about FGM from various sources, many may become convinced about the harms of the practice. However, to stop the practice, they need to be able to convince others, at least those in their immediate family circle, of the soundness of their decision. A mother needs to convince her husband and even her own mother or mother-in-law of the harms of the practice in order to be able to save her daughters. In this section, we provide two types of analysis. First, we look closely at the decision makers within households to determine who among household members makes the final decision on the circumcision of the girl. Second, we look at the level of self-efficacy among individuals who are against FGM.

Table 21: Individuals within the household responsible for the Decision to Circumcise

\begin{tabular}{lrr}
\hline & $\begin{array}{c}\text { C } \\
\%\end{array}$ & $\begin{array}{c}\text { I } \\
\%\end{array}$ \\
& & \\
\hline $\begin{array}{l}\text { Was the decision a joint decision or } \\
\text { one person's decision? }\end{array}$ & & \\
- A joint decision & 58 & 62 \\
- My own decision & 42 & 38 \\
Who supported the decision of the & & \\
woman: & 27 & 24 \\
- Mother-in-law & & \\
- Mother & 19 & 23 \\
- Husband & 93 & 92 \\
- Sister & 7 & 11 \\
- Brother & 5 & 2 \\
- Uncle & 3 & 1 \\
- Aunt & 6 & 5 \\
- Other & 5 & 7 \\
\hline
\end{tabular}

Mothers with circumcised daughters were asked about whether the decision to circumcise was a joint decision and who within the household took part in the decision. Table 21 shows that a significant proportion of mothers (nearly 58 percent and 62 percent in the control and intervention sites, respectively) noted that it was not their decision alone to circumcise. The table also shows that the decision was jointly taken by both the girl's parents, with grandmothers also playing a role in the decision-making process.

Since women were not the sole decision makers, it was important to look at their sense of self-efficacy and their ability to impact others. These questions were asked to women who intended not to circumcise their daughters. Table 22 shows that women in the intervention group had relatively better signs of self-efficacy. However, data for both samples show the complexities of issues related to women's empowerment, which are deeply ingrained in the gender norms of rural communities.

Overall, data from both groups demonstrate a link between FGM and other complex issues related to women's empowerment in these communities. These findings correspond with qualitative insights obtained through focus group discussions with women. In Assiut, a woman noted:

"If it was in our hands, we would have prevented this whole circumcision thing altogether." (respondent from Assiut)

Similarly, when asked about her views on FGM, a young woman in Sohag responded:

"We cannot talk about these things."

We used a separate module to examine 
Table 22: Sense of self-efficacy among women not intending to circumcise their daughters

\begin{tabular}{|c|c|c|}
\hline Issues of Self-Efficacy & C & I \\
\hline & $\%$ & $\%$ \\
\hline \multicolumn{3}{|c|}{$\begin{array}{l}\text { I can convince my neighbors/siblings that circumcision is harmful for } \\
\text { girls. }\end{array}$} \\
\hline - Always & 20 & 36 \\
\hline - Mostly & 34 & 24 \\
\hline - Very little & 14 & 21 \\
\hline - Absolutely no & 31 & 19 \\
\hline \multicolumn{3}{|c|}{$\begin{array}{l}\text { Usually I can find more than one solution if my family opposes my } \\
\text { decision not to circumcise my daughter. }\end{array}$} \\
\hline - Always & 46 & 52 \\
\hline - Mostly & 26 & 30 \\
\hline - Very little & 20 & 13 \\
\hline - Absolutely no & 14 & 5 \\
\hline \multicolumn{3}{|c|}{$\begin{array}{l}\text { If I decide not to circumcise my daughter, I can implement this } \\
\text { decision. }\end{array}$} \\
\hline - Always & 57 & 65 \\
\hline - Mostly & 17 & 22 \\
\hline - Very little & 23 & 10 \\
\hline - Absolutely no & 3 & 3 \\
\hline
\end{tabular}

the general sense of self-efficacy among groups other than women in both the intervention and control sites. In particular, we asked about their ability to talk about FGM and their willingness and ability to convince others. Table 23 demonstrates that older girls show signs of a stronger sense of self-efficacy compared to girls in the younger age group (10-15), which is understandable. More importantly, girls in the intervention group were more likely to be assertive in their views against FGM and willing to talk about it and seek assistance.
The results for young men require further explanation. It seems clear that their limited support for the message against FGM is one reason why women are unable to come out more strongly against the practice. As noted earlier, women are the ones most affected by the messages against FGM, which is reflected in the willingness of some of them to voice their opposition and talk to others. However, males were more open to discuss the issue of FGM with religious authorities, given their easier access to this group. 
Table 23: Sense of self-efficacy among Young Females (10-15 and 16-24) and Young Males (16-24) with regards to FGM

\begin{tabular}{|c|c|c|c|c|c|c|}
\hline & \multicolumn{2}{|c|}{$\begin{array}{c}\text { Girls (10-15) } \\
\%\end{array}$} & $\begin{array}{c}\text { Young women } \\
\%\end{array}$ & (16-24) & $\begin{array}{r}\text { Young men } \\
\%\end{array}$ & $(16-24)$ \\
\hline & $\mathrm{C}$ & I & $\mathrm{C}$ & I & $\mathrm{C}$ & I \\
\hline \multicolumn{7}{|c|}{$\begin{array}{l}\text { I can convince my family that } \\
\text { circumcision is harmful for girls. }\end{array}$} \\
\hline - Always & 12 & 26 & 29 & 48 & 32 & 26 \\
\hline - Most of the times & 16 & 34 & 26 & 31 & 44 & 46 \\
\hline - Rarely & 32 & 24 & 26 & 13 & 20 & 17 \\
\hline - Never & 40 & 17 & 19 & 8 & 4 & 11 \\
\hline \multicolumn{7}{|c|}{$\begin{array}{l}\text { I can talk to the sheikh of the } \\
\text { mosque to convince my family not to } \\
\text { circumcise me/my sister. }\end{array}$} \\
\hline - Always & 8 & 17 & 23 & 25 & 32 & 42 \\
\hline - Most of the times & 20 & 27 & 29 & 28 & 40 & 39 \\
\hline - Rarely & 24 & 21 & 19 & 16 & 8 & 9 \\
\hline - Never & 48 & 35 & 29 & 31 & 20 & 9 \\
\hline \multicolumn{7}{|c|}{$\begin{array}{l}\text { I can convince my family not to } \\
\text { circumcise me/my sister and they } \\
\text { would do what I want. }\end{array}$} \\
\hline - Always & 12 & 26 & 13 & 40 & 36 & 25 \\
\hline - Most of the times & 16 & 30 & 29 & 23 & 16 & 38 \\
\hline - Rarely & 24 & 17 & 26 & 20 & 32 & 27 \\
\hline - Never & 48 & 27 & 32 & 17 & 16 & 10 \\
\hline
\end{tabular}

\section{Committed groups against FGM}

The following section examines the impact of the project on various groups committed to the fight against FGM. Data is based on interviews with doctors, youth volunteers, religious leaders, and NGO activists.

The formation of community support groups is essential for the implementation of the project at the community level. This finding is consistent among all communities included in the intervention. Group members could include the local
NGO working with NCCM, village officials, influential members from large families, and members of youth centers. The composition of the groups varies between communities. These groups are responsible for the community work plan and the different activities of the project at the community level. Benban is a case in point of great coordination between a focal NGO and a community group. The focal NGO provided girls working at the community level with effective training on communications skills to confront opposition in the community. Another successful example comes from the village 
of Kom Gharib in Sohag, which has signed a declaration against FGM. The team consists of nine young women, both Muslim and Christian. With support from the focal $\mathrm{NGO}$, project activities include a vocational center, day care center, community school, credit, and awareness-raising classes. Support groups are an essential component which can ensure the sustainability of the project and a process of change within those communities. Successful support groups address a range of development issues and community problems.

\section{Doctors are influential members} of their communities and interviews with doctors show their dedication and commitment to the fight against FGM. As we note in the national-level impact analysis, the program trained doctors and mobilized the Declaration of Doctors in Aswan against FGM in December 2006. Medical students are another important target group at the national level. Interviews with doctors at the community level show that doctors as a group are very important in the fight against FGM because people are receptive to their explanations of the harms of the practice (interview, Assiut). Unfortunately, the fact that the practice is a source of income for some doctors limits the support of this group in efforts against FGM. One interviewed doctor highlighted the impact of the media in supporting doctors in their fight against FGM. For instance, this interviewed doctor noted that she uses an article on the Benban Village Declaration to talk to families about the harms of FGM. She uses other arguments in order to challenge myths connecting chastity and FGM. The same doctor highlighted the challenges posited by the religious discourse. She notes that more efforts are needed to gain the support of local religious leaders, teachers of religion in schools, and religious programs in the media. She notes that the film "Asrar El
Banat," which shows an uncircumcised girl getting pregnant out of the wedlock and then being circumcised by a religious doctor, gives a strong negative message connecting FGM to chastity.

It is important to note that doctors are part of the community and are hence subject to the same social pressures to circumcise girls. It is unfortunate that medical training fails to offset the impact of these traditional views. Moreover, doctors need the acceptance of their communities and of families in order to continue providing services and not lose income for their private clinics. They do not want to sacrifice their reputations by opposing a desirable practice like FGM. Income loss would not just be linked directly to the cost of the FGM operation but to the fact that entire families might seek the services of another doctor.

Another doctor interviewed in Qena noted that he is known in the community as "the doctor against FGM." This doctor, a gynecologist, noted that when women face complications during pregnancy, he makes sure to explain to them the types of complications that are caused by FGM. He also emphasized the economic incentives doctors gain by performing FGM, noting that doctors have limited salaries and that many complement their meager incomes by performing FGM. $^{13}$

UN Youth Volunteers (UNVs) are an important link to the community, as discussed earlier. The project relies on UNVs to spread anti-FGM messages throughout targeted communities. UNVs receive training about FGM and about how to communicate messages against the practice. Interviews with UNVs show that the medical, religious, and psychological health information they received helped them to develop a stance against FGM 
and a desire to combat the practice. UNVs are responsible for targeting the younger generation and presenting them with information about the dangers of FGM. Among UNVs interviewed, one was a teacher. Through relations and rapport established with the administration of a number of schools in his governorate, he managed to arrange several seminars against FGM in these schools. UNVs hold meetings with school administrators, teachers, parents, and students. They also provide school libraries with publications on FGM. In interviews with UNVs, they note that despite the resistance of certain individuals, there is always a group of students within every school that supports the cause.

Apart from schools, UNVs participate in summer camps organized by the National Council for Youth. These summer camps are well attended by university students. They participate in seminars and also engage in individual counseling. UNVs highlight the volume of questions they are asked by individuals eager to know about FGM during these camps. Female UNVs also talk to young girls and newly married girls to convince them not to circumcise their future daughters.

\section{Muslim and Christian religious leaders}

are important links in the fight against FGM. Sheikhs and priests against FGM participate in seminars held at the community level and answer local queries surrounding the practice. In the national-level analysis, we highlight the changes happening in the religious discourse on FGM. In this section, we only focus on committed religious leaders at the community level.

In a discussion with a Christian religious leader, he describes how he was against FGM before the project but had no venue or opportunity to talk to people about it and openly discuss the topic. He notes that the church already had a clear stance against FGM and instructs people not to perform it. The task of this group of religious leaders is to influence people in the community to abandon the practice. While the message against FGM from a Christian perspective is clear, Christians who still practice FGM need convincing. In Benban, daily church meetings that tackle the issue separately for different groups (young women, older women, and male youth) have been pivotal in disseminating the message. In Menya, a priest noted that he had to threaten a man with excommunication if he chose to circumcise his daughter. Interviews show that older people in this group are usually resistant to messages against FGM.

For Muslim religious leaders, the task is much more complex. At the community level, Muslim religious leaders against FGM face accusations that they are seeking financial benefits by supporting views against FGM. They are also accused by fundamentalist groups of backing the government at the expense of giving honest religious advice. These allegations make it very difficult for this group to openly support the message against FGM.

Seminars related to the medical consequences of FGM were useful in convincing religious leaders and in supporting them with arguments against the practice. One such conference was held in Alexandria in 2002, which covered topics of maternal and rural health as well as FGM. Further, in the case of Sohag, for instance, the Upper Egypt Association gathered 35 official imams from Tama, Tahta, and Maragha Markaz and presented them with various ideas surrounding the practice (particularly from the medical perspective) and tried to convince them to openly preach against it. 
A committed Muslim religious leader in Sohag was a member of the health caravan and was able to provide the religious point of view on FGM. This same sheikh was already convinced about the harms of FGM before the intervention. However, the FGM-Free Village Model allowed him the opportunity to talk to people about his conviction. He highlights the evidence supporting the religious argument against FGM, and notes that those supporting the practice do not have a strong evidence base. He also related his conviction in the fight against FGM to his belief that married couples should have a healthy sex life and that FGM hinders that.

In general, religious leaders suggested intensifying efforts in already targeted villages, especially through home visits, focusing on a media campaign, and increasing seminars attended by religious men.

NGO activists are important committed groups at the community level. According to in-depth interviews, some of the activists were actually for FGM before the project, the new religious and medical information presented during various trainings and seminars convinced them to change their stance. Activists face strong local resistance in several communities. In an interview with an activist from Assiut, he recounts how he would get abuse from people who accused him of wanting to corrupt their girls. However, he adds that things have improved with repeated television advertisements and seminars. Interestingly, he notes that at the community level, individuals from Saudi Arabia are a unique group of supporters in the fight against FGM. They note that FGM is not practiced in Saudi Arabia, which is a country respected for its religious role in the Muslim world.
In a focus group discussion with focal NGOs in the FGM-Free Village Model project, participants highlighted the role of the needs assessment stage in helping them understand the "real problems which people face in their everyday lives." In addition, the needs assessment helped in gaining the trust of community members through direct contact and networking with influential local leaders. The FGMFree Village Model project encouraged organizations to identify and address other needs in the community. Through this process, NGOs gained new experiences in formulating different entry points for interventions in each village. The project allowed NGOs to undertake activities in villages in which they had not previously worked. According to the NGOs, this was a positive factor, since it allowed them to expand their own areas of work. Moreover, it was noted in the discussion that the networking activities allowed NGOs to broaden their knowledge about other organizations, especially among those working in the same field. It was noted in the focus groups that working under the umbrella of NCCM gave NGOs credibility and legitimacy as civil society organizations working in partnership with a government entity. One particular aspect highlighted by NGOs was the fact that the project did not allow for the disbursement of monetary incentives to community members and participants. This was highlighted as giving credibility to the FGM-Free Village Model intervention.

Discussions also showed that at the individual level, NGO team members gained new skills in communicating and negotiating with community leaders. NGO members also noted that they became more informed about the harms of FGM and became well-versed in both the medical and religious arguments surrounding the issue. 
Data show that the Omda (mayor) and the Sheikh el-Balad are two prominent figures in village communities. Two elements are important for these officials to be effective in the fight against FGM: the open declaration of their position against FGM and the level of support and respect that community members give to these figures. This was clear in the case of Benban, where the signing of the anti-FGM declaration presented an opportunity for the whole village to learn about the clear stance of their community leaders against FGM.

\section{Public Village Declarations against FGM}

It is an important moment in the history of a village to make a public declaration against FGM. The event demonstrates the existence of pressure groups within the village that oppose the continuation of the practice. It also shows the support of influential community members who are willing to fight against FGM. Public declarations help alter long-standing beliefs in the universality and inevitability of the practice. Moreover, the declaration ceremony itself gives strong visibility to efforts to combat FGM. It legitimizes the role of the local $\mathrm{NGO}$ at the community level by showing the endorsement of community leaders in efforts against the practice.

It is vital to note that the declarations do not represent an end to program interventions but are an important milestone in creating an environment conducive for the eradication of FGM. Data on information and knowledge show that the decision to circumcise or not is greatly affected by the views of individuals or groups outside of local society. Declarations give people the message that opinion makers in their communities, such as officials, doctors, and religious leaders, are against FGM.

Moreover, it is a great event for a village to be visited by officials of the sort who attend these declarations. Before the ceremony, banners are hung in different parts of the village to welcome the guests. The magnitude of the event brings in a great crowd, including men and women who have been affected by the intervention and many others from neighboring villages who are either curious to see the visiting officials or curious to know about the nature of the declaration. During declarations, community leaders openly announce their views on FGM and denounce the practice. In the declaration attended by a member of the research team, the event also included performances by young girls from the village on the harms of FGM. The songs and music made it a special night to be remembered by villagers.

\section{The Path to Village Declarations}

Village declarations are the outcome of years of devoted and concerted efforts by program staff, community leaders, the $\mathrm{NGO}$, official and religious leaders, women activists, youth networks, and political leadership at the governorate level. The project technical unit provides training about FGM to the NGO project teams and coordinators, local community members, leaders and officials, religious leaders, and youth volunteers. These training activities pave the way for further anti-FGM advocacy and awareness-raising efforts by those who have received training. Awareness activities include seminars in youth clubs, mosques, churches, and homes of community leaders as well as home visits to families with daughters at risk of circumcision.

Gradually, these efforts help create core groups of anti-FGM advocates in the targeted villages, including community 
leaders and families who are ready to publicly declare their commitment to abandon FGM and to take a stand against those who want to perpetuate the practice. Committed project coordinators working with focal NGOs at the village level are important factors in building these core groups. This is shown by the successful example of Benban, where the personal commitment and dedication of the project coordinator helped to gain the trust and respect of the community and reinforced the project's anti-FGM messages and credibility.

Declarations are usually organized in the form of a public ceremony attended by NCCM's Secretary General, the media, as well as local, religious, and women leaders, representatives of NGOs and international organizations, and village youth of both genders. The declaration is signed by community members and leaders at the end of the ceremony, making it an official document that the village can be proud of.

Declarations have a great impact in reaching out to groups that were not reached through regular program activities. Those who are present because they are curious get a first-hand experience of views against FGM, perhaps for the first time. The setting and the official endorsement of these views against FGM constitute a great occasion for making the project more visible and for deepening its impact. In Sohag, one community member from Kom Gharib noted:

"I learned about this more on the day of the declaration."

It is worth noting that more recent declarations have received extensive media coverage. Families spoke very openly in media channels (on national television) against the practice. Furthermore, local people called for action against practitioners, both service providers and traditional practitioners.

We have listed the numerous declarations reached as a result of project activities in an earlier section of this report as part of the documentation of the FGMFree Village Model. The impact evaluation analysis focuses on the village of Benban as one successful model in order to deduce reasons for the success of the project in this particular village and to formulate overall lessons learned from this experience.

\section{A Focus on Benban}

The experience of the FGM-Free Village Model in the Benban village in the governorate of Aswan has been a major success story. The project was received with tremendous support by community members. Twenty community leaders, including religious, political, and women leaders together with a group of youth activists signed a public declaration which calls for preventing the practice of FGM in Abou Shawareb hamlet in Benban village of Aswan governorate. The declaration event was held on June 22, 2005 and was attended by the NCCM Secretary General, the Governor of Aswan, community leaders, media personnel, UN representatives, donors, and members of the project's steering committee.

This event resulted in increased support to the project by the Governor of Aswan. At the event, he issued a decree at the governorate level which called for banning doctors that practice FGM and subjecting them to legal interrogation.

Field work and focus group discussions in Benban confirm that it is one of the most successful villages in terms of the impact of the project on people's perceptions and 
their positions against FGM. Data from the field show that knowledge and information about the practice came primarily through the intervention. In focus group discussions with married women, they were outspoken against the practice. The information was uniform across all groups. One woman notes in a focus group discussion that:

"Circumcision causes death and hemorrhaging. There is a story we all know of a girl who became paralyzed after she was circumcised. We also heard of a girl who died from it in a village nearby."

Other reasons for opposing the practice include its effect on women's relations with their husbands.

"Circumcision also causes a lot of problems between a woman and her husband, and there are a lot of divorces because of it."

Women in focus group discussions also mentioned that they had access to the project's publications. One woman who is unable to read noted:

"My sons would read to me and tell me, 'Mother, do not circumcise.'"

This shows that the magnitude of the event has facilitated the trickling down of knowledge about the harms of FGM to different groups of people in the village.

Focus group discussions with men in Benban show that their perceptions of the views of opinion makers on FGM are very positive. One man noted that "at present more than 90 percent of the village members are against FGM and that the remaining undecided 10 percent are older men and women." While these statistics cannot be verified quantitatively, they show that there is a common perception of the universal abandonment of the practice in the village. As noted earlier, this is essential for the socio-cultural approach against FGM.

When probed about the main factors that affect the views of the community against FGM, the list of factors included activities by the NGO such as home visits, seminars, and research about the issue and the strong support of religious leaders to advocate the messages of the project. We look at these two factors separately in the following sections.

\section{The Role of the NGO}

The NGO responsible for Benban is the Egyptian Association for Community Development Initiatives. The community support group comprised a team of twelve local field workers selected by the focal NGO in Aswan. In addition, the NGO added two new individuals for the project team to support the different activities in the village and provide oversight.

The project's success in Benban shows that each village has a unique character which mandates different entry points. In Benban, the entry point was announcing prizes for papers written on the subject which succeeded in securing community attention to the issue.

It is important to emphasize the role of the project coordinator, a very active and committed woman who has been closely involved in all aspects of the project's activities. Having herself been circumcised at the age of seven, the coordinator later researched the issue and decided that the procedure was not religiously required. She then decided to dedicate herself to saving her daughter and other village girls from going through the same suffering. She is 
an example of a community worker with a mission to challenge harmful practices.

Activities in Benban started with small group meetings with women to listen to their understanding of FGM and answer all the questions they might not feel comfortable asking during bigger seminars. Later, group meetings for men were also organized. These were attended by a doctor and a religious leader at the mosque or church. Discussions with NGO staff reveal that at first, most women confessed to being unable to announce their decision to not circumcise their daughters. One strategy for these women was to pretend to take them to another village to have them circumcised there. However, this changed after the village declaration, a venue which allowed those against FGM to feel supported by the larger community.

Another aspect of Benban's success is the support of different leaders in the community for the efforts against FGM and their involvement in the project. Discussions with NGO staff reveal that community leaders interact and respond to people they trust and respect. They also attend meetings and seminars.

The lesson that can be drawn from this example is the need to rely on a strong $\mathrm{NGO}$ and committed community groups.

\section{The Role of Community and Religious Leaders}

The success of the Benban declaration reflects a strong degree among commitment of community leaders and families who decided to abandon the practice and among the many women who were willing to speak publicly about their bitter experiences and take a stand against those who want to perpetuate this practice. The event was also publicized in neighboring communities thus further emphasizing FGM as a key issue of child rights.

Similarly, the position taken by religious leaders and others at the community level was a determining factor. Comments made in focus group discussions confirm the support of these essential persons. Women noted:

"Our mayor is against FGM."

"Our doctors stopped circumcising."

The collaboration and joint efforts between the priest and the sheikh serving the village has created a unique village model which is reminiscent of Egypt's 1919 revolution. Benban shows a large degree of religious harmony, which allowed for a united message against FGM from all religious leaders. The church priest, Father Mousa, and the Muslim religious leader, Sheikh Khairallah, view this as a unique model which should be replicated because it brings the community together for the improvement and betterment of everyone. Both have denounced the practice of FGM in both churches and mosques.

\section{Stories from the Field}

Amal is 38 years old and the mother of three girls who supported the practice of FGM before the project got underway. She feared that village people would talk and that her husband and family would not understand her questioning of this custom. She also refused to discuss this issue openly as she felt it was a private matter. The FGM study coordinator approached her with information, gave her an opportunity to talk, and presented her with brochures about adolescence, sexuality, and other topics relevant to her daughters' health. Amal then asked the coordinator to convince her husband to attend seminars and after doing so, the couple decided to consult local leaders for their opinion about the practice. 
Luckily, doctors and sheikhs advised them to renounce FGM and to ignore peer pressure and local gossip. They both approached their families and are slowly working toward convincing them that FGM is harmful. Amal feels that the project is helping to convince many people that FGM is harmful and hopes that the practice will gradually disappear.

Hanan is a 23-year-old mother of three who strongly supported the practice of FGM during the initial stage of the project. She intended to circumcise her daughters despite having suffered from the procedure herself. Her parents had led her to believe that there were many benefits to the procedure and she ignored all doctor warnings that FGM might be dangerous. She talked with her husband, who thought that FGM is unnecessary. They then sought advice from the sheikh who also advised them that FGM is not religiously required. From then on, she attended seminars with the coordinator, which helped her convince her extended family and neighbors. She is grateful to the project staff that she was able to understand the dangers of FGM and save her daughters.

Mervat is a mother with one daughter and two sons. She had insisted that her daughter be circumcised and as a result, the daughter severely hemorrhaged and, as her mother notes, is still fearful of marriage and sexual contact. After receiving awareness messages against FGM, she was convinced that the practice can only be harmful to girls. When her neighbor came to circumcise her daughter, Mervat tried to dissuade her and brought the project coordinator to talk to her and save the girl from the practice. While her attempts with the neighbor were not successful, she was more successful with her brother who had also intended to circumcise his daughter. Mervat convinced him not to circumcise his daughter, informed him about the dangers of FGM, and even gave him the books distributed by the project. Upon reading them, he was convinced and changed his mind. Mervat feels that the project was very important for her community's wellbeing, particularly because of important social services such as microcredit and the introduction of water and sewage services to houses.

Hanan is 22 years old and the mother of three girls. She circumcised one of her daughters, who then suffered chronic infections and pain from the procedure. The coordinator spoke to her about the longterm dangers resulting from FGM and gave her books and brochures, which finally convinced her of the dangers of FGM. She has now changed her opinion and has become an advocate against FGM. She talks to her neighbors to dissuade them from circumcising their daughters.

Mona is 20 years old and unmarried. She recalls how she was circumcised at age 13 with 11 of her family members present. She bled heavily after the procedure and was hospitalized for a month to recover. As a result, she developed a fear of marriage and childbearing. She also decided she would not circumcise her daughters if she had any in the future. With the support of project doctors and staff, she encourages her colleagues and neighbors to attend seminars and meetings to be aware of the harms of FGM in the hope of saving girls from the practice.

\section{Community-Level Challenges and Opportunities}

Based on the data and the analysis provided in this section, we list the key opportunities and challenges for the intervention at the community level.

- Men as a group need more targeted efforts. Data shows that this group 
is the least receptive to messages against FGM. Data shows that men are primarily concerned with religious messages against FGM. It is hoped that through sustained efforts and media messages that FGM is not required by Islam, men will be more receptive to messages against FGM.

- The proven impact of the media and the widespread ownership of televisions present a great opportunity for the project to tap this resource to reach a very wide population.

- At the community level, the connection between FGM and chastity is a major challenge. More messages in the media are needed in order to demystify this connection. This was obvious in the discourse of men and women who were supportive of the practice and who specifically mentioned cleanliness and girls' chastity as important reasons to continue the practice of FGM.

- Another issue that seems to be of great importance for women in perpetuating the FGM practice is respect for customs and traditions. This is an untapped opportunity. Media messages can be formulated to address this issue with the simple message that customs and traditions need to be critically evaluated and not taken for granted.

- Data shows that school teachers were perceived by most respondents as the group most in support of FGM. While this is a challenge, some concentrated efforts will be needed to address this group through trainings to university students who will graduate to become teachers or to those who are already teaching.
- Local imams and their lack of support for the project pose another challenge. Efforts are needed to provide training to local imams.

- One of the opportunities highlighted in the focus group discussions is the potential support of men who worked and lived in Saudi Arabia. These men are usually against FGM because it is not practiced there. These men can be recruited as strong community mobilizers.

- For young men and women as a group, data in this section showed that the religious message is the most effective tool for reaching this group. Therefore, it is important to address young groups with a strong religious argument.

- Analysis of the Benban success story shows the important role of strong and committed NGOs in mobilizing communities against FGM. Organizations with solid relationships with communities and a list of successful developmental activities are shown to have a greater impact at the community level. These provide an entry point for interventions against FGM and deepen the impact of awareness-raising efforts. Similarly, organizations that are run by successful, influential, and respected community leaders showed a great level of program effectiveness.

- Youth and UNVs are another important linkage to the community. Their role needs to be reinforced with the involvement and recruitment of more young people in the fight against FGM. 


\section{EVALUATION OF NATIONAL-LEVEL EFFORTS}




\section{FGM-Free Village Model Impact: The National Level}

$\mathrm{n}$ assessing the impact of the project at the national level, we will focus on six main aspects:

1. The effectiveness of the project structure at the national level.

2. Program efforts to combat the medicalization of FGM.

3. Advocacy efforts on the legal aspects of FGM.

4. Program activities in the media.

5. Program efforts to raise awareness about the religious arguments against FGM.

6. Program efforts to mobilize youth as agents of change.

\section{The Effectiveness of the Project Structure at the National Level}

One of the essential elements of the FGM-Free Village Model has been the establishment of a project technical unit within NCCM. This unit brought together experts on FGM who were previously involved in the FGM task force and the Ministry of Health and Population to work full-time within NCCM. The main role of the technical unit as set out in project documents has been to:

" ... be responsible for day-to-day management of the project including: following up on the governorate-level implementation; overseeing financial management of the project; managing the social marketing and advertising component in addition to dissemination and documentation elements of the project at the national level; and finally, coordinating and supporting the different activities relevant to reporting and meetings of the various mechanisms that are included in the project organizational chart."

The project technical unit is located within NCCM premises, which has promoted direct contact between NCCM senior management and the project technical unit. This helped to ensure that senior management at NCCM were informed of the daily activities taking place at the grassroots level. This allowed for quick decision-making and swift action when needed on both the policy and implementation levels.

The presence of the technical unit at NCCM allowed for more rapid responses to different situations and the ability to mobilize staff, resources, relevant documents, media, and other networks. This was evident in the project's response to the FGM-related death in June 2007. NCCM was able to quickly mobilize a multi-pronged campaign that eventually led to the Ministry of Health issuing Ministerial Decree 271 banning FGM in all clinics, and public and private hospitals. This overruled the 1996 ministerial decision that had allowed FGM in hospitals for cases approved by doctors, as well as the issuance of a landmark religious fatwa by the Mufti condemning FGM.

The assessment of the project technical unit shows the following beneficial characteristics:

\section{a) A Flexible Structure}

An important characteristic of the structure of the FGM-Free Village Model has been its ability to adjust and incorporate 
new elements, team members, partners, and target groups throughout the project process and to design tools to address new situations and needs. These changes have been demand driven and based on lessons learned as the project evolved and developed. For example, when project staff realized the value of the contributions that could be made by young volunteers, they adjusted the project structure by adding a youth coordinator to the project team. This new team member recruited young volunteers (UNVs) into program activities therefore capitalizing on youth's ability to act as advocates against FGM and to provide valid services to their communities. The UNVs were also recruited by the project team to assist in monitoring activities at the governorate and village levels.

b) NCCM as a Reference Point on FGM in Egypt

NCCM constitutes a national reservoir of expertise and resources on FGM that is accessible to governmental bodies, civil society organizations, educational institutions, individuals, and other entities with queries regarding FGM. The project has built a resource of training materials, informative booklets, audiovisual materials, and publications that provide comprehensive information on FGM. The technical unit has attracted many university students who want to learn about FGM. These students have subsequently joined the project and the campaign as youth advocates.

A good example of NCCM taking a lead role in the field of FGM in Egypt was when it was the main government body invited to the Dar Al-Ifta conference on "Preventing the Mutilation of the Woman's Body" in November 2006 in Cairo under the guidance of Dr. Ali Gomaa, Grand Mufti of Egypt.
It was the expertise and resources available to NCCM that enabled the unit to act quickly and launch a strong media campaign after an FGM-related death had occurred. The unit received and responded to inquiries from the media regarding the issue and provided relevant materials and information. They also prepared a full document on the subject and distributed it among the ministries and government bodies, which helped promote greater awareness in combating FGM.

The project unit at NCCM has also been approached by other donors and international NGOs, such as the EU and Plan International, to implement other anti-FGM projects in Egypt using FGMFree Village Model interventions, curricula, methods, and established media messages.

\section{c) Policy-Level Change}

Two major achievements at the policy level need to be highlighted:

1. The issuance of the ministerial decree by the Ministry of Health and Population (Decree No. 271), which bans doctors from performing FGM.

2. The criminalization of FGM in the Egyptian penal code. In June 2008, the Egyptian Parliament approved the criminalization of FGM within the context of recent amendments made to the child law which were drafted and enacted through a comprehensive participatory process.

d) Mobilizing Advocates against FGM and Encouraging a National Dialogue on the Issue

The project technical unit mobilized advocates from different levels in the battle against FGM. These included physicians, 
media personnel, legal staff and judges, religious leaders, policy makers, youth groups and UNVs, community-level activists, leaders, and NGOs.

The impact of program interventions on each of these groups is described in detail later in the report. But it is important to note here that media campaigns, training workshops targeting advocacy groups, and the FGM curriculum and manual were all developed by the technical unit, which has been a pivotal point in the intervention process against FGM.

The technical unit initiated and maintained a public debate on FGM. Project staff helped engage the media, creating a vibrant platform for debating FGM issues. While the national media, especially national television, was the first to address FGM through NCCM's campaigns in 2003, the independent press, private satellite television, and the internet have all become important platforms for discussions and debates on the issue. Incidents, such as the FGM-related deaths of two young girls in Upper Egypt in the summer of 2007, were highlighted and discussed from different perspectives. While conservative and hard-line views on the matter still prevail, the anti-FGM voice has gained considerable space within the national and moderate independent media to advocate the cause of FGM abandonment. In addition, an important and widely accessed religious platform, Islam Online, has helped to deliver balanced coverage of the issue.

\section{Challenges Facing the Technical Unit and NCCM}

1. The sustainability of the project technical unit at NCCM is essential for the continuation of its role in coordinating different national and community efforts against FGM.

2. With the expansion of the project, there is a need for more human resources in the unit.

3. With the expansion of the project, there will be a need for more effective coordination mechanisms between the project and the governorates, governmental bodies, and NGOs at the governorate level.

4. There is also need for more human resources to target new stakeholders in the battle against FGM, such as the Ministry of Education, Ministry of Communications and Information, Ministry of Higher Education and the Egyptian Parliament

\section{Program Efforts to Combat the Medicalization of FGM}

The 2005 Egypt Health Demographic Survey (EDHS) has indicated that 75 percent of FGM procedures are performed by medical staff in hospitals and private facilities. The increasing medicalization of FGM is an outcome of the loophole in the ministerial decree of 1996, which allowed FGM only in cases that are deemed necessary by physicians, thus leaving decisions about FGM in the hands of physicians. Interviews with health professionals demonstrate that there is a lack of consensus about the practice. While some physicians are against FGM, others would perform it either because they believe that their intervention would be less harmful than traditional practitioners, in terms of hygienic standards, or because they believe in its value as a cultural practice. Physicians - especially at the local level - have a direct vested interest in the continuity of the practice, which 
constitutes a source of income for many of them, especially in rural areas where wages are low. In addition, physicians may lose credibility with girls' families if they refuse to perform the FGM procedure. As community members themselves, physicians are also affected by misconceptions surrounding the necessity of the practice.

It is important to note that some interventions against FGM have contributed to this medicalization trend by focusing on the physical and immediate harms of the practice, particularly those caused by unsterilized instruments. The overemphasis on the health implications of FGM has inadvertently led to a substantial increase in the number of circumcisions undertaken by medical and para-medical professionals.

Interviews with health professionals also show that when doctors at the local level refuse to perform the operation, community members go outside the village or bring midwives or doctors to the village to perform the procedure.

\section{a) Policy-Level Efforts to Combat the Medicalization of FGM}

Addressing the issue of medicalization has been critical for the FGM-Free Village Model project. A vital step in this process is to target health professionals through awareness-raising and training workshops as listed earlier in the project documentation section. This has also involved mobilizing physicians to form anti-FGM groups that could eventually develop into a national physician's movement against the practice. These awareness-raising and training workshops provide health professionals with the necessary skills and tools to become advocates against the practice by speaking out in their communities and with their peers in the medical profession.
At the policy level, NCCM lobbied for the issuance of a new ministerial decree in 2007 banning doctors and other practitioners from performing FGM. This decree was the culmination of advocacy efforts undertaken by NCCM during the past four years. The decree circumvented the loophole of the 1996 decree that had allowed doctors to perform FGM in cases described as having a "medical need." NCCM has been in dialogue with MOHP about this issue since the inception of the project.

The FGM-related death in June 2007 in a private clinic in the town of Maghgha in Menya governorate and NCCM's ensuing multi-pronged campaign against FGM prompted the Minister of Health to announce a formal absolute ban on FGM. The Ministerial Decree No. 271 in 2007 bans FGM in all clinics and public and private hospitals, stating that it is "prohibited for doctors, nurses, or any other person to carry out the cutting, flattening or modification of any natural part of the female reproductive system, either in government hospitals, non-government hospitals, or any other places," thus overruling the 1996 ministerial decision that allowed FGM in hospitals in cases approved by doctors. The MOHP warned that violators of the ban would be punished, but did not specify the penalty. The ban is, therefore, not as enforceable as a law, which requires passage in the national legislature.

The following events surrounding the FGM-related deaths involved a number of other stakeholders and social actors who showed support against FGM:

1. The Egyptian Doctors' Syndicate launched an official investigation into the deaths and warned doctors against performing the procedure either in 
homes or medical facilities, citing "detrimental health effects" to girls. The syndicate is also planning to launch a media awareness campaign to educate the public about the psychological and physical damage that results from this practice.

2. The Governor of Menya announced that 36 unlicensed private clinics in Menya were shut down for performing FGM.

These activities demonstrate how the FGM-Free Village Model project was able to reach out to the medical community at both the local and national levels and provide medical professionals with facts from a comprehensive perspective on FGM.

b) Impact of Efforts against the Medicalization of FGM on the Knowledge, Attitudes and Practices of Physicians

Capacity building workshops presented doctors with medical, historical, and religious information about FGM and the position of local and international medical associations regarding the issue. The workshops emphasized that FGM is not an accepted medical procedure and it is not included in either local or international medical curricula or medical references. It was further highlighted that FGM is an infringement on a girl's body that is against medical ethics. The workshops also presented participants with information about the short-term and long-term detrimental effects of FGM and the social misconceptions related to the practice.

Workshops also raised the awareness of participating physicians regarding the legal aspects of the practice and allowed for open discussions on the financial, social, and administrative rationale for doctors who perform FGM. Some doctors admitted that they were mistaken to have performed the procedure.
According to discussions with trained physicians, the project provided them with the necessary tools that would enable them to counsel families about the harms of FGM. The workshops also improved the skills of participating doctors, enabling them to communicate and disseminate appropriate information on FGM. This helped to provide clear and simple messages related to the health, religious, and cultural implications of FGM. Physicians were also provided with pamphlets and training materials that they could use to disseminate information. This enabled participants to provide information on FGM to female patients in health units and to actively participate in awareness seminars organized at the community level in some of the project's villages.

An important development resulting from the intervention was the incorporation of the topic of FGM in Sohag University Medical School's curriculum, showing that it is not a medical procedure and hence should not be practiced by doctors.

NCCM also worked toward the implementation of a Civic Document of Doctors Against FGM in order to create a movement among leading university professors and young doctors who would take a public stance against FGM, thus making the general public aware that FGM is a clear violation of the code of medical ethics and an act of malpractice. The project team held two meetings with the executive director of the Egyptian Fertility Care Society in which the project agreed that the association would develop the content of the Civic Document of Doctors against FGM. The document states that FGM is neither an accepted medical practice nor a religious obligation, but rather a social convention and tradition. The document stresses the fact that FGM is condemned by the international medical community. 
It is a violation of the medical code of ethics; it has serious health implications; and it infringes on a child's and a woman's right to a healthy body and on a woman's right to enjoy a healthy sexual life. The document also shed light on the position of the MOHP and the ministerial decree of 1996, as well as the position of Egyptian law. ${ }^{14}$ The document called on all Egyptian physicians and medical practitioners to stop performing FGM and to inform parents, religious, and media groups that physicians have no right to perform this practice.

A member of the evaluation team attended the Declaration of Doctors against FGM in Aswan. Such events are of great value because they raise the awareness of doctors about the harms of FGM. More of these events in other governorates will increase the impact of information trickling down to the governorate and community levels. Like many other groups, doctors need to be educated about the harmful effects of FGM and to listen to other doctors against FGM.

NCCM succeeded in forming support groups of doctors against FGM in all six governorates of the intervention project. These are composed of professors from the faculty of medicine, distinguished physicians, and medical practitioners who are against FGM. These support groups are important steps in creating an environment conducive for the abandonment of the practice and for stopping doctors from performing FGM.

\section{Challenges in addressing the} Medicalization of FGM:

- Doctors are one of the most difficult groups to influence in the fight against FGM since they have a vested interest in the persistence of the practice.
- Doctors are social agents and are greatly influenced by the prevailing socio-cultural environment that supports the practice of FGM.

- Interviews with medical professionals highlight the challenge of persistent conservative and hard-line religious trends in schools of medicine that support FGM and oppose efforts against FGM.

- A lack of awareness among physicians about FGM and the ministerial decree banning it.

- Ineffective advocacy and leadership from the Physicians Syndicate to combat FGM.

- A lack of anti-FGM messages in medical curricula.

- A lack of physicians who offer comprehensive counseling on FGM for families, girls, youth, and members of local communities.

\section{Advocacy Efforts on the Legal Aspects of FGM}

The Egyptian penal code (Articles 240, $241,242)$ prohibits and penalizes the deliberate infliction of injury or the causing of permanent disability. It imposes harsh criminal punishment on perpetrators, especially in cases where premeditation is established. Advocacy efforts on the legal aspect of FGM have focused on making these articles applicable to FGM, defining the procedure as a "deliberate infliction of injury" rather than a procedure for beatification. Activists against FGM have argued that this criminal legislation should apply to FGM since the "procedure causes permanent disability 
that cannot be remedied, i.e. the cutting of an organ and the loss of its function, which is a premeditated act. It is a case of infringement on the female body, which inflicts an injury by will and intention and results in depriving the female of a naturally functioning part of her reproductive organs."15

The criminalization of FGM in June 2008 within the context of recent amendments made to the child law constitutes a direct outcome of advocacy efforts on the legal aspects of FGM. The criminalization clause (Article 242) was added to the penal code and the minimum penalty was doubled as stated below. provided to the judges during the workshop and the discussions that took place resulted in a number of recommendations that reflect a strong anti-FGM stance. These recommendations were developed by the judges in the workshop and submitted formally through the Human Rights Department of the Ministry of Justice. These included:

1. Continue efforts aimed at criminalizing FGM and provide support for research and studies aimed at raising awareness of the harms the practice.

2. Establish legislation that would support children and women who

FGM criminalization article incorporated in Criminal Code

Article 242 (repeated) which states the following:

With the consideration of all other related articles in the criminal code, the practitioner of female genital mutilation or cutting shall be punished by a sentence that could include imprisonment detention between three months (minimum) and two years (maximum) or a fine not less than 1000 LE and not more than 5000 LE.

Participants in the training workshop for judges that took place in July 2006 noted that the workshop provided important information about FGM from a legal perspective. The workshop also provided legal personnel with in-depth information on the religious, social, and medical dimensions of FGM, taking a child's rights approach.

It was initially evident from the proceedings of the July 2006 workshop that judges - like other professionals and groups in society - did not have strong views against FGM. However, the information were victims of violence, including special therapy programs addressing their medical, social, and psychological needs.

3. Involve religious institutions and other organizations concerned with the negative impacts of violence against children and train social workers and psychologists to handle cases involving such violence.

4. Assist in efforts undertaken by NCCM to modify the child protection laws and incorporate key violence 
issues in order to comply with the new recommendations and suggested changes.

5. Continue the development of legal anti-FGM lobby groups through further workshops to iterate and envision a clear law and a unified procedure to punish practitioners of FGM.

As a result of the workshop addressing legal professionals, a core group of 15 judges volunteered to submit papers on ways to address FGM from a legal standpoint. These papers tackled possible compulsory social and community service for parents who circumcise their daughters (i.e., attending a training course on the detriments of FGM) as well as punishment of the practitioners (either health professionals or traditional practitioners) in order to reduce the magnitude of the practice in the future. The group also proposed to be involved in training and speaking to other judges and attorneys on the issue.

This core group of judges and their deliberations were pivotal to the success of NCCM's advocacy efforts to bring about a law criminalizing FGM in Egypt.

\section{Program Efforts in Media}

Up until the beginning of the FGMFree Village Model project, FGM was a culturally sensitive issue that was not addressed by the media, especially public television programs. Following the International Conference on Population and Development (ICPD) in 1994, Egyptian television began to sporadically broadcast a few programs that addressed the issue, but without a comprehensive information plan that would ensure continuity and achievement of the desired effect. In addition, these programs presented contradictory messages about FGM. Some of these programs included religious leaders in support of FGM. This further complicated the role of the media and gave confusing signals to the public.

The media has been an important element of targeting in the FGM-Free Village Model. The project aims to break the silence on the issue and bring it to the forefront of public debate. This focus stems from a belief that media messages can be particularly effective in creating a social environment conducive to change. The project has increasingly incorporated media campaigns into its strategies, using the power of television and documentaries. This policy allows for the Project/NCCM to disseminate information, increase awareness, and promote advocacy to stop FGM. The following section examines the media approach of the FGM-Free Village Model and the extent to which this approach has reached its objectives.

a) Phases of Communication and Media Approaches

Analysis of the media approach of NCCM demonstrates three specific phases:

Phase I: The "El Bent Mysria" (The Egyptian Girl) Campaign (2003-2005):

It is important to note that the "El Bent Mysria" campaign was part of a larger campaign marking 2003 as the "Year of the Egyptian Girl." The objective of the campaign was to communicate messages that support and advocate girls' education, FGM eradication, and the avoidance of early marriage. This was the first time that the Egyptian media tackled these issues in a focused manner. The campaign was very strong and succeeded in bringing these issues to the forefront. The "El Bent Mysria" campaign was not confined to television 
programs but also encompassed weekly radio programs on girls' rights issues.

In March 2003, NCCM launched a three-minute infomercial with the following three messages:

- "No to Deprivation from Education"

- "No to FGM"

- "No to Early Marriage"

As part of the same campaign, a second infomercial was aired with the title "Say No to FGM." This infomercial focused on the dangers of performing FGM and raised the question of why families carry out such a harmful practice on their daughters. It was clearly stated by the narrator that Muslim sheikhs and Christian priests are against the belief that FGM is a religious practice. The narrator also added that medical doctors are against FGM and that doctors who perform FGM are performing an unethical act. The voiceover was done by one of Egypt's most popular actresses, Mona Zaki. A major critique of the ad was that the girls seemed out of context and, according to some media experts, "too perfect" in terms of the cleanliness and tidiness of the setting, which did not reflect the realities of rural areas, where the practice is most prevalent. Nevertheless, the infomercial promoted changing people's perceptions on the practice and strongly advocated against it. This has been illustrated by using taglines such as "Let's break our silence"

The "El Bent Mysria" infomercial was aired frequently on national Egyptian television, which has a wide audience and is accessible without subscription. The campaign's aims were:

- To bring the issue of FGM to the forefront of media issues and raise debate regarding this practice (where it has been addressed by widely viewed television and satellite programs).

- To present the issue of FGM in a simple and clear manner with the message that FGM is harmful and the practice needs to be stopped.

A number of programs were also aired on national television as part of this early media phase. These included the following:

- Documentary on the "Benban Declaration" in Aswan: In this documentary, NCCM provided full media coverage of the public declaration for full abandonment of FGM in the village of Benban in Aswan governorate. The documentary was entitled "Watheeqet Bent Benban le Monahadet Khetan El-Enath," translated as "Benban Declaration against FGM." The documentary featured the public festival held in Aswan governorate with priests and sheikhs signing the declaration, people from the village approaching offices to sign the declaration and support it, a speech by the General Secretary of NCCM, a speech by Aswan's governor, and interviews with villagers who were asked about their reasons for stopping the tradition. Overall, the film is an excellent documentary of a pivotal event.

- Documentary "Al Khetan fi Kalemat" (FGM in Words): This documentary poses the question: "How long will this practice continue?" The documentary includes news clips on FGM; a brief history of the practice given by H.E. Moushira Khattab, General Secretary of NCCM; comments by Dr. Mohamed Selim El Awa, an Islamic thinker, explaining the Islamic stand regarding the practice; and comments by Dr. Magdy Helmy, member of NCCM's 
FGM project unit, discussing the different aspects of FGM and the efforts that have been carried out to combat it. The documentary also features Dr. Essmat Mansour, a representative from the Ministry of Health and Population; Dr. Mohamed Farid, a practicing doctor talking about the negative implications of FGM; and Mr. Antonio Vigilante, former Regional Representative of UNDP in Egypt. The documentary features a discussion between community people and a number of guest speakers and experts regarding the practice. The documentary was produced in cooperation with the Think Twice campaign of NCCM.

- Episode on FGM on Rula Kharsa's television show "El Qesa we Ma Fiha" (The Story and What's Behind It): This program interviewed women who had undergone FGM and who now feel that they should not circumcise their daughters, as it was a traumatic event. The show's host, Rula El Kharsa, invited people to speak against the practice. She raised the question of why FGM is practiced. The show was aired on Channel One which, as mentioned earlier, has a wide outreach.

As demonstrated above, the initial phase of the project's media approach relied mainly on a general message calling for combating FGM and providing religious, medical, and legal justifications. However, these different perspectives were not brought together in an integrated manner until the creation of the FGM training manual, which presented a comprehensive socio-cultural approach for the project and its vision. The articulation of an integrated vision and approach helped link the religious, medical, cultural, and legal perspectives in a tangible manner which then lead to a program shift from the phase of the "media thematic campaign" to a phase of "media policy."

Phase II: A Reassessment of the Media Policy Phase and Integrated Media Messages

During the second phase, the FGMFree-Village Model reassessed its media approach reaching order to develop a more integrated media policy for the project. This policy has four specific components:

1. Identification of the main media challenges.

2. Analysis of the media content that addresses FGM.

3. Development of integrated media messages that reflect the project's vision.

4. Production of a media guidebook that includes information, resources, and quality and ethical standards for the media.

As a result of consultations with media personnel, the following conclusions were reached in assessment of the program's media efforts:

- Most programs addressing FGM featured views both for and against the procedure. This ended up confusing viewers rather than providing them with clear messages.

- Some programs encouraged people to reject severe forms of FGM performed by dayas and barbers but gave an implicit message in support of the medicalization of the practice.

- Some programs aired on television and radio provided unclear and often contradictory messages. 
- Programs and press reviews that address FGM are traditional and repetitive. Talk shows and reports that present opinions both for and against FGM from physicians, religious clerics, and sociologists were badly prepared and presented very little evidence and research-based support. Insufficient attention was given to the purpose, form, or appropriate technique that would successfully disseminate information to the public.

- The credibility of the press, television, and radio as well as that of program presenters affects the interaction with the public and their beliefs in the messages aired or published, especially in rural areas.

- Satellite channels, privately-owned radio stations, and newspapers are often reluctant to address the issue of FGM. They prefer competition-type programs to maximize the number of viewers and to increase advertising accounts. Radio and television channels usually address FGM in the context of a major news item (for example, an FGM-related death or the controversial film that was broadcast by $\mathrm{CNN}$ ). The issue is addressed in the form of a political debate between proponents and opponents of FGM, not within an organized framework for raising awareness through which clear information against FGM is disseminated.

- The management of satellite channels, radio stations, and newspapers continues to regard FGM as a marginal issue and to relate it to a Western development agenda rather than a national agenda.
- The time and space allocated to FGM in various media (television, radio, and newspapers) is usually limited and not aired during prime time. The issue is addressed in unpopular programs or in the women's and children's sections of newspapers, which are not taken seriously.

- Target audiences for FGM messages are not defined according to age, gender, or social and educational level to determine the type of message appropriate to each group.

\section{Phase III: A National Media Campaign}

The FGM-related death in June 2007 was a turning point for media interventions in the project. The media policy of the project was elevated to the national level and adopted by the state and civil society organizations. An integrated media approach was developed to address targeted groups and convince them to abandon the practice of FGM.

While media messages on FGM were initially inconsistent, a more integrated media policy was developed by the NCCM project team. This process can be summarized as follows:

1. A newly articulated media policy with a holistic approach to the issue was developed, which incorporated social, religious, cultural, and medical messages against FGM.

2. Unified and culturally sensitive media messages were developed and provided to support media personnel and help them incorporate these messages in their work.

The new media approach focuses on four specific elements: 
The content of the message: the message should rely on evidencebased arguments calling for action and provide the public with all relevant information from a medical, sociocultural, and legal perspective.

- The media techniques: a greater focus on real life experiences; giving a broader voice to the public and their experiences in abandoning the practice; creating a greater level of interaction and communication between the public and the experts; portraying the experiences of other countries and communities with FGM; and human stories on victims of the practice.

- The target groups which should_ include all sectors of society: men and women, youth, religious leaders, physicians, judiciary, media personnel, decision makers, politicians, and the different institutions in society.

- Collaboration and coordination of all development partners under the umbrella of NCCM to ensure dissemination of clear and unified messages.

This constitutes a qualitative change in the media component of the project and its ability to effect impact at the national level. It is important to highlight the steep learning curve the project team at NCCM encountered with regards to their media approach. In the first stage, they assessed the media messages adopted by the project, analyzed their content, and identified the inconsistencies in these messages. Annex $V$ contains a listing of these inconsistencies as identified by the NCCM team. In the second stage, they developed integrated media messages that support the project's goal of FGM-abandonment by means of addressing inquiries, misconceptions, and traditions that perpetuate the practice. Annex $V$ contains a listing of these misconceptions and the media messages developed by the team to address them. These messages also focused on arguments supporting FGM by some media channels, which connect efforts against FGM as against Islam and label them as "Western" ideas. The messages also highlight the human rights perspective on FGM and identify approaches to present efforts against FGM as integral to advocating the rights of Egyptian children.

\section{Impact of the Media Campaigns on} other Program Components

After years of media silence, especially on national television, media campaigns launched by NCCM helped bring the issue of FGM into the forefront. With the increased media focus, a direct outcome has been the involvement of youth volunteers. These youth approached NCCM to inquire about FGM after the launching of the "El Bent Mysria" campaign. Also, the media spots aired on national television encouraged the public to contact NCCM on its hotline to discuss their concerns regarding FGM.

As mentioned earlier, impact assessment and analysis at the community level shows that the media has played an important role in spreading messages about FGM, to the extent that respondents from both the intervention and control samples were able to identify sources of information on FGM. Television, in particular, was mentioned by large proportions of both groups as a key source of information on FGM. Data shows that more than 81 percent of young men and women admitted receiving information on FGM through television. 
By 2007, FGM became a widely debated issue in both the private and independent media and on internet sites. This trend can also be observed in 2006, when media channels started to allocate greater space to the issue and broadcasted programs on FGM during primetime. This indicates an increase in social demand among the public to discuss the issue of FGM.

The impact of the media efforts was shown when the independent newspaper "Al Masry El Youm" adopted the FGM issue and continued to include reports on it. Another example is the privately owned AIMahwar satellite television channel, which gave prime attention to the fatwa (religious decree) of the Grand Mufti of Egypt, Sheikh Ali Gomaa, in which he stressed that Islam is against FGM and that "it is prohibited, prohibited, prohibited" following the FGMrelated deaths of two girls in the summer of 2007.

\section{The Program Impact on Engaging and} Mobilizing Advocates against FGM among Media Professionals

Media personnel who were trained by project staff or had attended awareness workshops became FGM advocates within their media specialization. A journalist in "Sabah El Kheir" magazine produced a series of exceptional reports on FGM, covering the religious, medical, legal, and human dimensions of the practice and focusing on girls and women in rural communities. She highlighted opponents of the practice in these communities.

Another journalist from the independent newspaper "Al Masry El Youm" contacted NCCM and the project team to inform them of an FGM-related death. This reporter had participated in one of the project's workshops and had been in close contact with the project team since that time. She also participated in the media campaign launched by the newspaper following the FGM-related death in Menya.

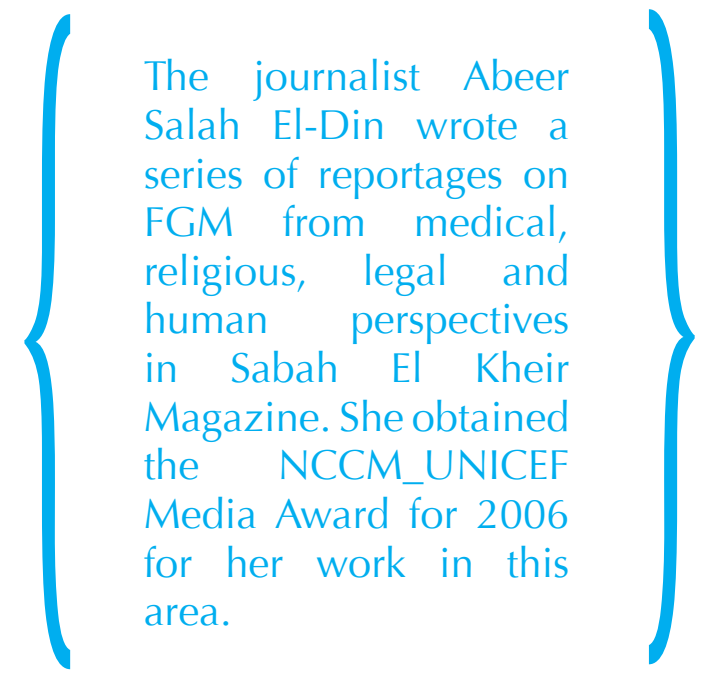

One reporter from Islam Online, who attended a workshop organized by the project on how to create a communications policy on FGM, contacted NCCM and conducted a live interview with the mother of the deceased girl.

With the developments of the summer of 2007, media coverage of FGM was significantly transformed from being covered in the form of short articles and news flashes to more analytical coverage reports which included success stories, the social implications of the practice, and the legal mandate for FGM court cases.

The project has mobilized leading journalists to adopt FGM as a major issue that should be raised in leading national and opposition newspapers. The project has created a social movement against FGM. 
Challenges to Efforts with the Media:-

- Traditional and repetitive media approaches in both national and independent television programs.

- Insufficient preparation of media programs in terms of accurate information or approaches necessary to tackle the issue.

- Confusing and conflicting messages. The issue of FGM is increasingly debated in many platforms, where conservative and hard-line opinions supportive of FGM are voiced on air and in different media channels. This causes confusion among the public.

- The need to identify key indicators to monitor the media and assess impact.

\section{Program Efforts with the Religious Discourse on FGM}

One important milestone has been the issuance of a landmark religious fatwa by the Grand Mufti of Egypt, which unequivocally condemned FGM in the summer of 2007.

It is relevant to note that the religious views on FGM have undergone significant changes. For decades, mainstream religious discourse expressed by prominent Islamic scholars was not in favor of the practice. The emergence of a more hardline trend that was harshly critical of the anti-FGM movement marked a shift in the discourse on FGM. Declarations on FGM during the ICPD in 1994 and the CNN footage mentioned earlier triggered strong opposition among this group. The issue was characterized by two main factors:

- Opposition to the West: This factor emerged with the changing international climate in the early 1990s and the media coverage of ideas such as the "clash of civilizations," which supported the notion of a conflict between Islam and the West. ${ }^{16}$ This led to an increased sense of apprehension toward issues that had religious dimensions and were related to culture and identity. There was a sense that religion was under threat and thus the issue of combating FGM was seen as part of a Western agenda despite the fact that it had been addressed from an Islamic perspective since 1904.

- Opposition to the State: Political Islam has in some cases adopted FGM and used it as way to oppose the state and its efforts against the practice. This politicization of the issue of FGM leads to confusion for people who receive opposing religious views about the practice from different Islamist thinkers.

Despite the increased opposition of the proponents of FGM, moderate religious scholars maintained their position. In recent years, this was expressed in the fatwa of the Grand Mufti, Sheikh Mohamed Sayed Tantawi, who publicly declared that FGM was not required by Islam and that it was a "habit not a worship" in 1994. These views were repeated in 2007 when the Islamic Research Academy of Al-Azhar, (Magma' El Bouhouth Al-Islamiya), the highest seat of religious learning in the Sunni world, issued a statement that FGM is a harm with no Islamic basis.

While FGM is practiced by both Muslims and Christians in Egypt, the Coptic Orthodox Church has played an important role in sending a strong message against FGM. As noted in the section on early efforts against FGM, the Church published a book on FGM in 1960 noting that FGM was not a Christian practice. However, 
community-level efforts need to continue to support religious community leaders as advocates against FGM.

NCCM has worked on answering both Islamic and Christian inquiries regarding FGM. The team aimed to refute the practice not only because of the lack of textual evidence in religious books supporting the practice, but based on the fact that FGM is a practice that contradicts fundamental religious principles that call for the respect of child's rights, the human dignity of women, and the welfare of human beings.

The project has aimed toward formulating a unified religious message that condemns the practice. To do so, NCCM had to refute the religious arguments in support of FGM by tracking early opinions of Islamic scholars against FGM, highlighting views against the practice, and developing a strong religious argument in support of efforts against FGM.

The following questions have been central to the debate:

1. Is FGM an Islamic practice since it is mentioned in the Sunna?

2. What if the different schools of Islamic law hold different opinions on female circumcision?

\section{Does a "weak" Hadith}

(unauthenticated prophetic saying) provide sufficient evidence to prohibit FGM? Some people maintain that one can adhere to a weak Hadith because it encourages good morals or good deeds.

4. Is it possible to have a form of FGM that complies with Islamic law or the Sunna, but not to African or Pharaonic customs?
FGM is a norm and an old practice, and norms constitute a source of religious legislation. Can this be a reason for its religious acceptability?

5. Does parental consent or the consent of the girl herself give FGM a form of legality?

6. Permissibility is generally the rule in Islam. If no religious stipulation against FGM exists, then why prohibit it?

NCCM sought to provide simple and direct answers to these queries and to make such answers accessible to those who work against FGM in the field and are often faced with these questions. Two major documents were produced and widely disseminated for this purpose:

1. A study undertaken by Dr. Mohamed Selim Al-Awa, General Secretary of the International Federation of Muslim Scholars entitled "FGM from an Islamic Perspective," published in 2005.

2. The FGM curriculum and manual, which was developed in 2005 . The FGM religious curriculum included reference to the medical perspective on the issue and the physical and psychological harms that result from this practice. This was the basis for developing a comprehensive religious approach against FGM. This approach did not refute FGM simply because it was not mentioned in the Quran or because of weak Hadith. Instead, it based its objection to the practice on the fact that Islam upholds the right of women to a healthy body free from any mutilation as advocated by the authentic prophetic Hadith, "Do not harm yourself or others." The approach also adopted the medical views 
regarding the harm inflicted by this practice, underlining the fact that FGM is not a medical practice. The precepts of Islam refute the social beliefs behind FGM because the practice may bring physical or psychological harm to girls or women for reasons that are far from science or logic. The religious approach also underlined the fact that the precepts of Islam ensure a woman's right to an enriching and satisfying marital relationship.

\section{Project Impact on Knowledge,} Awareness, and Attitudes on the Religious Views on FGM

The religious approach adopted by the project eschewed a sole focus on religious textual evidence. This approach also focused on the physical and psychological implications of the practice and how these conflict with the main precepts of Islam which safeguard human dignity and integrity.

This was the approach undertaken in the book published by the project team and written by the Islamic thinker, Dr. Mohamed Selim Al-Awa, the General Secretary of the International Federation for Muslim Scholars. The book, entitled "FGM from an Islamic Perspective," stressed the following points:

- Detailed and thorough answers to inquiries based on the principles of Islamic Shari'a and the accepted sources of Islamic Law. Arguments about prophetic sayings have to be traced to a credible source. A valid argument can only be based on an authenticated Hadith (prophetic saying). The book found that "for FGM, there is neither Hadith nor Sunna to follow."
- The need for an accurate medical and social understanding of FGM that includes knowledge about the following:

- The natural functions for which organs were created.

- The physical and psychological consequences of the practice for the girl child and the mature woman.

- The precept of Islam that it is forbidden to alter God's creation.

- The precepts of Islam refute the social beliefs behind FGM and there is no such thing as FGM Sunna.

The book represents an important development on the religious front since most religious leaders know very little about FGM. Dr. Farid Wassel, the former Grand Mufti of Egypt, pointed out that 90 percent of religious leaders know nothing about FGM from a medical perspective and this has led to contradictory religious views. ${ }^{17}$

Around 50,000 copies of Dr. Al-Awa's book were printed, of which 10,000 were distributed nationwide. This means that the Islamic perspective on FGM has reached a wide audience. The book was also made available to other programs that provide awareness-raising on FGM. This represents a sign of collaboration and cumulative learning in the field.

Advocacy efforts with religious leaders have yielded positive results. For example, the conference entitled "On Preventing the Mutilation of the Woman's Body" was organized by Dar Al-Ifta in Cairo on November 22-23, 2006. This conference was attended by some of Egypt's most senior and influential Islamic figures, such as the 
Grand Imam of Al Azhar, the Minister of Awkaf (religious endowments), the current Grand Mufti of Egypt, the former Grand Mufti of Egypt, the Head of the World League of Muslim Scholars (Dr. Youssef El Qaradawi), and a Professor of Islamic Philosophy (Dr. Amna Nosseir). Most of the participants spoke against FGM and the main message of the conference was that "female genital mutilation was never mandated in Islam." The recommendations of the conference called upon all Muslims to refrain from performing this practice in compliance with the teachings of Islam, which prohibit all forms of physical or psychological harm to men and women. The recommendations also called upon legislative institutions to enact laws banning female circumcision and penalizing the perpetrators. They also called on educational and media institutions to explain to the public the harmful effects of this practice in order to abandon it.

Dr. Youssef El Qaradawi pointed out in his speech at the conference that:

"An act permissible under Islamic law can, if harmful, be prohibited on the basis of the principle 'Do not harm yourselves or others.' Therefore, female circumcision may be prohibited on the basis of the principle 'curtail what is permissible if it is a cause for harm or evil.'"

This statement by a top Islamic scholar signifies an important breakthrough after decades of work toward creating a unified religious anti-FGM message. The November 2006 Conference was a significant event, indicating that the religious approach developed by NCCM has been fruitful in getting the support of this religious authority as well as other scholars who took part in this conference.

The major achievement of NCCM on the religious front was achieved by the strong campaign championed by NCCM in response to two FGM-related deaths of young girls in the summer of 2007 . The efforts of this campaign led to the following results:

1. The fatwa issued by Grand Mufti Ali Gomaa. This fatwa condemned the practice and forbade it, saying that it had nothing to do with Islam and that it was haram or sinful. This was a historical landmark in the battle against FGM in Egypt.

\section{The Islamic Research Academy of} Al-Azhar (Magma' El Bouhouth AlIslamiya), the highest seat of religious learning in the Sunni world, issued a statement on June 28, 2007 stating that FGM is a harmful practice and tradition and is not an Islamic practice. The statement called for an awareness campaign in the media against the unIslamic practice.

\section{Challenges:}

- Conservative and hard-line Islamic trends have persisted in their opposition and critique of anti-FGM activities. They have been critical of the Dar AlIfta Conference, Al-Azhar's statement, and the Grand Mufti's fatwa.

- Conservative religious interpretations are still expressed in different platforms. They maintain that FGM is "dignity for women" (makrama) or that it is the physician who should decide whether or not a girl should undergo the procedure. They also allude to Western and foreign influences behind the antiFGM campaign.

- Moreover, although official religious establishments, both Muslim and 
Christian, have taken a clear position against FGM, the practice is still widely supported by religious leaders at the grassroots level in villages and small towns.

\section{Program Efforts in Mobilizing Youth as Agents of Social Change}

Mobilizing youth volunteers to work on the FGM issue was not originally a distinct component of the project activities as laid out in the project documents. However, the focus on youth developed as the project proceeded. The television spot "El Bent Mysria" played an important role in creating interest and debate on the topic, thus attracting the attention of youth. This helped set off two movements among Egyptian youth: a movement led by university students and another movement led by youth across Egypt, particularly in villages in Upper Egypt where the practice is more prevalent. All of these young volunteers had prior experience with FGM, either through personal experience and/or through members of their families and their communities. As a result, some funds were allocated for making use of UN Volunteers (UNVs) in the FGM project.

The youth movement against FGM started when a young group from Helwan University showed interest in the issue and helped organize the first youth seminar with NCCM in 2004 on the different aspects of FGM: medical, religious and cultural. The project team provided these young people with training on communications and TOT in order to enhance their communications skills. This training helped the youth to facilitate effective interventions and avoid any backlashes within their communities. Eventually, the most exceptional of these youth were contracted by the project as UN Volunteers (UNVs).
These student "mobilizers" became very active inside schools, faculties, universities, and their communities and worked to raise awareness among students, their families, and community members through different activities. Their efforts aimed at formulating anti-FGM pressure groups, changing attitudes, and if possible changing behaviors toward abandonment of the practice.

Many of the young people who had initially approached NCCM to inquire about FGM had no clear stance against FGM and wanted to gain more information. Following the seminars organized by NCCM, they became convinced of the harms of the practice.

Some of the female UNVs note that their own painful personal experiences with FGM led them to take part in the program. Others note that the messages of the program encouraged them to think over the practice and its impact. For example, one young woman from Aswan was recruited from the field and trained to conduct the initial survey in her village. Her involvement and commitment to combating FGM began with the questionnaire which, in her own words, "made me think and want to learn more about the issue because I had always felt that female circumcision was a very harsh practice, especially in Aswan where the operation takes the 'Sudanese' form" (infibulations). ${ }^{18}$

Many young men who have been mobilized as part of this program talk about a significant change in their attitude, from supporting or knowing very little about the practice to actively denouncing it and taking part in program activities. One young male volunteer in Beni Suef noted, "Before knowing about the program through a friend, I didn't care about FGM and I didn't even know what it really was." 
UNVs stated that their perceptions on the issue of FGM changed radically through the project. In addition, through training and other activities, they gained skills and knowledge which enabled them to relate to other members of the community, especially the younger generation. It is clear that the project has had a positive impact on the UNVs chosen for this task. This group is innovative and committed to social work that targets change in society as a whole as well as their respective communities and fields of work.

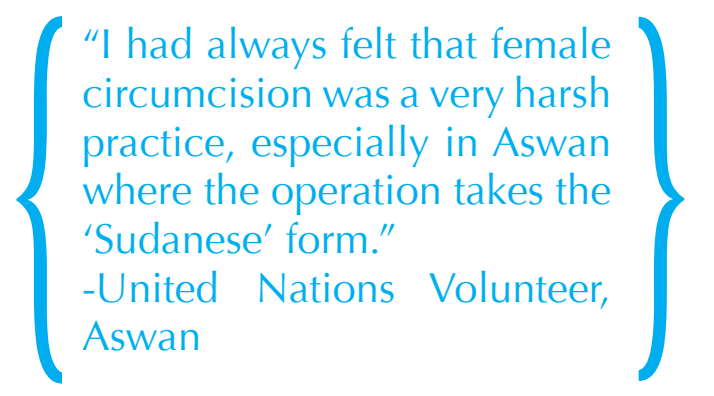

\section{Project Impact on Mobilizing Advocates Against FGM}

The project's activities attracted youth from different villages and governorates, particularly in Upper Egypt. Among them were girls and women who were themselves subjected to the practice of FGM. They had a lot of information and first- hand experience about the harmful effects of FGM. The project team provided these committed youth with the necessary knowledge and skills in order for them to become equipped field workers inside their communities. The personal experience of these young volunteers coupled with the training they received has allowed them to become active members in their communities. They are able to convey anti-FGM messages in a persuasive manner while offering services tailored to their communities' needs. They have also played an important role in mobilizing other youth in their peer groups to work as youth advocates against FGM.

It is worth noting that these youth volunteers represent an important shift in the pool of activists involved in combating FGM. While previous activists in this field during the 1990s were largely from urban middle- and upper-middle classes, many of these young advocates come from middle- and lower-middle class families in rural villages and small towns. This is an indication of a move toward a more grassroots-based movement against the practice and the increased participation of members from local communities.

These young people also show a very strong will against those who support the practice in their families and communities. One UNV from Aswan notes that she became severely under attack from village leaders upon joining the project. The pressure from her community extended, in her own words, to staging a court 'Maglis Arab' for her in her community. She notes:

"I was stopped twice, the first time for raising the issue, upon which a 'Maglis Arab' was staged and I was stopped from working for eight months. The second was for reporting a doctor who performed FGM and they stopped me from working for three months."

The UNVs are not necessarily linked to any one organization, but they find diverse entry points to the different communities that they are connected to and gain trust through service provision. Therefore, they have the flexibility to work through NGOs, schools, universities, and/or any other forums or platforms that exist. One of the activities that they all participated in was to visit the youth camps held in Port Said, where they started dialogues with 
supervisors and youth on the issue of FGM. The UNV from Aswan also stated that she sent a group from Aswan to these camps. She said that the camp had a positive effect on them and helped them to become more open about the issue through exchange with young women who had not been circumcised.

UNVs have encouraged discussion about the issue of FGM among youth on university campuses and in youth camps. The UNVs played a critical role in the campaign that followed an FGM-related death in June 2007. In coordination with the project team at NCCM, the UNVs in Menya contacted the girl's mother and brought her to Cairo to address the media. They also participated in other activities that were organized by NCCM to protest the death of the young girl. These activities received extensive media coverage in the press, national television, and satellite channels. Their quick response to this incident and their dynamism contributed toward putting the issue at the forefront of the media and the public's attention.

Youth volunteers have networked together, collaborated, exchanged experiences, and gained further knowledge about the different entry points that could be used in order to gain trust and stimulate the interest of their communities as well as create necessary change. Their connection to NCCM and UNDP provided them with access to different activities, which broadened their perceptions and experience. They have attended all the general activities organized by NCCM related to this issue, including the signing of the declarations and conferences. They have also participated in the national campaign "Sailing the Nile for MDGs," an annual festival during which different partners from Aswan to Cairo advocate for the MDGs and promote volunteerism.
In addition, they have learned to work as a team and conduct joint activities. Through their involvement in this project, one of them stated "we rediscovered ourselves," while another stated that "we learned to listen to the pains of others." These experiences are crucial in developing the social conscience of youth in Egypt, which can have a spillover effect on the rest of society.

\section{Challenges:}

- $\quad$ Some people might find it difficult to receive information from a volunteer who is perceived as young.

- $\quad$ UNVs also face conservative and hard-line trends that are opposed to the anti-FGM campaign both in local communities and in universities.

- The sustainability of the participation of these young advocates is an important issue that needs to be part of a larger plan for program sustainability after donor support ends. 


\section{Recommendations}

- he FGM-Free Village Model has provided a sensitive, innovative, and multi-dimensional solution to the complex issue of FGM in Egypt. The project strategy was designed to empower girls and their families to make well-informed and sound decisions about female circumcision. The approach of the project corresponds with the approaches recommended in the international literature on the eradication of FGM. For instance, DeJong and Shepard (2005) recommend a three-pronged approach for the elimination of FGM, which includes the following components:

1. Make all forms of FGM/C illegal, with enforcement mechanisms.

2. Finance media campaigns that reach rural areas.

3. Support community-based programs that mobilize communities to develop their own strategies for eradicating the practice.

The FGM-Free Village Model includes these three major elements and also includes advocacy and lobbying with religious authorities and physicians and the incorporation of young people in efforts against FGM.

\section{National-Level Recommendations}

1. The NCCM Project Technical Unit

- The eradication of FGM is a long-term process that will require concerted efforts over an extended period of time. This will require scaling up the current project and expanding into additional governorates. However, this entails ensuring the sustainability of the project technical unit and addressing the need for additional qualified human resources to perform more intensive lobbying and coordination of activities. The same level of quality has to be maintained in order to ensure efficiency and credibility.

- More resources and coordinating mechanisms are needed to target other ministries and governmental bodies such as MOE, MOHP, Ministry of Communications and Information, Ministry of Higher Education, Ministry of Religious Endowments (Awkaf), and the Egyptian Parliament.

- More technical field support (more coordinators and more support staff), particularly for the NCCM hotline, are needed to respond to queries or emergencies regarding FGM.

- Increased levels of human resources will require continued advocacy training, lobbying on FGM issues, and capacity building to expand the knowledge and skills of new staff members of the project technical unit at the central, governorate and community levels so as to maintain the same level of quality, efficiency and credibility.

- Expansion and scaling up of the project into new villages in the same intervention governorates and eventually involving new governorates as well as increased lobbying activities will require additional funding to sustain these efforts on a long-term basis. This may require including antiFGM activities and initiatives in the national budget rather than continuing as a solely donor-supported initiative.

- The experiences of the telephone helpline should be evaluated in terms of the need for outreach services 
for counseling, consultation, or enforcement at the governorate level.

2. Policy Level/Lobbying Different Ministries:

- The positioning of the project technical unit within NCCM has allowed it to have access to decision-making bodies and relevant ministries through the technical advisory committee of NCCM. This has allowed for greater dialogue at the policy level and a greater ability to lobby for needed policy changes on FGM. It has also put the NCCM/Project in a position to work on building national consensus against this practice, especially among decision makers and major players like the media, religious leaders, and doctors. Thus, the NCCM/ Project's comparative advantage lies in its capacity to play a role that others cannot play and in coordinating that role nationwide.

- This role should be maximized through dialogue and high-level lobbying of relevant ministries and legislative bodies while focusing on the achievement of clear objectives and goals. These efforts can include the following:

- Ministry of Education: NCCM needs to continue dialogue with the MOE on how to incorporate reproductive health issues and antiFGM messages in MOE curricula and other MOE activities that aim to sensitize teachers and students regarding FGM.

- Ministry of Higher Education: NCCM needs to continue dialogue with MHE to incorporate antiFGM messages on a wider scale in medical schools.
- Ministry of Justice: NCCM needs to initiate a dialogue with $\mathrm{MOJ}$ on outreach to wider groups of legal personnel and on including antiFGM messages in legal curricula, with a particular focus on the curricula designed for continuing legal education. The latter already covers issues such as human rights and women's rights.

- Ministry of Health and Population:

NCCM needs to work with $\mathrm{MOHP}$ to ensure circulation of the Ministerial Decree No. 271 of 2007 and related enforcement mechanisms.

- National Council for Youth: NCCM needs to initiate a dialogue with the National Council for Youth on establishing sustainable structures that can channel the efforts of youth volunteers and advocates toward FGM-abandonment efforts.

- Ministry of Awkaf: NCCM should work with MOA to prepare a cadre of preachers, especially at the local community level, who would support the case against FGM and possibly establish a taskforce of Islamic scholars supportive of the case against FGM.

- Ministry of Communications and Information: NCCM should engage $\mathrm{MCl}$ to ensure its commitment to granting free primetime broadcasting for anti-FGM spots and issues.

- The NCCM/Project can prepare curricula with anti-FGM messages for certain Ministries (MOE and MOHP). The process of developing these curricula should occur in 
collaboration with UN and with the involvement of the ministries. In this way, anti-FGM curricula can be provided to the ministries at very little cost to them.

3. Development Partners and UN and Donor Agencies:

- UNDP has played an important role in providing the impetus for the development of this project, mobilizing resources for the program from different donors, and providing technical assistance. This continued effort and the longterm support and commitment of international partners will be important for continuing the FGMabandonment process. Moreover, development partners can be more effective if they continue to focus their collective efforts on supporting change at the national level, particularly in the area of policy change and media messages.

- Coordination mechanisms such as the steering committee and the coordination committee have been important for avoiding overlap among $\mathrm{UN}$ and international partner efforts and for harmonization, joint planning, and implementation of joint initiatives through a unified approach among UN agencies. The coordination efforts that have been implemented under the umbrella of NCCM, especially those that have focused on the medical, legal, and communications components, should continue.

- UN agencies should continue working toward greater coordination efforts, especially at the governorate level, in order to maintain the quality of future expansions. Efforts should be made toward sharing and utilizing best practices, tools, and resources that have proven effective on the ground in combating FGM.

- NGOs are important partners in this process. NCCM is equipped to provide training to different civil society organizations to combat FGM within their local communities. It is recommended that NCCM utilize this capacity by providing a strong training curriculum against FGM and a toolkit of best practices which would be part of NGO training and would be available to all NGOs, even those that are not part of the FGM-Free Village Model.

\section{Recommendations regarding UNVs and Youth}

- This group has the potential to be extremely effective not only within this project but in becoming vital social actors who promote social conscience in society. Their knowledge and involvement in other programs would therefore be important to this project.

- UNVs can be used as a pool of candidates for the expansion of the NCCM/Project's technical unit. They are a well-trained cadre of advocates that would enrich the activities of different civil society organizations.

- It is recommended that NCCM consider the establishment of a sustainable structure or mechanism that can utilize this pool of young advocates as resource persons for other FGM-abandonment programs. 
5. Recommendations regarding the Medicalization of the Practice:

- Continued efforts need to be made with MOHP to ensure the implementation of Ministerial Decree No. 271 of 2007 which bans FGM in all clinics and public and private hospitals. NCCM and MOHP should work together to clearly define the standard procedures for implementing and enforcing this decree.

- NCCM should open a dialogue with the Ministry of Higher Education to increase anti-FGM messages in medical curricula, undertake sponsored research on the health consequences of FGM, and garner support from medical students. This would ensure the sustainability of the FGM-abandonment message.

- NCCM should disseminate the FGM manual and curricula among physicians, especially at the governorate level, in order to enhance their capacity to respond to the inquiries of families with at-risk girls and others in the community regarding the decision to continue or abandon the practice.

- NCCM should provide capacity building of physicians in the governorates in order to equip them with necessary tools and skills to provide more in-depth, comprehensive counseling to parents, girls and youth in schools regarding FGM.

- Capacity building for physicians to mobilize and train other doctors on FGM and provide them with counseling skills and a clear unified message on FGM.
6. Recommendations regarding the Religious Aspect of the Practice:

- NCCM should increase efforts with the Ministry of Awkaf to prepare qualified religious leaders to attend seminars at the local level and lead debates about the issue. NCCM should coordinate with the Ministry of Awkaf to establish a task force of religious scholars who are supportive of the case against FGM and to use religious media to convey the FGM-abandonment message.

- Such efforts need to be supported by the wide dissemination of publications which provide arguments that refute the allegations of the Islamic religious roots of FGM. In particular, wider dissemination of the fatwa condemning and forbidding FGM as well as the Al-Awa booklet is needed. The internet can be an important tool in this respect.

- While the Grand Mufti of Egypt has been supportive to the cause against FGM, more efforts are needed to train imams and preachers at the community level on the harms of FGM/C. Moreover, the fatwa needs to be formulated in a way that clearly prohibits the practice instead of showing that it is not required.

- During discussions about recommendations with some NGOs active in the field, it was noted that a focus on female religious preachers would be of great benefit since they have greater access to women. It is hoped that female preachers would be more receptive to the message against FGM 
because they also experienced the suffering of the practice.

\section{Recommendations regarding Media} $\underline{\text { Status }}$

- The NCCM/Project's media policy should be developed into a comprehensive media strategy which can ensure the continuity of dealing with the issue.

- Policy makers in the media should be targeted to ensure that there are coherent and non-conflicting messages about the issue.

- Greater outreach to religious leaders is needed.

- Media materials, including visual stories and features, can be developed with the cooperation of experts. These can be given to the media for broadcast/publication, thereby making it easier to cover more stories of interest.

- Important events related to people's own initiatives should be monitored and sent to the media for coverage. These stories would present the issue from different entry points and would ensure that the issue remains on the agenda of the media without repetitiveness.

- Booklets and publications produced by the NCCM/Project on FGM must be distributed more widely to stimulate interest and generate information.

- An anti-FGM website should be developed where the FGM manual and curriculum can be downloaded. The site can be designed in an interactive form, with discussion forums and a section on questions and answers about FGM issues. This would support one of the important principles of the project's approach, which is furthering an interactive dialogue on the issue and responding to the inquiries of families, girls, men, and women. The Al-Awa booklet can be uploaded on other websites such as Islam Online. ${ }^{19}$

- A media consultant or coordinator should be assigned to the project, which would ensure that there is a constant flow of information. Key indicators to follow up and monitor the media should be developed to assess the impact of the project's media component.

- The experience of the helpline in relation to the media should be assessed.

- A media group consisting of committed people against FGM in the media should meet regularly to discuss strategies against FGM. This group could potentially be part of a larger group from different sectors (NGOs, UNVs, judges, doctors) to exchange ideas, experiences, and progress.

- NCCM/Project should have a mediawatch center to monitor messages on the media, especially media that supports the practice of FGM.

\section{Governorate-Level Recommendations}

In order to develop and support a cadre of advocates against FGM at the governorate level, the following steps are recommended: 
a. NCCM should establish a governoratelevel committee against FGM.

The committee could include representatives of the different line ministries (Education, Awkaf, and Health) at the governorate level as well as a representative from the governor's office. It should also include civil society organizations working on the FGM issue with different donors. A unified committee for all local and international interventions against FGM at the governorate level is needed to ensure full coordination. The committee should also include a permanent NCCM staff member for each governorate. The envisioned role of the committee is as follows:

- Coordinate access to schools and health units throughout the governorate.

- $\quad$ Coordinate with NGOs in selecting doctors and sheikhs to receive training against FGM in workshops.

- Coordinate with NGOs in selecting doctors and sheikhs to lecture and facilitate discussions in seminars against FGM at the community level.

The permanent NCCM staff member at the governorate level should be responsible for coordinating regular meetings for this committee. NCCM should seek to institutionalize the presence of this committee at the governorate level. One option for the institutionalization of this committee is to affiliate it with the governor's office. To further institutionalize this committee, MOUs between NCCM and line ministries can be signed whereby each ministry will assign a governorate-level representative to be part of this committee. b. To support this committee, it is recommended that a group of advocates against FGM be mobilized at the governorate level. This governoratelevel FGM task force would include different core groups and individuals that are committed to the fight against FGM. These would include NGOs working against FGM, UNVs, university professors, doctors, judges and the media. This task force would replicate the role of the national task force against FGM. As such, members of the governorate-level task force will take part in efforts to create awareness about the harms of FGM. They are also expected to act as resource persons and supporters of the different efforts against FGM at the governorate level. The objective of this task force is to maintain a flow of information and linkages between the different levels of implementation in order to reach out to communities. Members of this task force would be focal points to provide materials and to intervene to support the program with their expertise at the governorate level. Ways to involve this group include participation in meetings and seminars against FGM.

\section{Community-Level Recommendations}

- $\quad$ NGOs are important partners at the community level. Focal NGOs are important conduits of knowledge to local NGOs and CDAs. NCCM has invested in training focal NGOs and providing them with the materials to train local NGOs. NCCM's approach with NGOs has been innovative in transforming NGOs from grant recipients to sub-contractors and implementers based on one-year renewable contracts. This arrangement has provided the project with greater flexibility, more accountability from 
NGOs, and the ability to replace NGOs whose performance does not meet project requirements. In order to achieve more effective ways to deal with NGOs as strategic partners, the study recommends the following:

a. The provision of regular training activities on the messages against FGM and the different issues and challenges faced at the community level.

b. The facilitation of networking opportunities among different NGOs working against FGM to allow for cross-fertilization and the development of best practices models.

c. The provision of strong and flexible monitoring and evaluation tools for NGOs through which they can assess their own performance. These monitoring and evaluation tools will also assist NCCM in evaluating NGOs and ranking them in terms of activities and outreach.

d. Continued recruitment of quality and committed people in NGOs to secure the continuation of their work.

The above recommendations relate to two major issues:

1. That NCCM strengthens its communication channels with NGOs through continuous training.

2. That NCCM provides an incentive package to NGOs that is based on performance and specific monitoring and evaluation indicators.
- New outreach strategies at the local level:

a. Adolescents in school are an important target group. The school is an important venue for building awareness. This serves two objectives: first, addressing them at a young age ensures a new generation with views against FGM;second, utilizing youth and children as educators helps them to influence their parents about FGM. To reach this group, the study has three recommendations:

i. Conduct seminars and workshops in schools targeting children and adolescents;

ii. Include messages against FGM in school curricula;

iii. Target school teachers by raising their awareness against FGM through special trainings and seminars. Teachers are important discourse makers and have a tremendous impact on the views of students and their families.

b. Youth in universities are another very important target group. The project has actively recruited youth and has been conscious of the potential of this group as agents of social change. It is therefore recommended that outreach and awareness activities to reach this group continue at universities and campuses in different governorates. It is particularly recommended to reach out to students training to become teachers within the faculties of education, as this is an important group as noted earlier.

c. At the community level, more targeted efforts are needed to reach men, both young and old, with awareness activities against FGM. 
d. The proven impact of the media and the widespread ownership of televisions presents a great opportunity. The project should continue to tap into this resource in order to reach a very wide population. It is recommended that the project uses both satellite channels and local television channels. The former are widely watched in both urban and rural areas. Moreover, local television channels and local (generally governorate-level) newspapers are important venues to build awareness about FGM.

e. Counseling is needed for women who have undergone FGM and their husbands. While it is important to raise awareness about the harms of FGM, those who already went through the practice cannot undo the harm. Counseling should be provided for these women, particularly with regards to marital problems and unfulfilling sexual relationships, both of which were highlighted in field findings. The FGMAP made people connect problems in sexual martial relationships to FGM/C. However, it did not give them any messages on how to deal with the consequences of FGM.

f. The study recommends focusing on local Muslim religious leaders (imams) and providing them with training and targeted awareness-raising activities. Analysis of the data shows that opposing imams at the community level poses a major challenge to project activities.

g. New implementing partners need to be introduced to the efforts against FGM. The study recommends utilizing the existing infrastructure and cadre of advocates within the Ministry of Health and Population. We highlight the need to collaborate with the ministry and train doctors at the national level. At the community level, it is recommended that the project use MOHP facilities, which are available in virtually every Egyptian village, as venues for raising awareness against FGM. Project implementation should build on the MOHP's long experience with family planning. Community health workers (raeda rifia) and maternal and child health nurses have been very successful in raising awareness about family planning, as documented by many studies. Health workers can target families who have at-risk girls with messages against FGM and include these messages as part of the outreach visits and counseling they provide to women. These health workers will need awareness-raising as well as extensive training on the harms of FGM.

\section{- Successful Approaches and Best}

Practices: The FGM-Free Village Model has adopted a number of successful strategies that are central to interventions against FGM. These include the following:

a. Use of an integrated development approach which combines the objective of raising awareness against FGM with the provision of other services and empowering education..$^{20}$ Of particular impact were the renovations of health facilities and the services of medical caravans, which were provided in a number of governorates. These caravans address a real need at the community level and are appreciated by different community members. It is therefore recommended that more of these activities are incorporated into the program. It is also important to note 
that the presence of an integrated package of social services supports efforts against FGM and pacifies groups that are supportive of the practice and hence would be against the intervention.

b. The dissemination of unified integrated messages against FGM that incorporate and yet go beyond the medical and religious perspectives of the practice. Taking a rights-based framework, the unified messages against FGM should be integrated within the framework of a girl's rights to bodily integrity, education, play, and healthy nourishment. The unification of the messages does not mean that they should not be tailored to different target groups. For instance, as data from the field shows, men and women practice FGM for different reasons, with men more interested in issues related to the religious message and women more interested in FGM's relationship to customs and tradition.

c. The mobilization of a critical mass and pressure groups against FGM that publicly declare their stance against FGM. Declarations against FGM are turning points in the community and provide strong momentum in reaching a critical mass against FGM.

d. Program activities allowed a venue for opening dialogue against FGM, which has been a taboo subject for generations.

e. Monitoring and evaluation and data collection. The design of appropriate monitoring and evaluation tools is an ongoing process. Similar to the project's approach, the tools need to be flexible and adaptive and based on common indicators defining program outputs (immediate results) and outcomes (long term results). The study recommends the development of a strong system that would incorporate and measure different parameters, verify these indicators, and allow for resultsbased and targeted reporting on activities, outreach, and other output parameters. 
Annex I: Time Line of Anti-FGM Efforts and Approaches in Egypt Since 1904

\begin{tabular}{|c|c|c|c|c|c|c|c|}
\hline है & $\begin{array}{l}\text { Religious } \\
\text { Discourse }\end{array}$ & Medical & Media & $\begin{array}{c}\text { Social } \\
\text { Research }\end{array}$ & $\begin{array}{c}\text { Civil Society } \\
\text { Efforts }\end{array}$ & $\begin{array}{c}\text { National } \\
\text { Efforts }\end{array}$ & $\begin{array}{c}\text { International } \\
\text { Forums }\end{array}$ \\
\hline ఫे & $\begin{array}{l}\text { Sheikh Rashed } \\
\text { Reda writes in "El } \\
\text { Manar" newspaper } \\
\text { that there is no } \\
\text { concrete evidence } \\
\text { to support FGM as } \\
\text { an act of Sunna. }\end{array}$ & & & & & & \\
\hline ڤू & & $\begin{array}{l}\text { The Egyptian NGO } \\
\text { for Doctors calls for } \\
\text { a ban FGM based on } \\
\text { medical evidence. } \\
\text { This plea is } \\
\text { supported by senior } \\
\text { religious scientists, } \\
\text { doctors from the } \\
\text { Ministry of Health, } \\
\text { and the press. }\end{array}$ & & & & & \\
\hline 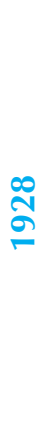 & & $\begin{array}{l}\text { At Cairo Medical } \\
\text { Conference, Doctors } \\
\text { Ali Ibrahim and } \\
\text { Salah Moussa } \\
\text { announce that they } \\
\text { do not teach FGM } \\
\text { to their students and } \\
\text { advise all people to } \\
\text { stop practicing FGM. }\end{array}$ & & & & & \\
\hline ồ & & & $\begin{array}{l}\text { Mr. } \\
\text { Salamah } \\
\text { Mousa } \\
\text { writes an } \\
\text { article on } \\
\text { FGM as } \\
\text { a social } \\
\text { problem. }\end{array}$ & & & & \\
\hline
\end{tabular}

continued $»$ 


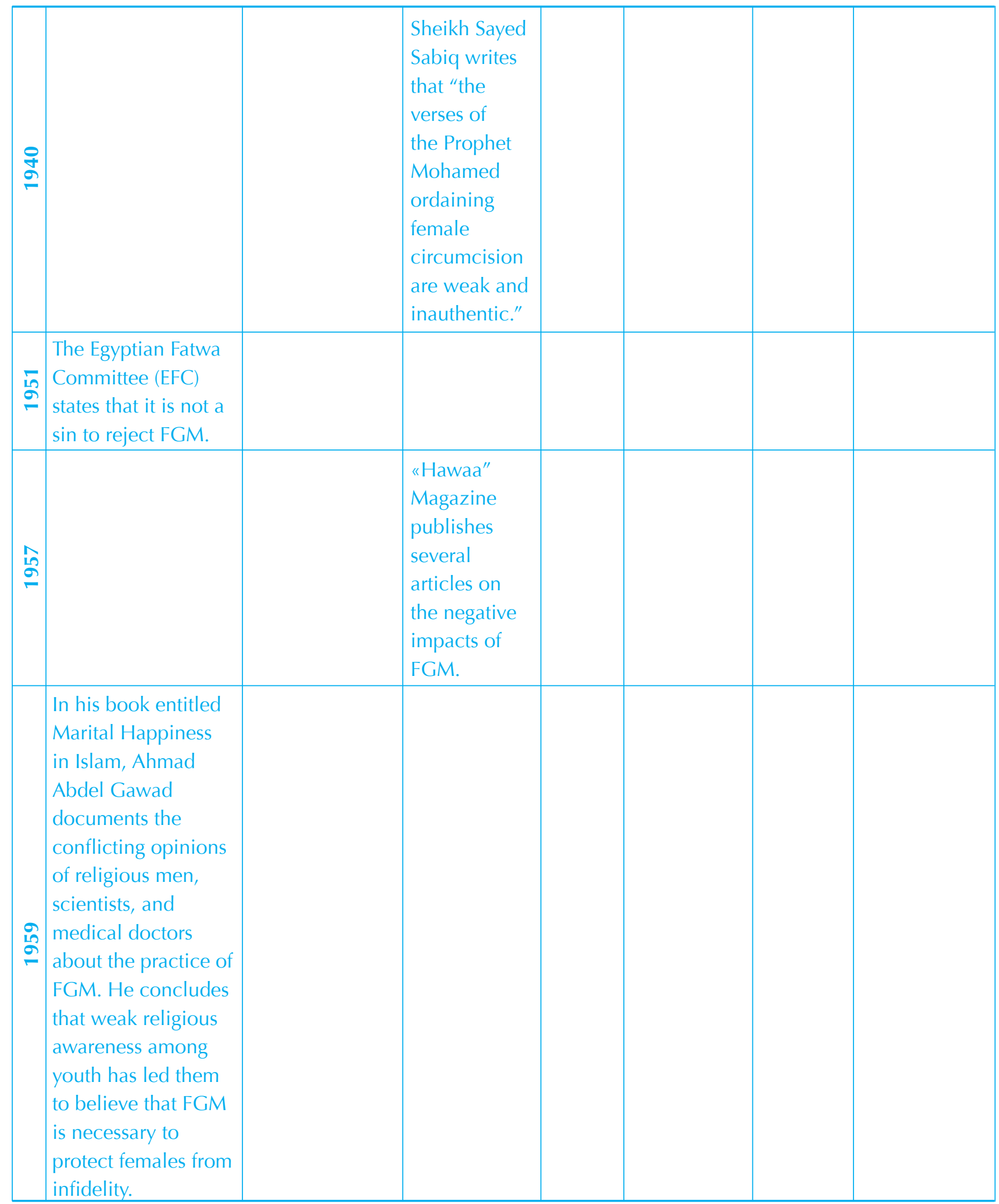

continued $»$ 


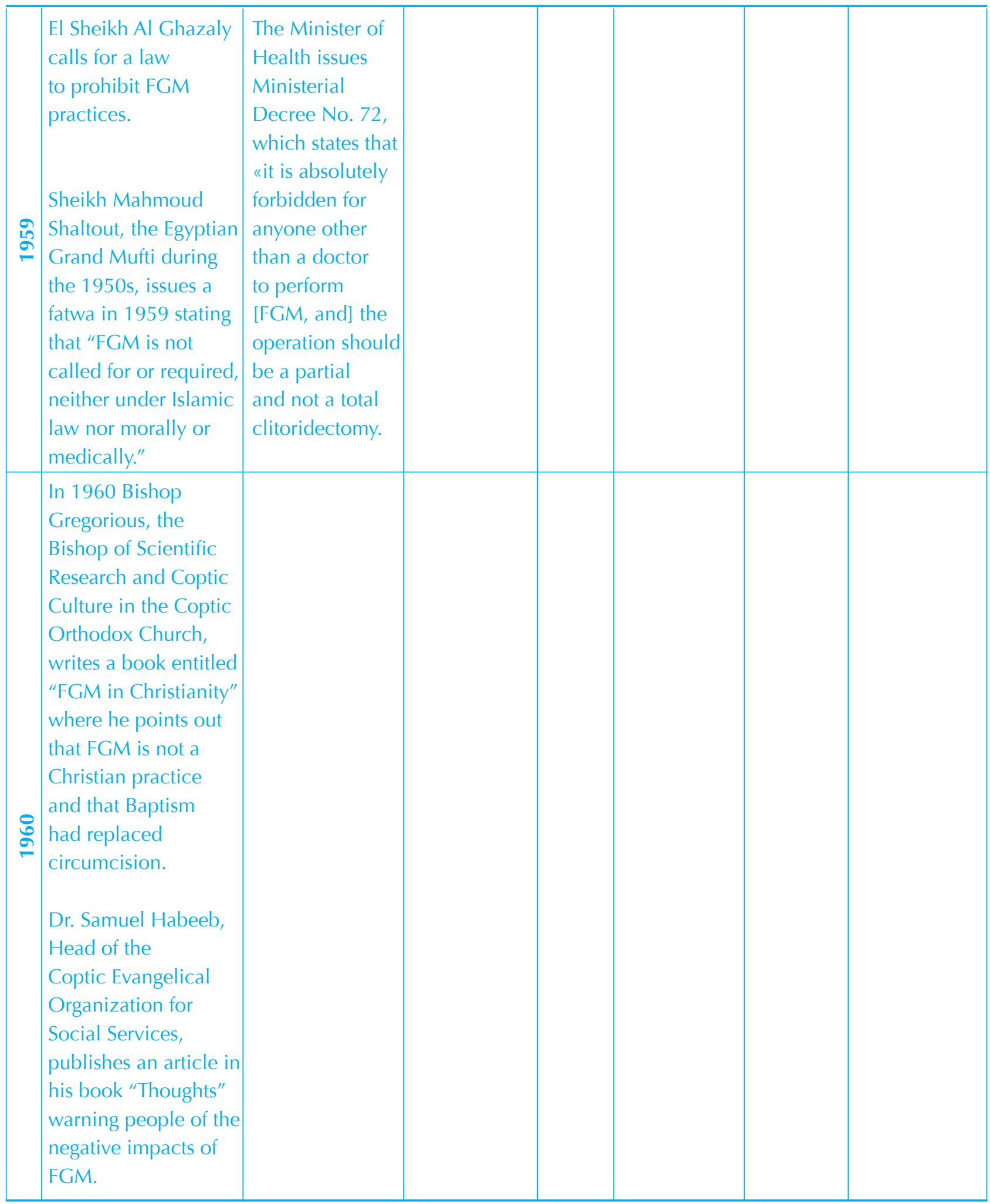

continued » 


\begin{tabular}{|c|c|c|c|}
\hline$\stackrel{R}{\sigma}$ & $\begin{array}{l}\text { Eleanor Smith } \\
\text { conducts a } \\
\text { study on FGM } \\
\text { in Alexandria, } \\
\text { which examines } \\
\text { the extent of } \\
\text { legal awareness } \\
\text { among nurses } \\
\text { who practice } \\
\text { FGM. Seventy- } \\
\text { six percent were } \\
\text { not sure of the } \\
\text { legality of the } \\
\text { practice and } 83 \\
\text { percent felt there } \\
\text { were no negative } \\
\text { health effects. }\end{array}$ & & \\
\hline $\begin{array}{l}\stackrel{\Omega}{\sigma} \\
\stackrel{2}{2}\end{array}$ & & $\begin{array}{l}\text { During the } \\
\text { International } \\
\text { Year of the } \\
\text { Child, Marie } \\
\text { Assaad } \\
\text { undertakes a } \\
\text { landmark study } \\
\text { on the practice } \\
\text { of FGM in } \\
\text { Egypt, which } \\
\text { highlights } \\
\text { the negative } \\
\text { impacts of } \\
\text { FGM. }\end{array}$ & $\begin{array}{l}\text { The Cairo } \\
\text { Family Planning } \\
\text { Association } \\
\text { organizes a } \\
\text { conference } \\
\text { which } \\
\text { includes an } \\
\text { interdisciplinary } \\
\text { panel of experts } \\
\text { to speak out } \\
\text { against FGM. } \\
\text { (Marie Assaad } \\
\text { presents her } \\
\text { study at this } \\
\text { conference). }\end{array}$ \\
\hline
\end{tabular}

continued » 


\begin{tabular}{|c|c|c|c|c|c|}
\hline 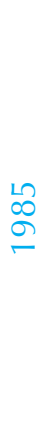 & & & & $\begin{array}{l}\text { The Cairo } \\
\text { Family Planning } \\
\text { Association } \\
\text { becomes a } \\
\text { member of the } \\
\text { Intra-Africa } \\
\text { Committee for } \\
\text { the Abandonment } \\
\text { of FGM. }\end{array}$ & \\
\hline ू̆ & & & & $\begin{array}{l}\text { The Egyptian } \\
\text { Society to Prevent } \\
\text { Harmful Practices } \\
\text { against Women } \\
\text { and Children is } \\
\text { formed. }\end{array}$ & \\
\hline $\begin{array}{l}\sigma \\
\sigma \\
\sigma\end{array}$ & $\begin{array}{l}\text { The Grand Mufti, } \\
\text { Sheikh Mohamed } \\
\text { Sayed Tantawi, } \\
\text { publicly declares } \\
\text { that FGM is not } \\
\text { required by Islam } \\
\text { and that it is a "habit } \\
\text { not a worship." }\end{array}$ & $\begin{array}{l}\text { Following } \\
\text { the CNN } \\
\text { documentary, } \\
\text { the Minister of } \\
\text { Health decrees } \\
\text { that FGM should } \\
\text { only be practiced } \\
\text { once a week at } \\
\text { a governmental } \\
\text { facility by a } \\
\text { trained medical } \\
\text { profession, } \\
\text { and only if the } \\
\text { parents could } \\
\text { not be convinced } \\
\text { otherwise. }\end{array}$ & $\begin{array}{l}\text { CNN } \\
\text { broadcasts a } \\
\text { documentary } \\
\text { of a 9-year- } \\
\text { old Egyptian } \\
\text { girl being } \\
\text { circumcised by } \\
\text { a local barber. }\end{array}$ & & $\begin{array}{l}\text { The } \\
\text { International } \\
\text { Conference } \\
\text { on Population } \\
\text { and } \\
\text { Development } \\
\text { is held in } \\
\text { Cairo. }\end{array}$ \\
\hline
\end{tabular}

continued $\gg$ 


\begin{tabular}{|c|c|c|c|}
\hline \multirow{2}{*}{$\stackrel{L}{\sigma}$} & $\begin{array}{l}\text { The Minister of } \\
\text { Health issues a } \\
\text { decree banning } \\
\text { FGM in public } \\
\text { hospitals. }\end{array}$ & $\begin{array}{l}\text { The Egyptian Task } \\
\text { Force against FGM } \\
\text { organizes a workshop } \\
\text { in cooperation with } \\
\text { the Ministry of Health } \\
\text { and Population in order } \\
\text { to develop a uniform } \\
\text { strategy against FGM. }\end{array}$ & \\
\hline & & $\begin{array}{l}\text { The Egyptian Task } \\
\text { Force against FGM } \\
\text { holds workshops in the } \\
\text { governorates to raise } \\
\text { awareness on FGM and } \\
\text { develop materials to } \\
\text { help NGOs put FGM on } \\
\text { their agenda. }\end{array}$ & \\
\hline \multirow[t]{2}{*}{ } & $\begin{array}{l}\text { The Minister of } \\
\text { Health issues a } \\
\text { decree banning } \\
\text { doctors and any } \\
\text { other practitioner } \\
\text { from performing } \\
\text { FGM, regardless of } \\
\text { the location. The } \\
\text { only exception is } \\
\text { those cases "who } \\
\text { need it, as decided } \\
\text { by the head of } \\
\text { the gynecological } \\
\text { department of a } \\
\text { hospital." }\end{array}$ & & $\begin{array}{l}\text { Amendment } \\
\text { of the child } \\
\text { law to ban } \\
\text { FGM and } \\
\text { address } \\
\text { other child } \\
\text { rights issues. }\end{array}$ \\
\hline & $\begin{array}{l}\text { The } 1995 \text { EDHS } \\
\text { finds that } 97 \\
\text { percent of ever- } \\
\text { married women } \\
\text { between the ages } \\
\text { of } 15 \text { and } 49 \text { have } \\
\text { undergone FGM. }\end{array}$ & & \\
\hline
\end{tabular}

continued $»$ 


\begin{tabular}{|c|c|c|c|c|}
\hline Sิ & & $\begin{array}{l}\text { The Court of } \\
\text { Cassation upholdls } \\
\text { the ministerial } \\
\text { decree of } 1996 \\
\text { banning FGM. }\end{array}$ & $\begin{array}{l}\text { The Egyptian Task } \\
\text { Force against } \\
\text { FGM launches the } \\
\text { campaign "Our } \\
\text { Position Against } \\
\text { FGM." }\end{array}$ & \\
\hline$\stackrel{\infty}{\sigma}$ & $\begin{array}{l}\text { The } \\
\text { Conference on } \\
\text { Population and } \\
\text { Reproductive } \\
\text { Health in } \\
\text { the Islamic } \\
\text { World is held } \\
\text { at Al-Azhar } \\
\text { University. }\end{array}$ & $\begin{array}{l}\text { The Annual } \\
\text { Conference for } \\
\text { Gynecologists } \\
\text { is held. FGM is } \\
\text { discussed and } \\
\text { a statement } \\
\text { is issued that } \\
\text { FGM is harmful, } \\
\text { unnecessary, } \\
\text { and unethical. }\end{array}$ & $\begin{array}{l}\text { The Ministry } \\
\text { of Health and } \\
\text { Population, } \\
\text { the Ministry of } \\
\text { Social Affairs, } \\
\text { and various } \\
\text { NGOs unite and } \\
\text { announce their } \\
\text { fight against FGM. }\end{array}$ & \\
\hline §̊̊̆ & & $\begin{array}{l}\text { The } 2000 \text { EDHS } \\
\text { indicates that } 97 \\
\text { percent of ever- } \\
\text { married women } \\
\text { between the } \\
\text { ages of } 15 \text { and } \\
49 \text { have } \\
\text { undergone } \\
\text { FGM. }\end{array}$ & & \\
\hline 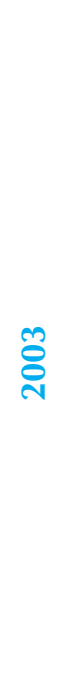 & $\begin{array}{l}\text { Bishop Moussa } \\
\text { declares } \\
\text { that "female } \\
\text { circumcision is } \\
\text { rejected totally } \\
\text { by Christianity" } \\
\text { and that it is a } \\
\text { "harmful habit } \\
\text { that should } \\
\text { be attacked } \\
\text { vigorously" } \\
\text { by the media } \\
\text { and religious } \\
\text { leaders. }\end{array}$ & & & $\begin{array}{l}\text { The National } \\
\text { Council for } \\
\text { Childhood and } \\
\text { Motherhood } \\
\text { places FGM } \\
\text { permanently } \\
\text { on its agenda } \\
\text { and launches } \\
\text { the FGM-Free } \\
\text { Village Model. }\end{array}$ \\
\hline
\end{tabular}

continued » 


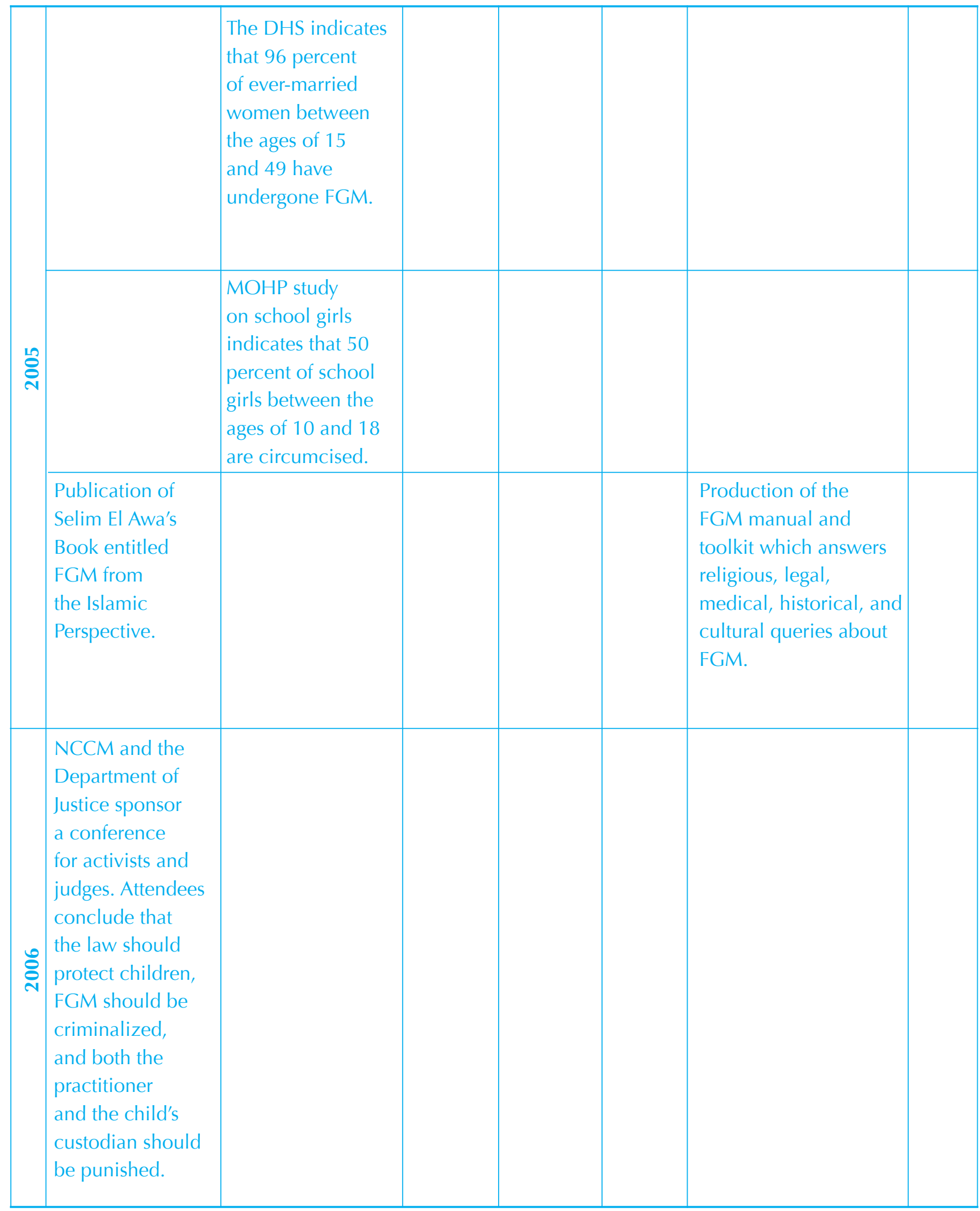

continued $»$ 


\begin{tabular}{|c|c|c|c|}
\hline 옹 & $\begin{array}{l}\text { Fatwa by } \\
\text { the Mufti } \\
\text { condemning } \\
\text { FGM. } \\
\text { Publication of } \\
\text { a booklet by } \\
\text { the Ministry } \\
\text { of Religious } \\
\text { Endowments } \\
\text { (Awkaf) entitled } \\
\text { "FGM is not } \\
\text { an Islamic } \\
\text { Practice.» }\end{array}$ & $\begin{array}{l}\text { The MOHP } \\
\text { issues } \\
\text { Ministerial } \\
\text { Decree No. } \\
271 \text { banning } \\
\text { FGM in } \\
\text { all clinics } \\
\text { and public } \\
\text { and private } \\
\text { hospitals. }\end{array}$ & $\begin{array}{l}\text { Launching of the } \\
\text { anti-FGM National } \\
\text { Campaign entitled } \\
\text { "Beginning of the } \\
\text { End." }\end{array}$ \\
\hline ڤ્ڤ & & & $\begin{array}{l}\text { Parliament } \\
\text { approves the } \\
\text { criminalization of } \\
\text { FGM. }\end{array}$ \\
\hline
\end{tabular}

Annex II: Research Supported by the Resource Center on FGM and Violence against Women

- An evaluation of the activities of NGOs by Samiha El Katsha, Sherine Ibrahim, and Noha Sedky, which highlights the best approaches at the grassroots level. Experiences of Non-Governmental Organizations Working Toward the Elimination of Female Genital Mutilation in Egypt, CEDPA, 1997.

- A manual by Seham Abdel Salam and Magdy Helmy on reproductive health entitled Mafaheem Gadida Li Hayat Afdal: Daleel Al Seha AlIngabya (New Concepts for a Better Life: A Reproductive Health Manual),
1998. This manual analyses prevailing concepts and beliefs about reproductive health issues among families practicing FGM. It also addresses misconceptions about FGM and provides accurate information on the matter.

- A documentation by Nadia Wasif on the history of the campaign against FGM in Egypt. Da Min Zaman: Mundharar al-Mady Wa'ilhadir hawl al-tashweeh al-ginsy lil-inath fi misr (From Long Ago: Past and Present Discourses on Female Genital Mutilation in Egypt), FriedrichEbert-Stiftung, 1998.

- A study by Amal Abdel Hadi and Seham Abdel Salam entitled Physicians' Attitudes Toward Female Circumcision, 
Cairo Institute for Human Rights Studies, 1999. This study highlights the fact that physicians' attitudes toward FGM do not differ much from those of the general population despite their additional knowledge of human physiology. This information was used as the basis for developing training materials that target to doctors and medical students.

- A documentary report entitled Female Genital Mutilation in Egypt, written by Magdy Helmy for UNICEF Egypt in 1999.

\section{Annex III: FGM-Free Village Model Advocacy and Capacity Building Efforts among University Students}

- A four-day training course was held in January 2004 in Alexandria on reproductive health and communications skills which emphasized the role of youth as advocates for change. Approximately 25 girls and staff from the communications unit of NCCM participated.

- A youth forum was held in Aswan on December 21, 2003 which brought together four young leaders (two girls and two boys) from each of the sixty villages involved in the project. A total of about 300 young people attended in addition to governors from five governorates, speakers, donor representatives (UNDP and the Canadian Embassy), and members of the media.

- A seminar was held at NCCM in February 2004 on the social reasons for the continuity of the FGM as a traditional cultural practice. Sixty-five university girls from Lower Egyptian governorates were selected by their peers to participate in the seminar.

- A one-day seminar for 175 students at Alexandria University's Faculty of Law, which was a follow-up to the FGM conference on legal tools in June 2003.

- Three training courses for youth groups from different universities (from the Faculty of Arts, Faculty of Mass Communications, Medical School, and Nursing School) in August and September 2004. The training courses emphasized communications skills on FGM and strategies for tackling FGM from the medical, religious, legal, and social angles. Forty students participated in these training courses and some of them were recruited as UNVs for the project.

- The UNVs organized the first youth conference for 150 female and male students in December 2004 at Zagazig University in Kalyobiya governorate (Lower Egypt). The conference included technical support experts who presented the medical and Islamic perspectives on FGM. The students asked many questions about FGM related to the two perspectives. From the evaluation forms of the conference, it was estimated that approximately 68 percent of the attendants condemn the practice, 15 percent are convinced of the harms of FGM with some confusion, and 14 percent still want the practice to continue. Over 90 percent of the attendants realized that FGM is not a practice related to religion.

- In Menya, UNVs collaborated with youth activists from the National Democratic Party to hold five awareness-raising sessions for a total of 100 participants. 
- UNVs organized seminars on FGM in high schools in Beni Suef and Menya for students and school board members. The issue of FGM was presented within its social context and as violence against children. The seminars provided an opportunity for open dialogue on the practice with students, especially since many of them had suffered directly or witnessed FGM indirectly through family members. In some schools, students created small lobby groups to convince parents of the detriments of the practice. In other schools, anti-FGM task forces were formulated. In Menya, feedback received from parents on the seminars was very positive; they wrote to NCCM thanking them for raising the issue in schools because even parents lack information that could positively influence their decision to abandon the practice.

- In Menya, UNVs held three seminars at the office of the National Democratic Party to address youth on FGM and involve them in youth activities related to FGM. For example, youth believe that FGM should be incorporated in the activities of youth centers.

- $\quad$ The UNV group at Helwan University organized a seminar at the Social Affairs Directorate of Gharbeya governorate for the staff of the Motherhood and Childhood Department. The goal of this seminar was to gain public support from the Ministry of Social Affairs prior to the implementation of the project in the governorate. The seminar was held in response to the requests of directorate staff because they had helped identify partners to work with in Gharbeya. The NGO coordinator addressed FGM from a comprehensive perspective and the head of the department expressed support publicly as she is identified as a key anti-FGM advocate.
- The UNVs from Ain Shams University Medical School incorporated FGM as the main theme of awareness education used during their "medical caravan" which was implemented in July 2005. The medical caravans are a traditional activity of the university in which the medical department selects a community deprived of medical services and various departments provide public heath outreach services. Volunteers suggested incorporating FGM messages in the advocacy and awareness program of the caravan. The FGM-Free Village Model project provided nominal funds to support purchasing lab materials and medication for the caravan. Ten UNVs from the project, in addition to the medical school volunteers, were responsible for the public awareness campaign and home visits on FGM. The medical caravan provided health checkups, lab testing, and medication in two villages in Beni Suef and reached 530 households. The medical students also provided anti-FGM messages to the families that came for other medical services.

- UNVs at Ain Shams University Medical School established a family group (Osra Fekra) inside the Faculty of Medicine to create an anti-FGM awareness and educational group. The group chose distinguished Ob/Gyn professors to facilitate the educational group. This quickly provided a groundswell of support and activities among students, including the production of examination notebooks containing child rights inserts and other vital public health information like first-aid training courses. They also organized a one week training course for a group of supportive and active students to prepare them to tackle FGM from a comprehensive perspective. This 
training was supported by a number of professors, which reflects a growing anti-FGM movement within Egyptian medical schools.

- UNV groups supported the project team and the focal NGO in Aswan in the preparation and organization of the Aswan Benban Declaration Event.

- UNVs at Helwan University organized a number of activities targeting FGM in different youth outlets. They partnered with the Supreme Council for Youth and collaborated in the youth summer camps, which began in June 2006 and ended in mid-September 2006. Each camp targeted 250-300 young girls and boys. The group also organized a medical caravan in Kalyobiya in addition to regular follow-up visits in the newly selected villages in Lower Egyptian governorates. Assisted by UNVs from Menya and Beni Suef, they also supported the project team during the village profile training for the Lower Egyptian NGOs during the village profiling activities.

\section{Annex IV: A Listing of Awareness Activities and Social Services at the Community Level in all Six Governorates}

\section{Awareness Activities and Social Services in the Governorate of Beni Suef}

The two focal NGOs in Beni Suef organized a Community Leaders Conference in October 2003 and invited community leaders from the ten villages; women leaders; religious leaders (Muslim and Christian); Parliament Members; directorate representatives from the Ministries of Health, Education, and Social Affairs; and members of the local councils (a total of 200 leaders). Ambassador Moushira Khattab, NCCM's Secretary General, and the Governor of Beni Suef, Engineer Saeed El Naggar, each made a presentation on FGM as a priority development issue on their political agendas. They reiterated that there needs to be relevant support for the focal NGOs as the NCCM's mandate is to work with civil society in order to ensure that its programs are developed with the participation of communities. The conference presented FGM from all its different perspectives and included a whole session on the Cairo Declaration and the legal implications of FGM.

Other initiatives included awareness seminars with youth (males and females), awareness sessions in high schools targeting girls and parents, and home visits by field coordinators to the most responsive families in the villages. Some very creative initiatives were also developed. For example, "No to FGM" teams within youth centers of the villages organized marathons and football matches for the community during which messages on FGM were delivered to the community. In addition, messages on FGM were integrated into NGO activities such as Quran classes. Both focal NGOs signed agreement protocols with village NGOs in order to give a sense of ownership and sustainability to the interventions.

In addition, focus group discussions targeting influential community leaders were organized which resulted in the creation of pressure groups of 20 leaders in each village.

A health program was implemented by the Coptic Evangelical Organization for Social Services (CEOSS) which included 
awareness sessions on different social issues such as FGM, environmental issues, and tropical diseases common in the summer. Furthermore, awareness classes for young men and girls were implemented as well as classes from the Child-to-Child program, which is based on the CEDPA model of raising awareness about FGM. In addition to these activities, training courses on advocacy skills and report writing were held for field coordinators in the villages.

Beni Suef is one of the governorates where both focal NGOs have villages ready to announce their anti-FGM stance. One village has already drafted a declaration and has held a small local ceremony announcing their rejection of the practice.

In terms of service provision, a health program was implemented in which field coordinators undertook home visits to families with at-risk girls and provided these families with basic health services. A medical center was established in one of the villages and basic equipment was purchased for it. Other services include developing public water closets, supporting the provision of water and electricity services to the neediest families, renovating three nurseries in Ashmant, Beni Khalil, and Zawyet El Masloub, and establishing meeting spots for women in the villages within the space provided inside the NGOs.

\section{Awareness Activities and Social Services in the Governorate of Menya}

Cultural awareness classes using the curriculum of New Horizons CEDPA targeted youth in the 15-25 age group. Classes for a total of 455 youth were organized, as well as seminars for families with at-risk girls and other youth. Also, "El-Bent Mysria" corners were created in village community development associations. These corners consist of small collections of books, pamphlets, and project materials displayed for individuals to learn about FGM.

Training was provided for NGO personnel, religious leaders (Muslim and Christian), community leaders, and women leaders. The course curriculum for this training addressed FGM, volunteerism, and community mobilization.

Social services provided in Menya included training for youth on the development of different skills such as computers and tailoring. There were skills development classes for girls' empowerment and training for young men and women to develop their computer skills by the IT Mobile Club in Abou Korkas El Balad, which was an activity implemented in collaboration with the Ministry of Technology and UNDP. Support was given to women who recently obtained national ID cards and small loans were provided to families with at-risk girls to implement small informal-sector projects. Girl students were also supported in paying their school fees, which enhanced the status of girls in the villages. Quran teaching classes were opened in some of the villages. Meeting spots were established for the local community to utilize during different events.

\section{Awareness Activities and Social Services in the Governorate of Sohag}

Seminars were organized in the villages to discuss FGM from an overall social perspective. Seminars for parents with at-risk girls were held in youth centers or in the homes of women most concerned about the issue. The seminars focused on reproductive health issues, especially traditional harmful practices like early 
marriage and FGM. Cultural awareness classes targeting families with at-risk girls were implemented by community leaders trained by the project with the participation of community religious leaders.

Home visits in all the villages were undertaken by field coordinators each month, targeting mainly families with at-risk girls. Some of the visits were intended to follow up and check the sustainability of attitudes among families that had abandoned the practice. Moreover, youth camps were organized to create empowered youth caravans which performed home visits and organized community activities for the parents on the issue of FGM.

NGOs also established a month of "No to $\mathrm{FGM}^{\prime \prime}$ in which all social activities in the villages addressed FGM and youth were mobilized to announce their stance against the practice.

Training activities were implemented. These included FGM training for doctors which was incorporated in Sohag University Medical School's curriculum. Activities on the prevention of avian influenza (bird flu) were also introduced in order to cope with the community's needs during the epidemic in the earlier part of the year.

Other social services in Sohag included the incorporation of direct messages on FGM into functional literacy classes by the focal NGO. The initiatives also included cultural and sports competitions, like an ongoing sports festival, where information on FGM was disseminated. Other initiatives in the remaining villages included support to medical units that were established by the donations of key community leaders.

\section{Awareness Activities and Social Services in the Governorate of Assiut}

Targeted seminars were organized for men, women, and youth. In the village of Beni Mohamedayat, the focal NGO chose resource persons from Assiut University to facilitate a seminar which addressed both men and women, based on the request of the community.

Classes targeting high school and junior high school students that provided messages on FGM from a comprehensive perspective were organized in five villages. Furthermore, because youth are seen as a main target group and potential agents for change, a series of informal meetings were conducted in youth centers targeting 1200 youth in five villages.

Activities also included refresher training courses for community leaders and doctors who support the cause and the creation of lobbying groups of religious leaders and doctors. Seminars were held for community leaders to ensure that they would not hinder the progress of the project and to encourage feelings of ownership and inclusion regarding the ongoing movement in the villages.

Computer classes for youth and first aid training courses for men and women were provided in selected villages. Support was also provided for the establishment of village nurseries, a women's club, and a medical unit, in addition to providing school scholarships for the most marginalized groups in the villages, mainly girls.

\section{Awareness Activities and Social \\ Services in the Governorate of Qena}

Activities included organizing meetings with women and men in the villages at youth centers and CDAs; awareness seminars on reproductive health issues with a focus on traditional harmful practices like 
early marriage and FGM; and home visits by the community field coordinators to the families that have girls who are in the target age range. Religious meetings were also held for the community where messages on FGM were passed on by both sheikhs and priests. The collaborating sheikhs and priests were previously trained by MOHP/ UNFPA.

A series of meetings were also held with the Social Services Institute, Caritas, and NCCM to explore a protocol on introducing FGM seminars for students. These seminars were established to empower students with program messages and basic communications skills. With these skills, students would be able to play the role of social counselors in schools in the future and convince parents and youth about abandonment of the practice.

In the village of Marees, a local conference was held in which religious leaders announced the recommendations of the Dar Al-Ifta Conference at Al-Azhar, where leading religious leaders called for the prevention and criminalization of FGM from an Islamic perspective. The local conference was attended by project staff and village religious leaders and was designed to give them a greater understanding of the detriments of FGM and thus encourage families to abandon the practice.

Social services included the establishment of small village libraries, the upgrading of village nurseries, the creation of sports festivals, and the establishment of women development centers to empower women and encourage families to abandon FGM.

\section{Awareness Activities and Social Services in the Governorate of Aswan}

Numerous awareness seminars and focus group discussions were held. Other initiatives included contests in village schools, which followed a series of sessions on child's rights during the school year for children in grades 6-9, and the creation of a lobby of doctors against FGM in Aswan (one of the most responsive groups of trained doctors).

The Egyptian Association for Community Initiatives and Development renovated the local council's conference space and nursery, established public restrooms for the village, and built a library that included all project materials. Technology clubs, "Egyptian Girl" corners, and health education classes were also provided. 


\section{Annex V: Characteristics of Control and Intervention Samples}

Table 24: Background Characteristics of women in the intervention and control villages

\begin{tabular}{|c|c|c|}
\hline Background Characteristic & $\begin{array}{c}\text { Intervention } \\
\text { Group [n=305] } \\
\%\end{array}$ & $\begin{array}{c}\text { Control Group } \\
{\left[\begin{array}{c}{[\mathrm{N}=203]} \\
\%\end{array}\right.}\end{array}$ \\
\hline Mean age \pm standard deviation & $39.1 \pm 6.6$ & $38.9 \pm 6.9$ \\
\hline $\begin{array}{l}\text { Marital status } \\
\text { - Married } \\
\text { - Divorced/separated } \\
\text {-Widowed }\end{array}$ & $\begin{array}{r}91.4 \\
1.3 \\
7.2\end{array}$ & $\begin{array}{r}93.1 \\
1.0 \\
5.9\end{array}$ \\
\hline $\begin{array}{l}\text { Religion* } \\
\text { - Muslim } \\
\text { - Christian }\end{array}$ & $\begin{array}{r}98.0 \\
2.0\end{array}$ & $\begin{array}{r}97.5 \\
2.5\end{array}$ \\
\hline $\begin{array}{l}\text { Education* } \\
\text { - No schooling } \\
\text { - Incomplete primary } \\
\text { - Primary } \\
\text { - Preparatory } \\
\text { - Secondary } \\
\text { - University degree or above }\end{array}$ & $\begin{array}{r}50.0 \\
24.3 \\
6.6 \\
4.6 \\
12.8 \\
1.6\end{array}$ & $\begin{array}{r}64.5 \\
19.2 \\
6.4 \\
1.5 \\
7.9 \\
0.5\end{array}$ \\
\hline $\begin{array}{l}\text { Work for cash } \\
\quad \text { •Yes } \\
\quad \text { •No (Housewife) }\end{array}$ & $\begin{array}{r}9.9 \\
90.1\end{array}$ & $\begin{array}{l}11.3 \\
88.7\end{array}$ \\
\hline $\begin{array}{l}\text { Husband's level of education } \\
\text { - No schooling } \\
\text { - Incomplete primary } \\
\text { - Primary } \\
\text { - Preparatory } \\
\text { - Secondary } \\
\text { - University degree or above } \\
\text { - Don't know }\end{array}$ & $\begin{array}{r}27.0 \\
20.9 \\
14.7 \\
4.3 \\
28.4 \\
4.3 \\
0.4\end{array}$ & $\begin{array}{r}38.1 \\
23.8 \\
7.4 \\
5.8 \\
20.1 \\
4.8 \\
0.0\end{array}$ \\
\hline $\begin{array}{l}\text { Husband's work status } \\
\bullet \text { Not working } \\
\bullet \text { Working }\end{array}$ & $\begin{array}{r}4.3 \\
95.7\end{array}$ & $\begin{array}{r}1.6 \\
98.4\end{array}$ \\
\hline $\begin{array}{l}\text { Socio-economic status } \\
\text { - Highest } \\
\text { - Middle } \\
\text { - Lowest }\end{array}$ & $\begin{array}{l}24.4 \\
48.1 \\
27.5\end{array}$ & $\begin{array}{l}17.3 \\
52.3 \\
30.5\end{array}$ \\
\hline $\begin{array}{l}\text { Extended or nuclear family } \\
\text { - Nuclear } \\
\text { - Extended }\end{array}$ & $\begin{array}{l}77.9 \\
22.1\end{array}$ & $\begin{array}{l}73.4 \\
26.6\end{array}$ \\
\hline Woman's mean number of living children & $5.1 \pm 1.6^{* * *}$ & $5.5 \pm 1.8$ \\
\hline
\end{tabular}


Table 25: Circumcision status of women in the sample in both intervention and control sites

\begin{tabular}{lrrr}
\hline Age Group & $\begin{array}{c}\text { Intervention } \\
\text { Group } \\
\%\end{array}$ & $\begin{array}{c}\text { Control } \\
\text { Group } \\
\%\end{array}$ & $\begin{array}{c}\text { Total } \\
\mathbf{N}\end{array}$ \\
\hline $20-24$ years & 100.0 & 100.0 & 3 \\
$25-29$ years & 88.9 & 100.0 & 38 \\
$30-34$ years & 89.5 & 97.1 & 110 \\
$35-39$ years & 94.0 & 100.0 & 143 \\
$40-44$ years & 96.6 & 100.0 & 138 \\
$45-49$ years & 96.9 & 100.0 & 87 \\
$50-54$ years & 100.0 & 100.0 & 13 \\
$55+$ years & 100.0 & 100.0 & 5 \\
\hline
\end{tabular}

Table 26: Mothers' personal and past experiences with circumcision

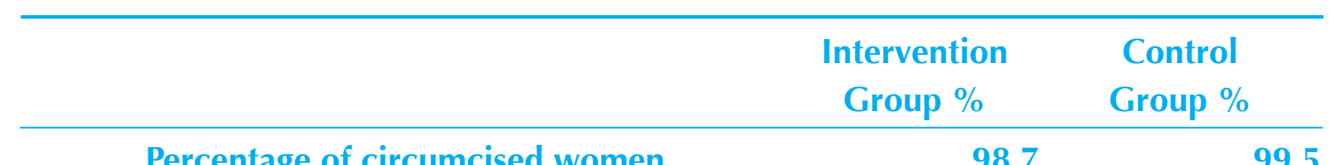

Prior to the operation did your parents seek your approval? Were you informed or were you taken with a group of girls without knowing what was going to happen?

- Took my approval

-Informed me

-I was taken without knowing

- Other

$\begin{array}{rr}4.7 & 12.4 \\ 23.7 & 25.4 \\ 68.7 & 59.2 \\ 3.0 & 3.0\end{array}$

Who performed the circumcision?

- Daya

90.0

89.5

- Doctor/nurse

- Other

Following the circumcision did your family explain to you why they circumcised you?

$\bullet$ No

$\bullet$ Yes

What is your feeling about being circumcised?

-Accepting/happy

- Regretting/unhappy

$37.7 \quad 55.2$

- Makes no difference

$13.0 \quad 5.0$

-Other

$\begin{array}{ll}41.7 & 35.3\end{array}$

-Don't know

$0.3 \quad 0.0$

\begin{tabular}{ll}
$7.3 \quad 4.5$ \\
\hline
\end{tabular}


Table 27: Characteristics of girls aged 10-15 in the intervention and control villages

\begin{tabular}{lrr}
\hline Background Characteristic & $\begin{array}{c}\text { Intervention Group } \\
\text { \% }\end{array}$ & $\begin{array}{c}\text { Control Group } \\
\%\end{array}$ \\
\hline Mean age \pm standard deviation & $12.28 \pm 1.48$ & $12.29 \pm 1.45$ \\
Education & 6.2 & 3.7 \\
- No schooling & 45.3 & 42.6 \\
- Incomplete primary & 41.1 & 45.1 \\
- Primary & 7.0 & 8.6 \\
- Preparatory & 0.4 & 0.0 \\
- Secondary & & 1.9 \\
Work for cash & 1.5 & 98.1 \\
- Yes & 98.5 & \\
- No & & \\
Religion* & 96.1 & \\
- Muslim & 3.9 & \\
- Christian & & \\
\hline
\end{tabular}

Table 28: Characteristics of youth girls aged 16-24 in the intervention and control villages

\begin{tabular}{lrr}
\hline \multicolumn{1}{c}{ Background Characteristic } & $\begin{array}{c}\text { Intervention Group } \\
\text { \% }\end{array}$ & $\begin{array}{c}\text { Control Group } \\
\%\end{array}$ \\
\hline Mean age \pm standard deviation & $18.4 \pm 2.15$ & $18.2 \pm 2.04$ \\
Education & & \\
- No schooling & 15.6 & 11.1 \\
- Incomplete primary & 3.5 & 5.3 \\
- Primary & 8.0 & 7.9 \\
- Preparatory & 25.7 & 31.2 \\
- Secondary & 42.7 & 40.7 \\
- University degree or above & 4.5 & 3.7 \\
Work for cash & & \\
- Yes & 8.5 & 4.8 \\
- No & 91.5 & 95.2 \\
Religion* & & \\
- Muslim & 98.3 & 99.5 \\
• Christian & 1.7 & 0.5 \\
\hline
\end{tabular}


Table 29: Characteristics of Young Men aged 16-24 in the intervention and control villages

\begin{tabular}{lrr}
\hline \multicolumn{1}{c}{ Background Characteristic } & $\begin{array}{c}\text { Intervention } \\
\text { Group } \%\end{array}$ & $\begin{array}{c}\text { Control Group } \\
\%\end{array}$ \\
\hline Mean age \pm standard deviation & $18.7 \pm 2.4$ & $18.7 \pm 2.2$ \\
Education & & 3.4 \\
- No schooling & 5.2 & 2.3 \\
- Incomplete primary & 1.4 & 7.3 \\
- Primary & 5.9 & 16.9 \\
- Preparatory & 21.0 & 62.7 \\
- Secondary & 55.2 & 7.3 \\
- University or above & 11.2 & \\
Work status & & 39.0 \\
- Working & 42.0 & 61.0 \\
- Not working & 58.0 & \\
Religion* & & 98.9 \\
- Muslim & 98.3 & 1.1 \\
- Christian & 1.7 & \\
\hline
\end{tabular}


Table 30: Characteristics of Men aged 24 and older in the intervention and control villages

\begin{tabular}{|c|c|c|}
\hline Background Characteristic & $\begin{array}{c}\text { Intervention Group } \\
\%\end{array}$ & $\begin{array}{c}\text { Control Group } \\
\%\end{array}$ \\
\hline Mean age \pm standard deviation & $46.1 \pm 9.1^{*}$ & $47.8 \pm 8.6$ \\
\hline \multicolumn{3}{|l|}{ Marital Status } \\
\hline - Married & 100.0 & 100.0 \\
\hline \multicolumn{3}{|l|}{ Education } \\
\hline • No schooling & 21.2 & 19.9 \\
\hline - Incomplete primary & 18.5 & 26.3 \\
\hline - Primary & 15.2 & 14.6 \\
\hline - Preparatory & 5.2 & 4.7 \\
\hline - Secondary & 32.6 & 29.8 \\
\hline - University or above & 7.4 & 4.7 \\
\hline \multicolumn{3}{|l|}{ Wife's education level } \\
\hline • No schooling & 51.1 & 63.7 \\
\hline - Incomplete primary & 14.1 & 13.5 \\
\hline - Primary & 7.0 & 5.3 \\
\hline - Preparatory & 6.3 & 4.1 \\
\hline - Secondary & 18.9 & 11.7 \\
\hline - University or above & 2.6 & 1.8 \\
\hline \multicolumn{3}{|l|}{ Wife's work status } \\
\hline •Working & 7.4 & 5.3 \\
\hline - Not working & 92.6 & 94.7 \\
\hline \multicolumn{3}{|l|}{ Work status } \\
\hline • Working & 90.7 & 93.0 \\
\hline - Not working & 9.3 & 7.0 \\
\hline \multicolumn{3}{|l|}{ Religion } \\
\hline - Muslim & 98.1 & 98.8 \\
\hline - Christian & 1.9 & 1.2 \\
\hline
\end{tabular}




\section{Annex VI: Different Religious, Medical and Legal messages on FGM}

\section{A. Religious Messages:}

\begin{tabular}{llll}
\hline \multicolumn{1}{c}{ Type of Message } & \multicolumn{1}{c}{ Message Content } & \multicolumn{1}{c}{ Message Outreach } & \multicolumn{1}{c}{ Outcome } \\
\hline $\begin{array}{l}\text { 1) Inconclusive } \\
\text { messages }\end{array}$ & $\begin{array}{l}\text { No religious obligation as per } \\
\text { the Quran or Sunna, but the } \\
\text { matter is left to physicians. }\end{array}$ & $\begin{array}{l}\text { Prominent in national and } \\
\text { independent media }\end{array}$ & $\begin{array}{l}\text { Traditions and practices } \\
\text { are continued. }\end{array}$ \\
$\begin{array}{l}\text { 2) Binding religious } \\
\text { messages }\end{array}$ & $\begin{array}{l}\text { FGM is a religious duty and } \\
\text { even an obligation. }\end{array}$ & $\begin{array}{l}\text { Prominent in conservative } \\
\text { media }\end{array}$ & Religious duty \\
3) Refuting messages & $\begin{array}{l}\text { FGM is not a religious } \\
\text { obligation, infringes on } \\
\text { human dignity, and must be } \\
\text { criminalized. }\end{array}$ & $\begin{array}{l}\text { Not widely disseminated in } \\
\text { media }\end{array}$ & Limited response \\
\end{tabular}

\section{B. Medical Messages:}

\begin{tabular}{llll}
\hline \multicolumn{1}{c}{ Type of Message } & \multicolumn{1}{c}{ Message Content } & Message Outreach & Outcome \\
\hline $\begin{array}{ll}\text { 1) Medicalization } \\
\text { message }\end{array}$ & $\begin{array}{l}\text { The procedure has to be undertaken } \\
\text { by a physician in appropriate medical } \\
\text { conditions to safeguard the health of } \\
\text { girls. }\end{array}$ & $\begin{array}{l}\text { Prevalent in the media and } \\
\text { disseminated by physicians }\end{array}$ & \multicolumn{1}{c}{ Confusion of } \\
& $\begin{array}{l}\text { It is not a medical procedure, is not } \\
\text { included in medical curricula, and is a } \\
\text { 2) Not a medical } \\
\text { procedure message }\end{array}$ & $\begin{array}{l}\text { Prevalent in media and } \\
\text { disseminated by physicians }\end{array}$ \\
& & \\
\hline
\end{tabular}

\section{Legal Messages:}

\section{Type of Message}

Message Content

Message Outreach

Outcome

1) The weight of tradition, A deep rooted practice and tradition Prevalent in the media widespread practice that bypasses any law.

2) No legal provision or law

3) The need to have a law that criminalizes FGM

4) A law would contradict Shari'a
Refers to the Egyptian penal code to Prevalent in the media criminalize FGM

Legal experts call for a specific law that criminalizes FGM.

It is not possible to pass a law that contradicts Shari'a as the latter has priority and religion allows this practice.
The contradiction in messages with no criminalization supports proponents of the practice of FGM and does not provide protection to others. 


\title{
Table 31: the Development of integrated media messages
}

\author{
Inquiries and Common \\ Media Messages \\ Misconceptions Regarding FGM \\ among Proponents of FGM
}

- Misconceptions regarding the nature and function of female genital organs.

- FGM involves cutting unnecessary parts of the female organs.

- FGM controls the sexual desire of women.

- If not removed, female external genitalia will grow until it reaches the size and length of a male penis.

- FGM makes a girl reach full puberty sooner.

FGM is the removal of vital organs responsible for important and vital functions in a girl's body.

- The female external genitalia removed in FGM is responsible for many vital functions.

- FGM does not control or lessen sexual desire in females before or after marriage. Sexual desire is controlled by the brain.

- The external female genitalia grow to a certain size after which growth ceases. It will never reach the size of a penis.

- There is no link between puberty and circumcision; a girl will attain puberty whether she is circumcised or not.

- FGM ensures that a wife is faithful to $\bullet$ her husband.

- Women cannot control their sexual desires because they are too emotional and light minded. Therefore, FGM is necessary to control women's desires.

- Women, like men, are capable of controlling their desires through their minds and will power.

- Sexual desire in women, like that in men, is controlled by the brain. It is not affected by the presence or absence of external sexual organs or their size.

- Developing a girls mind and will power is the only way to control her desire and conduct, not FGM.

- We want to raise our girls from childhood with self confidence and teach them to strike a balance between emotions and the mind by means of proper upbringing, not by FGM. 
- The family has the right to decide whether or not to circumcise their daughters.
- Messages regarding the rights of the Egyptian girl child.

- FGM violates the basic rights of the Egyptian child. One of the most important rights of the girl child is the right to know everything about FGM.

- The main child rights that are infringed on by FGM:

o The right to life: FGM could lead to the death of a young girl for no reason other than conforming to existing traditions and customs.

- The right to a healthy physical and psychological life free of injury or mutilation.

o The right to human dignity: FGM sends a negative message to the girl child. She receives a message that physical and psychological violence is an acceptable method of upbringing to ensure her proper conduct throughout her life. She also receives the message that in all cases she stands accused of the possibility of perversion or moral misconduct.

o The right to protection: The girl who is subject to FGM loses her sense of safety, security, and trust toward the persons closest to her, mainly her father and mother, whom she sees as responsible for the pain and injury she has suffered.

o The right to know: Most girls are forced to undergo FGM without knowing beforehand about the physical and psychological harm they will undergo as a result of this practice. In addition, they undergo FGM without any knowledge of the function and role of these organs for a girl's body and that of a mature woman.

- The right of children to express themselves: Article 12 of the Convention on the Rights of the Child stipulates the right of the child to express his views freely in all matters affecting that affect them.

continued » 
If a woman is not circumcised, this will infringe on a man's rights and his ability to control his wife, daughters and sisters.

- FGM infringes on the rights of men just as it infringes on the rights of women.

- FGM infringes on a mature and married woman's right to a healthy and happy marital relationship and her right to a healthy body, free from disease and mutilation. FGM causes short-term and long-term physical and psychological harm.

- FGM infringes on a man's basic rights, such as:

o His right to a healthy and happy married life.

- His right to know and make decisions: A husband has the right before marriage to know everything about FGM and the fact that it has nothing to do with a woman's chastity. A father has a right to know about the harmful implications of FGM and the fact that it is an unnecessary practice so that he may protect his daughters from it. Correct knowledge about women's sexual organs and their functions will free men of the myths and misconceptions that link a woman's chastity with FGM.

- FGM affects a man and woman's right to a happy and equal marital relationship.

FGM is a practice rooted in Islam and Christianity.
- FGM is rejected by Islam and Christianity not only because there is no obligation to perform the practice either in the Holy Quran or the Holy Bible, but also because it impinges on the rights of the girl child, women and men. This is refused by religion.

- FGM was practiced in Egypt long before the advent of Christianity or Islam. It is a practice with African roots.

- FGM is not an Islamic practice or tradition.

- The Quran is void of any reference to FGM.

- There is no evidenced of authenticated Hadith that call for this practice.

- The value and sanctity of the body as well as the right of a human being, male or female, to enjoy physical and psychological health are among the precepts of all divine religions and are advocated by the authentic prophetic Hadith "Do not harm yourself or others"(La darar wa la daraar).

- Altering God's creation is forbidden.

- The precepts of Islam ensure a woman's right to a fulfilling and satisfying marital relationship.

- The precepts of Islam refute the social beliefs behind FGM because they demean women.

- The precepts of Islam respect science and scientists. Science has proven that this practice is harmful and has no benefit whatsoever.

- FGM is not a Christian practice.

- Christian families, like Muslim families, perform FGM because of erroneous social beliefs and misconceptions.

- There is no reference to FGM in the Bible.

- Christianity considers the human body (male and female) sacred and opposes subjecting it to any form of humiliation.

- Christianity respects a woman's right to a fulfilling sexual relationship. 
FGM is harmful if performed by a midwife (daya). Thus, it should be performed by a specialized physician.
Some girls need FGM and should be referred to a physician to decide whether she should undergo FGM or not.

Why talk about FGM now?
- FGM is not a medical practice. MOHP's ministerial decree categorically prohibits performing FGM and punishes those who violate this decree.

- FGM is a practice to which there is no medical or scientific reference in medical curricula,

- FGM is not a part of the medical curricula in faculties of medicine in Egypt or the rest of the world.

- International medical bodies (WHO, International Federation for Obstetricians) criminalize FGM and consider physicians who perform the practice in violation of the medical code of ethics. A physician cannot legally perform FGM under any pretext, be it for beautifying reasons or necessity. The four conditions for surgical intervention determined by the law are as follows: to discover a disease, to cure a disease, to alleviate existing pain, and to prevent oncoming pain.

- MOHP Ministerial Decree No. 271 of 2007 categorically prohibits the performance of FGM on any girl by physicians or any other person.

- FGM is an act of mutilation, not beautification of external female genitalia. There is no legitimate reason for cutting part of a girl's sexual organs.

- Combating FGM started a long time ago in Egypt. 


\section{Works Cited}

Assaad, Marie. 1980. "Female

Circumcision in Egypt: Social

Implications, Current Research and

Prospects for Change." January 1980.

DeJong, Jocelyn and Bonnie Shepard. 2005. "Breaking the Silence and Saving Lives: Young People's Sexual and Reproductive Health in the Arab States and Iran." Boston: International Health and Human Rights Program.

El Dawla, Aida Seif. 1999. "The Political and Legal Struggle over Female Genital Mutilation in Egypt: Five Years since the ICPD." Reproductive Health Matters, 7(13): 128-36.

El-Gibaly, Omaima, Barbara Ibrahim, Barbara S. Mensch, and Wesley $\mathrm{H}$. Clark. 1999. "The Decline of Female Circumcision in Egypt: Evidence and Interpretation," Social Science and Medicine 54(2): 205-220.* Also issued as Policy Research Division Working Paper No. 132. New York: Population Council, 1999.

El Zanaty, Fatma and Ann Way. 2006. Egypt Demographic and Health Survey 2005. Cairo, Egypt: Ministry of Health and Population, National Population Council, El-Zanaty and Associates, and ORC Macro.

Helmy, Magdy. 1999. "Documentary Report on Female Genital Mutilation in Egypt." Cairo: UNICEF Women's Program.

Helmy, Magdy. 2000. FGM in Egypt: A Documentation Report. Cairo: Caritas Egypt.
Helmy, Magdy and Vivian Fouad. 1994. Female Circumcision...till When? Questions and Common Beliefs regarding Female Circumcision. Cairo: National Project for Eradicating FGM, NCCM.

Hussein, Aziza. 2003. Legal Tools for the Prevention of FGM in Egypt: A 20-Year Overview. Arab Afro Expert Consultation on Legal Tools for the Prevention of FGM.

"NGO Task Force for Eradication of Female Circumcision - Activities until December 1996." Proceedings of the meeting to develop a media campaign for FGM eradication, NGO Task Force, Cairo, January 1997.

Tadros, M. 2000. "Breaking the Silence: An Egyptian Experience." Hadithi 2: $1-35$.

Tag-Eldin, Mohammed, Mohsen A. Gadallah, Mahmoud N. Al-Tayeb, Mostafa Abdel-Aty, Esmat Mansour, and Mona Sallem. 2008. "Prevalence of Female Genital Cutting among Egyptian Girls." Bulletin of World Health Organization 86(4): 269-274.

UNICEF. 2005. "Female Genital Mutilation/Cutting: A Statistical Exploration."

UNICEF, 2005. "Changing a Harmful Social Convention: Female Genital Mutilation/ Cutting." Innocenti Digest.

Wassef, Nadia. 1998. "Dah Min Zaman: Past and present discourse on FGM in Egypt." Friedrich-Ebert-Stiftung. 
World Health Organization. 2008. "Eliminating Female Genital Mutilation: An Interagency Statement." OHCHR, UNAIDS, UNDP, UNECA, UNESCO, UNFPA, UNHCR, UNICEF, UNIFEM, WHO.

World Health Organization. 2008. "Female Genital Mutilation: A Joint
WHO/UNICEF/UNFPA Statement."

Yoder, P. Stanley, Noureddine Abderrahim, and Arlinga Zhuzhuni. 2004. Female Genital Cutting in the Demographic and Health Surveys: A Critical and Comparative Analysis. DHS Comparative Reports No. 7. Calverton, Maryland: ORC Macro. 


\section{Notes}

${ }^{1}$ See El-Gibaly and others on the decline of circumcision in Egypt.

${ }^{2}$ Ibrahim was also the first Egyptian to be elected Dean of the Faculty of Medicine at Cairo University in 1929.

${ }^{3}$ Sunna refers to the deeds of the Prophet Mohammad and the model of behavior that all pious Muslims seek to emulate.

${ }^{4}$ The Egyptian Task Force against FGM started as a movement of upper- and uppermiddle class men and women. It had Muslim and Christian members who were primarily well-educated. The founding members of the Task Force were:

1. Marie Assaad, an activist and one of the early social scientists writing on the issue of FGM. She was Deputy of the World Council of Churches, and acted as Coordinator of the Task Force.

2. Aziza Hussein, the first Egyptian woman to work in the UN. She was head of the Egyptian Family Planning Association and the Inter-African Committee for the Eradication of Harmful Traditional Practices.

3. Nahed Tobia, a Sudanese researcher and founder of RAINBO, who spoke about FGM at the 1993 Vienna Conference of Human Rights, bringing the issue into the international arena and setting the stage for the ICPD.

4. Amal Abdel Hadi, a medical doctor and prominent feminist and human rights activist.

5. Siham Abdel Salam, a medical doctor and activist.

6. Magdy Helmy, a medical doctor, expert in development, and Health Program Officer at Caritas Egypt at that time.
7. Aziza Kamel Mahmoud, Executive Director of the Egyptian Society for the Prevention of Practices Harmful to Women and Children.

8. Samira Luka, Program Officer, Cultural Development Division, Coptic Evangelical Organization for Social Services.

9. Aida Seif El Dawla, a psychiatrist and medical school professor..

${ }^{5}$ Interview with Marie Assaad, Task Force Coordinator.

${ }^{6}$ Article 24 (3) of the Convention on the Rights of the Child states that "States Parties shall take all effective and appropriate measures with a view to abolishing traditional practices prejudicial to the health of children." Article (19) stipulates that "States Parties shall take all appropriate legislative, administrative, social and educational measures to protect the child from all forms of physical or mental violence, injury or abuse, neglect or negligent treatment, maltreatment or exploitation." Article (16) states that "No child shall be subjected to arbitrary or unlawful interference with his or her privacy...." Article (37) also states that "No child shall be subjected to torture or other cruel, inhuman or degrading treatment or punishment..."

${ }^{7}$ For further information about UNICEF in Egypt, see http://www.unicef.org/egypt/ index.html.

${ }^{8}$ For further information about UNFPA in Egypt, see http://www.unfpa.org.eg/ UNFPAEgypt/Default.htm. For further information about UNIFEM, see http:// www.unifem.org.

${ }^{9}$ For further information about the UNV program in Egypt, see http://www.un.org.eg/ Default.aspx?tabid=55.

${ }^{10}$ In 2005, the EU signed a financial 
agreement with NCCM to support a program on children at risk, whose five main components were: child labor, the status of street children, girls' education, disabled children, and FGM. The FGM component and its funding ( 3 million Euros) were channeled to the FGM-Free Village model and managed by UNDP.

${ }^{11}$ Interview with UNDP program officer.

${ }^{12}$ It is important to note that data was collected before the unfortunate deaths of two girls while being circumcised in the summer of 2007 . As such, control sites were less aware of such cases. Given the wide media coverage of these two deaths, the difference between intervention and control communities in this respect must have declined considerably in recent months.

${ }^{13}$ This interview was conducted before the Ministry of Health's decree in 2007 banning doctors from performing FGM (Decree No. 271), and prior to the criminalization of FGM in 2008 (Article 242).

${ }^{14}$ This document was formulated before the 2007 ministerial decree and the 2008 criminalization of FGM.

${ }^{15}$ Aziza Hussein. 2003. "Legal Tools for the Prevention of FGM in Egypt: A 20 Year Review," in Stop FGM: Proceedings of the Afro Arab Cairo Expert Consultation, Cairo, June 21-23.

${ }^{16}$ Huntington, Samuel. 1997. The Clash of Civilizations and the Remaking of the World Order. New York: Touchstone.

${ }^{17}$ From Dr. Fardi Wassel's comments at the conference on "Preventing the Mutilation of the Woman's Body," Cairo, November 2006.

${ }^{18}$ This is the common term for Type III of FGM in Egypt which refers to the excision of part or all of the external genitalia and the stitching or narrowing of the vaginal opening (infibulation).

${ }^{19}$ Islam Online can be accessed on the following link: www. islamonline.net.

${ }^{20}$ Empowering education provides a forum for participants to exchange experiences. It also helps people to examine their own values and beliefs related to the practice of FGM in a dynamic and open way which is not experienced as threatening $(\mathrm{WHO}$ 2005). 


